\title{
A Review of the Use of Eutectic Solvents, Terpenes and Terpenoids in Liquid-liquid Extraction Processes
}

\author{
Diego Rodríguez-Llorente, Andrés Cañada-Barcala, Silvia Álvarez-Torrellas, \\ Vicente Ismael Águeda, Juan García and Marcos Larriba *(D) \\ Catalysis and Separation Processes Group (CyPS), Chemical Engineering and Materials Department, \\ Faculty of Chemistry, Complutense University of Madrid, Avda. Complutense s/n, 28040 Madrid, Spain; \\ diegor@ucm.es (D.R.-L.); acanad01@ucm.es (A.C.-B.); satorrellas@ucm.es (S.Á.-T.); viam@quim.ucm.es (V.I.Á.); \\ jgarciar@ucm.es (J.G.) \\ * Correspondence: marcoslarriba@ucm.es; Tel.: +34-91-394-4135
}

Received: 17 August 2020; Accepted: 28 September 2020; Published: 30 September 2020

\begin{abstract}
Diverse and abundant applications of the eutectic solvents have appeared in the last years. Their promising tunable properties, eco-friendly character and the possibility of being prepared from numerous compounds have led to the publication of numerous papers addressing their use in different areas. Terpenes and terpenoids have been employed in the formulation of eutectic solvents, though they also have been applied as solvents in extraction processes. For their hydrophobic nature, renewable character, low environmental impact, cost and being non-hazardous, they have also been proposed as possible substitutes of conventional solvents in the separation of organic compounds from aqueous streams, similarly to hydrophobic eutectic solvents. The present work reviews the application of eutectic solvents in liquid-liquid extraction and terpenes and terpenoids in extraction processes. It has been made a research in the current state-of-the-art in these fields, describing the proposed applications of the solvents. It has been highlighted the scale-up feasibility, solvent regeneration and reuse procedures and the comparison of the performance of eutectic solvents, terpenes and terpenoids in extraction with conventional organic solvents or ionic liquids. Ultimately, it has been also discussed the employ of predictive methods in extraction, the reliability of thermodynamic models in correlation of liquid-liquid equilibria and simulation of liquid-liquid extraction processes.
\end{abstract}

Keywords: liquid-liquid extraction; eutectic solvents; terpenes; terpenoids; separation

\section{Introduction}

In the past two decades, the number of research papers focused on the application of deep eutectic solvents as an alternative to conventional solvents and ionic liquids in various and numerous areas has increased. This rise is due to the search of processes environmentally friendly as eutectic solvent present promising and advantageous characteristics [1].

By the first time, Abbott et al. in 2003 [2] described a novel eutectic solvent formed by a mixture of quaternary ammonium salts with urea that presented a great depression in the melting point compared to the pure substances due to complexation between hydrogen bond acceptors and donors. Later, the term deep eutectic solvent (DES) was introduced to describe solvents composed of eutectic mixtures of Lewis or Brønsted acids and bases, which can include a variety of anionic and cationic compounds [1].

DES present similar tunable physicochemical properties to ionic liquids. Nevertheless, DES have notable advantages as starting materials could cost 10 times less than ionic liquids and can be prepared under mild conditions by simply mixing the components without further purification stages. For this reason, their potential scale-up is much bigger than the production of ionic liquids. Other 
interesting properties of eutectic solvents are the low melting points, thermal and chemical stability, biodegradability, volatility and low toxicity, although these features depend on the constituents that compose them [3]. The possibility of starting from a great variety of compounds, such solid materials, has open the door for a great generation of DES and applications.

It should be noted that the term "deep" in DES has been subject to debate. Deep eutectic solvent, it must be applied to systems with eutectic point lower than the melting temperature of pure compounds but being a temperature much lower than that predicted by an ideal thermodynamic behavior [4]. Therefore, the presence of a eutectic point in a mixture cannot reflect whether a mixture is a deep eutectic solvent [5]. According to Martins et al. (2019), to properly characterize a DES, the solid-liquid phase diagram should be measured and compared with the ideal behavior to identify the real temperature depression [5]. Besides, some eutectic mixtures do not present a melting point, only a glass transition temperature. Because of this, they were also named as low-transition-temperature or low melting mixtures [6-8]. In many of the articles in this field, the solid-liquid phase diagram has not been studied, so hereinafter we will simply refer to "eutectic solvents" for the deep eutectic solvents found in the literature.

In the formulation of the eutectic solvents, natural compounds have been also employed, resulting in the term that can be found in literature as "natural deep eutectic solvents" or NADES $[9,10]$. The use of natural compounds presents certain advantages as biocompatibility and biodegradability, being able to be more environmentally friendly than conventional organic solvents and some ionic liquids [11]. Similarly to biocompatible ionic liquids, eutectic solvents can be based on natural products as sugars, organic acids or amino acids [12]. Furthermore, terpenes and terpenoids have been recently proposed as good candidates in the formation of eutectic solvents [13-16].

Terpenes and terpenoids are well-known natural compounds and the most numerous and various plant products. Terpenes generally relate to hydrocarbons derived from the basic unit of isoprene, while terpenoids are modified terpenes, with the addition of oxygen for example, although the term terpene can encompass both types of compounds [17].

They can be obtained from natural sources or produced from feedstocks as turpentine or petrochemical sources [18]. Terpenes and terpenoids are extensively used in perfumery and cosmetics and can be found in applications in medicine [18]. In this field, promising properties of terpenes and terpenoids have been reported, as biocidal effects on microorganisms in vitro, capacity for the reduction of tumor size and inhibition of cancer cell growth or lowering cholesterol levels [16].

Due to the increasing environmental regulations, in the search of greener solvents terpenes and terpenoids have been also investigated as possible substitutes of petroleum-based solvents. From their biomass origin could be considered renewable solvents, with low hazard risk and environmental impact [19]. The most commonly used terpene is limonene, a by-product of the citrus fruits industry. Limonene has been proposed for the substitution of $n$-hexane in some extraction processes, as well as other terpenes and terpenoids $[20,21]$. Nevertheless, the presence of other possible applications is still scarce and their future as solvents still unknown.

On the other hand, since the apparition of the eutectic solvents with their novel characteristics, numerous applications have appeared and it has been published reviews of the use of eutectic solvents as organic reaction media [6], employment in analytical chemistry [22], production and application in new materials [23] and separation and extraction processes [24,25]. Otherwise, it has been noted by the authors the lack of diverse reviews of the usage of terpenes and terpenoids in extraction processes.

Owing to the presence of numerous, various and increasing utilization of the eutectic solvents, the aim of this work is the establishment of the up-to-date state-of-the-art of the applications of eutectic solvents in liquid-liquid extraction processes, specifically. Besides, it will be reviewed the employment of terpenes and terpenoids in extraction processes as the presence of published works is notably lower than the eutectic solvents. Due to the hydrophobic nature of terpenes and terpenoids, these natural solvents have recently been used in the extraction of organic compounds from aqueous solutions, showing extractive properties comparable or higher than those of hydrophobic eutectic solvents [26,27]. 
A review of the current situation of the use of both types of solvents in liquid-liquid extraction is presented in this work since hydrophobic eutectic solvents and terpenes or terpenoids are currently being proposed for the separation of solutes or pollutants from aqueous streams.

Specifically, this review has been focused on discussing the technological feasibility of these applications, highlighting the industrial scalability by reviewing the extraction and reusability solvent methods and the comparison with conventional solvents and ionic liquids. Additionally, it has been addressed the use of predictive methodologies, correlation to thermodynamic models and simulation of industrial processes employed eutectic solvents, terpenes and terpenoids in liquid-liquid extraction.

\section{Application of Eutectic Solvents in Liquid-liquid Extraction}

To analyze the evolution of the use of eutectic solvents in recent years, a search was made in the Scopus database with the keywords: "eutectic solvents." A total of 3766 publications on eutectic solvents were found in the cited database, until June 2020. In Figure 1, the evolution of the number of publications on eutectic solvents from 2004 to 2020 is plotted. As can be observed, the first paper with the term "deep eutectic solvent" was published in 2004, although in 2003 Abbott et al. [2] had previously published an article on a liquid solvent formed by mixing urea and several solid quaternary ammonium salts. Until 2010, the number of articles on eutectic solvents grew slowly but since 2012 an almost exponential growth has been observed. In 2019, more than 900 articles on eutectic solvents have been published and from January to June 2020, more than 630 works have already been published. Thus, it is expected that 2020 will be the year with the largest number of articles published in this field.

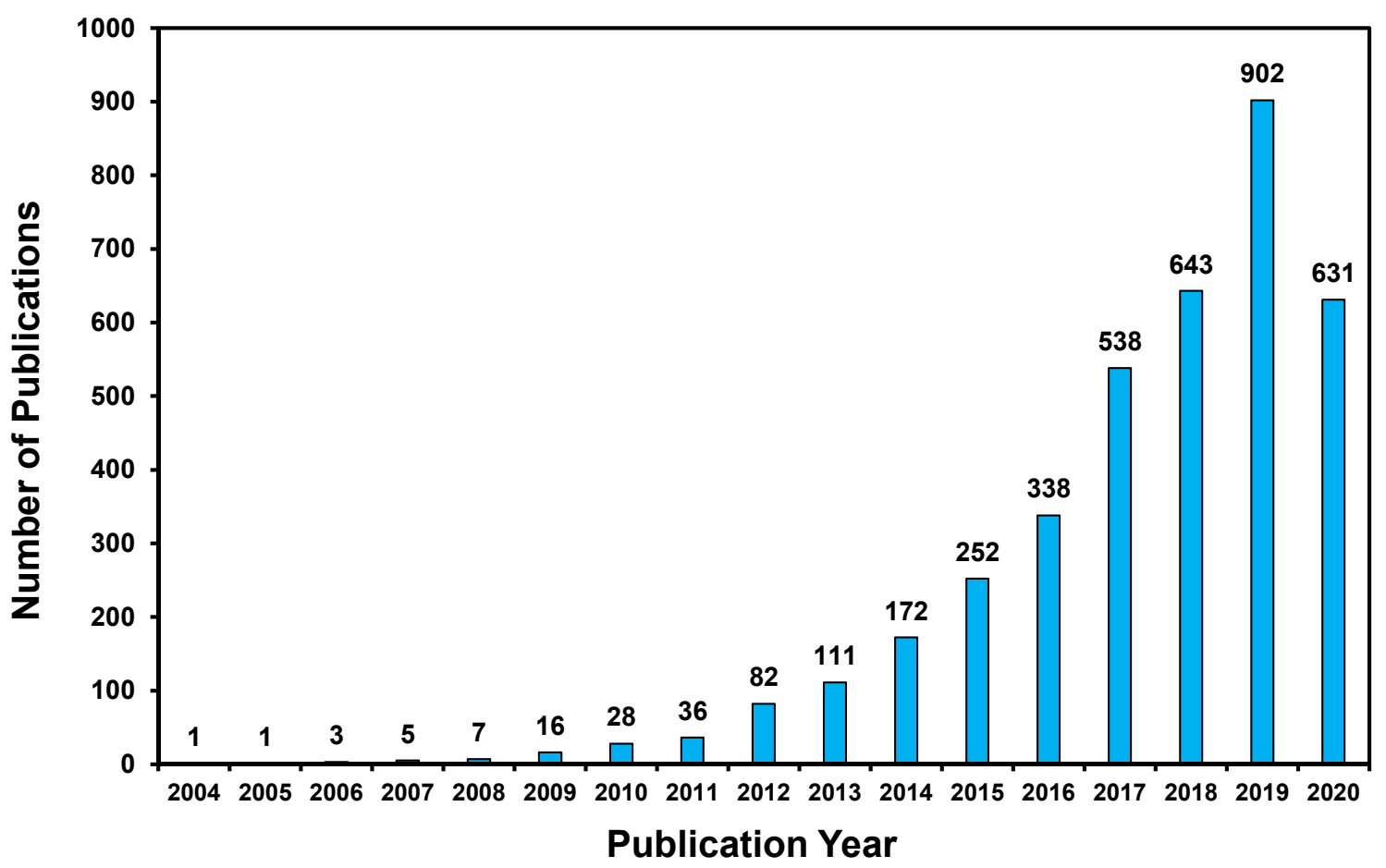

Figure 1. Number of papers in the field of eutectic solvents from 2004 to 2020 (internet search on Scopus, 15 June 2020). Keywords: "eutectic solvents."

Among the more than 3700 articles found on the use of eutectic solvents, 217 of them have been focused on the application of these solvents in liquid-liquid extraction. In Figure 2, the evolution of the number of articles related to the use of eutectic solvents in liquid-liquid extraction processes is showed from 2007 to 2020. As can be seen, the growth of the publications in this specific application has been later than the growth previously commented for the general field of eutectic solvents, beginning to 
increase substantially from the year 2017. In 2019, 54 publications were focused on the use of eutectic solvents in liquid-liquid extraction and 40 works have been already published in the first half of 2020 .

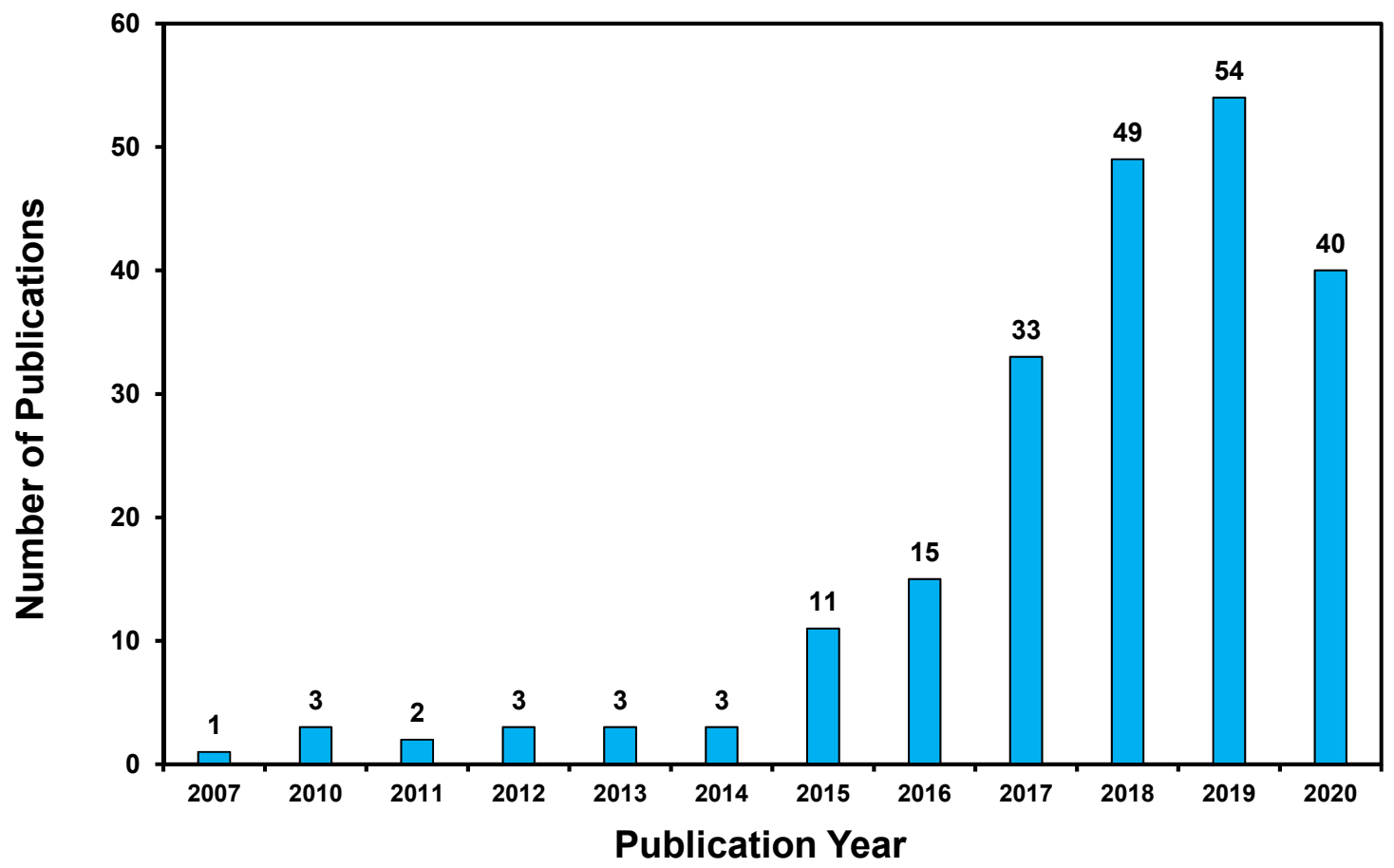

Figure 2. Number of papers on eutectic solvents in liquid-liquid extraction processes from 2007 to 2020 (internet search on Scopus, 15 June 2020). Keywords: "eutectic solvents" and "liquid-liquid extraction."

To analyze in more detail the 217 publications found on liquid-liquid extraction with eutectic solvents, these works have been grouped into a total of 8 categories according to the type of application. These categories are listed below ordered from earliest to newest applications. Later, the articles published in each of these categories are analyzed:

1. Separation of solutes from oils and biodiesel.

2. Separation of hydrocarbons.

3. Separation of alcohols from hydrocarbons.

4. Separation of value-added compounds.

5. Formation of Aqueous Biphasic Systems (ABS) using eutectic solvents.

6. Separation of organic compounds using hydrophobic eutectic solvents (HES).

7. Separation of metals using hydrophobic eutectic solvents (HES).

8. Development of analytical methods using eutectic solvents.

Considering the categories described above, Figure 3 represents the percentage distribution of the 217 articles published on liquid-liquid extraction using eutectic solvents. As seen, eutectic solvents are being widely studied in the development of new analytical methodologies, being the category with the largest number of published articles. 


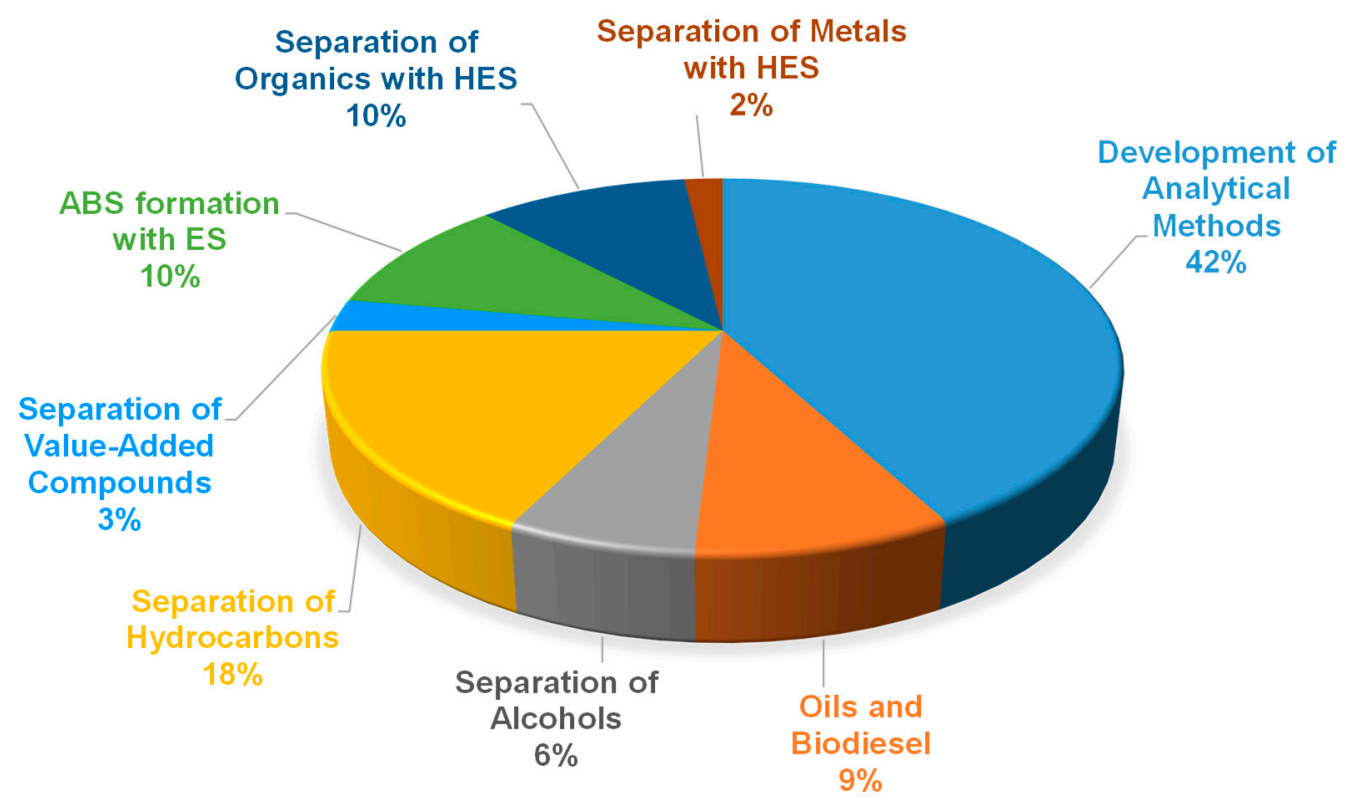

Figure 3. Percentage distribution of the 217 published papers (2007-2020) on eutectic solvents (ES) in liquid-liquid extraction as a function of the application.

This review is focused on the application of eutectic solvents in liquid-liquid extraction separation processes, so the development of analytical methods is out of the main objective of this work. Despite this, a global review of the analytical methods developed with these solvents will be carried out at the end of the section dedicated to eutectic solvents to describe the application of these alternative solvents in liquid-liquid microextraction. Recently, three reviews have been published focused on the analytical application of eutectic solvents [28-30]. In these works, the variables of analytical methods are analyzed in greater depth.

Among the 217 works found, 126 are focused on the development of separation and purification processes of solutes by liquid-liquid extraction. As seen in Figure 3, the application of eutectic solvents in hydrocarbon separation has been the most studied to date, followed by two other more recent applications, which are the formation of aqueous biphasic systems and the extraction of organic compounds using hydrophobic eutectic solvents. Two of the earliest proposed applications of eutectic solvents in liquid-liquid extraction, the separation of solutes from oils and biodiesel and the separation of alcohols from hydrocarbons are found below with $9 \%$ and $6 \%$ of the published papers, respectively.

\subsection{Eutectic Solvents in Liquid-liquid Extraction Processes}

In this subsection, a critical review of the articles published to date on the application of eutectic solvents in liquid-liquid extraction processes is done. In each of the eight categories, a description of the evolution of the use of these solvents is made, highlighting the main results obtained. Special emphasis has been placed on comparing the results obtained using eutectic solvents with those using conventional organic solvents or other alternative solvents, such as ionic liquids. Besides, the extraction of solutes from real streams and the use of large scales have been also analyzed in the reviewed papers. Thus, the potential use of eutectic solvents at the industrial scale will be assessed in each of the applications.

Another important aspect that has been highlighted in the different articles is the regeneration and reuse of eutectic solvents to ensure the economic viability of the extraction process. At the end of this subsection, a review of the different predictive methods used in the selection of eutectic solvents, the thermodynamic models used for the correlation of the liquid-liquid equilibria and the simulation methodologies of the separation processes are also described. 


\subsubsection{Separation of Organic Compounds from Oils and Biodiesel}

In 2007, Abbott et al. [31] proposed the use of the (quaternary ammonium salts + glycerol) eutectic solvent to extract glycerol from biodiesel. This was the first application of eutectic solvents in liquid-liquid extraction processes. From 2007 to 2020, the extraction of organic compounds from biodiesels and oils has been widely studied, as can be observed in the papers listed in Table 1.

Table 1. Eutectic Solvents (ES) in the Liquid-liquid Extraction from Vegetable Oils and Biodiesel.

\begin{tabular}{|c|c|c|c|c|}
\hline Solute & Raffinate & Eutectic Solvent & Year & Ref. \\
\hline Glycerol & Biodiesel & Quaternary ammonium salts + glycerol & 2007 & [31] \\
\hline Glycerol & Palm Oil-Biodiesel & $\begin{array}{l}\text { Choline chloride }(\mathrm{ChCl})+\text { ethylene glycol } \\
\mathrm{ChCl}+2,2,2 \text {-trifluoroacetamide }\end{array}$ & 2010 & [32] \\
\hline Glycerol & Palm Oil-Biodiesel & $\mathrm{ChCl}+$ glycerol & 2010 & {$[33]$} \\
\hline Glycerol & Palm Oil-Biodiesel & $\begin{array}{l}\text { Methyl triphenyl phosphonium bromide }+ \\
\text { (glycerol, ethylene glycol or triethylene glycol) }\end{array}$ & 2011 & [34] \\
\hline Glycerol & Palm Oil-Biodiesel & Ternary ES: $\mathrm{ChCl}+$ glycerol + ethylene glycol & 2015 & {$[35]$} \\
\hline $\mathrm{KOH}$ & Palm Oil-Biodiesel & $\begin{array}{c}\text { methyltriphenylphosphonium } \\
\text { bromide (MTPB) }\end{array}$ & 2011 & {$[36]$} \\
\hline Palmitic Acid & Palm Oil & $\begin{array}{l}\text { Betaine monohydrate + propionic acid } \\
\text { Binary ES: Betaine monohydrate + (glycerol or }\end{array}$ & 2017 & {$[37]$} \\
\hline $\begin{array}{c}\text { Palmitic acid, } \\
\beta \text {-Carotene, } \\
\alpha \text {-tocopherol }\end{array}$ & Palm Oil & $\begin{array}{l}\text { propylene glycol) } \\
\text { Ternary ES: Betaine monohydrate + (propylene } \\
\text { glycol + glycerol) or (propylene glycol + } \\
\text { propionic acid) or (glycerol + propionic acid) }\end{array}$ & 2018 & {$[38]$} \\
\hline Palmitic Acid & Palm Oil & $\begin{array}{c}\text { Betaine monohydrate + propionic acid } \\
\text { Betaine monohydrate + acetic acid } \\
\mathrm{ChCl}+\text { acetic acid }\end{array}$ & 2020 & [39] \\
\hline Tocols & Palm Oil & $\begin{array}{l}\mathrm{ChCl}+\text { malonic acid } \\
\mathrm{ChCl}+\text { citric acid }\end{array}$ & 2015 & {$[40]$} \\
\hline $\begin{array}{l}\text { Phenol, } p \text {-Cresol, } \\
\quad \beta \text {-naphthol }\end{array}$ & Model Oil & $\begin{array}{c}\mathrm{ChCl}+\text { ethylene glycol } \\
\mathrm{ChCl}+\text { glycerol } \\
\mathrm{ChCl}+\text { urea } \\
\text { MTPB + ethylene glycol }\end{array}$ & 2014 & {$[41]$} \\
\hline $\begin{array}{l}\text { Hydroxybenzoic acid, } \\
\text { Protocathecuic acid, } \\
\text { Vanillic acid, Tyrosol, } \\
\text { p-Coumaric acid, } \\
\text { Caffeic acid, Apigenin, } \\
\text { Pinoresinol }\end{array}$ & Virgin Olive Oil & Lactic acid + glucose + water (mole ratio 6:1:6) & 2016 & [42] \\
\hline $\begin{array}{l}\text { Hydroxytyrosol and } \\
\text { Tyrosol derivatives }\end{array}$ & Olive Oil & Lactic acid + glucose + water (mole ratio 3:1:3) & 2019 & [43] \\
\hline Free Fatty Acids & Crude Rice Bran Oil & $\begin{array}{c}\mathrm{ChCl}+\text { ethylene glycol, } \mathrm{ChCl}+\text { glycerol, } \\
\mathrm{ChCl}+\text { Urea, } \mathrm{ChCl}+\text { Oxalic acid, } \\
\text { and Betaine Monohydrate + Glycerol } \\
\mathrm{ChCl}+\text { glycerol }\end{array}$ & 2019 & {$[44]$} \\
\hline Terpenes & Citrus Essential Oils & $\begin{array}{c}\mathrm{ChCl}+(1,3 \text {-butanediol, 2,3-butanediol, } \\
\text { 1,2-propanediol or 1,3-propanediol) }\end{array}$ & \multicolumn{2}{|c|}{ 2018-2019 [45,46] } \\
\hline
\end{tabular}

The separation of glycerol from biodiesel has been studied in several published articles by extraction with eutectic solvents. Abbott et al. [31] tested various combinations of quaternary ammonium salts in the extraction of glycerol from biodiesel produced using $\mathrm{KOH}$, ethanol and vegetable oils. A batch procedure was also used with both rapeseed and soybean oil $(500 \mathrm{~g})$ and $150 \mathrm{~g}$ of $\mathrm{KOH}$, confirming the applicability of eutectic solvents in the extraction of glycerol from biodiesel at larger scales. The reuse of the eutectic solvent was also studied. To recycle the salt, the separation of choline chloride from glycerol was successfully done using 1-butanol as anti-solvent. The most outstanding results were obtained using the eutectic solvent formed by choline chloride and glycerol with a 1:1 glycerol:salt molar ratio.

Research on the separation of glycerol from biodiesel has been continued in several articles published by Shahbaz et al. [32,34], Hayyan et al. [33] and Ho et al. [35]. In all these works, the liquid-liquid extraction of glycerol from palm oil-based biodiesel has been studied using different eutectic solvents. Shahbaz et al. (2010) [32] used eutectic solvents formed by choline chloride and 
(ethylene glycol or 2,2,2-trifluoroacetamide) in several mole ratios. According to the results, the optimal molar compositions of the eutectic solvents to maximize the removal of glycerol from palm oil-based biodiesel were (1:2.5) for the (choline chloride + ethylene glycol) eutectic solvent and (1:1.75) for the (choline chloride + 2,2,2-trifluoroacetamide) solvent.

Hayyan et al. (2010) [33] used the eutectic solvent formed by choline chloride and glycerol at 1:1, 1:1.5 and 1:2 molar ratios to separate glycerol from palm oil-based biodiesel. The optimal mole ratio in the solvent was 1:1, being this result in agreement with the optimization done by Abbott et al. [31]. In this work, the used solvent was recovered after the extraction by crystallizing the ammonium salt with 1-butanol and an industrial process for the recovery is fully described. The purified biodiesel was compared with the international standards EN 14214 and ASTM D6751, fulfilling both standards regarding glycerol content in biodiesel.

Shahbaz et al. (2011) [34] studied the application of methyl triphenyl phosphonium bromide-based eutectic solvents in the recovery of glycerol from palm oil-based biodiesel. Solvents formed by methyl triphenyl phosphonium bromide as hydrogen bond acceptor and three different hydrogen bond donors: glycerol, ethylene glycol and triethylene glycol were tested. The obtained biodiesel after the extraction was compared with the ASTM D6751 international biodiesel standard. The ethylene glycol and triethylene glycol were found to be successful to remove all of the free glycerol from palm-oil-based biodiesel fulfilling the cited standard. The optimum molar ratio for the ethylene glycol and triethylene glycol eutectic solvents was found to be $0.75: 1$ (DES:biodiesel) based on the high removal of total glycerol and minimum usage of solvent.

Shahbaz et al. (2011) [36] also used eutectic solvents to remove the residual catalyst (KOH) from palm oil-based biodiesel. Nine eutectic solvents based on choline chloride $(\mathrm{ChCl})$ and another nine solvents based on methyltriphenylphosphonium bromide (MTPB) were studied. The highest values of $\mathrm{KOH}$ removal were obtained for the ChCl:glycerol and MTPB:glycerol eutectic solvents, with yields of $98.59 \%$ and $97.57 \%$, respectively. In this work, the reusability of the solvents to remove $\mathrm{KOH}$ from biodiesel was also studied in five successive extractions using fresh biodiesel batches.

More recently, Ho et al. (2015) [35] studied the separation of glycerol from palm oil-based biodiesel using ternary eutectic solvents. These ternary mixtures were formed by choline chloride, glycerol and ethylene glycol in several proportions. The average total glycerol removal efficiency for the studied ternary eutectic solvents was $81.43 \%$, which was higher than both ammonium and phosphunium-based solvents reported in the previously described works of Hayyan et al. (2010) and Shahbaz et al. (2011) [33,34]. Therefore, the use of ternary eutectic solvents seems to be justified as it has shown better yields than binary eutectic solvents.

Analyzing all the works that have studied the separation of glycerol from biodiesel, it should be noted that real biodiesel streams have been used and eutectic solvents have reached the requirements set by international standards. In addition, solvent recovery has been studied and relatively large-scale tests have been carried out. To confirm the real application of these solvents, successive extraction and regeneration cycles at larger scales should be done.

As seen in Table 1, the extraction of palmitic acid from palm oil using eutectic solvents has been studied in several works. In the papers published by Israyandi et al. (2017), Zahrina et al. (2018) and Mulia et al. (2020) [37-39], betaine monohydrate-based eutectic solvents were used for this application. The highest extraction yields of palmitic acids were obtained using the mixture of betaine monohydrate and glycerol in a molar ratio of 1:8, achieving an extraction efficiency of $49.4 \%$ [38]. The selective extraction of palmitic acid was studied, also analyzing the extraction efficiency of antioxidants ( $\beta$-Carotene and $\alpha$-tocopherol) present in the palm oil. According to the obtained results, most of the antioxidants were preserved in the refined palm oil, so the eutectic solvents for could be used in the deacidification of palm oil for food purposes [38]. The solvent recovery was also evaluated by simple cooling of the extract phase. The extracted palmitic acid solid was recovered using a vacuum filter [39]. In this application, real samples of palm oil have been used to study the selective separation of palmitic acid and the recovery of the extracted solute has been achieved. Larger 
scale and successive cycle studies should be performed to demonstrate the technical feasibility of using eutectic solvents in the extraction of palmitic acid.

The separation of phenolic and value-added compounds from oils using eutectic solvents has also been studied in different works. In 2014, Gu et al. [41] proposed the use of solvents formed by choline chloride and (ethylene glycol, glycerol or urea) and the mixture (methyltriphenylphosphonium bromide + ethylene glycol) to extract phenol, $p$-cresol and $\beta$-naphthol from a model oil. The obtained extraction efficiencies using the eutectic solvents were comparable to those using the 1-ethyl-3-methylimizadolium tetrafluoroborate $\left([\mathrm{bmim}]\left[\mathrm{BF}_{4}\right]\right)$ ionic liquid and were substantially higher than the efficiencies using water, ethylene glycol or the aqueous solution of choline chloride.

In 2015, the extraction of tocols from palm oil was studied by Abdul Hadi et al. [40] using eutectic solvents formed by choline chloride and (acetic, malonic or citric acid). The highest extraction yields were obtained for the choline chloride + malonic acid eutectic solvents. The regeneration and reuse of the solvents was studied using a mixture of water and hexane $(4: 1, v / v)$ to separate the extracted tocols. The eutectic solvent was regenerated in a rotary evaporator to remove volatiles at $60{ }^{\circ} \mathrm{C}$ for $15 \mathrm{~h}$. The regenerated solvent showed a slightly yellow color, possibly due to traces of oil and tocols entrapped but it was successfully used in another set of extraction.

The application of eutectic solvents in the production of biodiesel from non-vegetable oils has been also studied. Pan et al. (2017) [47] used eutectic solvents formed by choline chloride and formic, acetic, oxalic and propandioic acids in the obtaining of biodiesel from wet and unbroken microalgae biomass. The highest yields were obtained using the eutectic solvent composed of choline chloride and acetic acid in one step of lipid extraction from microalgae and biodiesel production using $\mathrm{H}_{2} \mathrm{SO}_{4}$ as the catalyst.

The use of eutectic solvents in the production of biodiesel from animal fats has been also reported in the literature. Sander et al. (2018) [48] applied the eutectic solvent formed by choline-chloride and ethylene glycol in a molar ratio of 1:2.5 in the extraction of glycerol from biodiesel obtained from veal and beef tallow, lard, chicken and goose fats. The effect of temperature in the extraction of glycerol was studied obtaining extraction yields of glycerol close to $100 \%$ at $50{ }^{\circ} \mathrm{C}$ using the previously cited eutectic solvents in the extraction of glycerol from all tested biodiesels from animal fats.

Recently, Sander et al. (2020) [49] have also applied the eutectic solvents in the synthesis of biodiesel from waste coffee grounds. The eutectic solvent composed of potassium carbonate and ethylene glycol with a 1:10 molar ratio was used in the extractive deacidification of waste coffee grounds oil, obtaining extraction yields of $86-94 \%$, being these values higher than those achieved using the conventional method based on esterification with $\mathrm{H}_{2} \mathrm{SO}_{4}$. In this work, the eutectic solvent composed of choline chloride and ethylene glycol with a 1.0:2.5 molar ratio was also used in the extraction of glycerol and glycerides from the obtained biodiesel. This extraction was performed in batch experiments and a continuous column extractor, achieving glycerol and glyceride contents in the purified biodiesel below the EN 14214 limit using the continuous method. Therefore, the eutectic solvents were successfully used in the deacidification of waste coffee grounds and the purification of the obtained biodiesel from the same waste.

Eutectic solvents have been also used to recover value-added compounds from olive oil. Paradiso et al. (2016 and 2019) [42,43] have reported the separation of hydroxybenzoic acid, protocathecuic acid, vanillic acid, $p$-coumaric acid, caffeic acid, apigenin, pinoresinol, tyrosol, hydroxytyrosol and tyrosol derivatives. In these works, ternary eutectic solvents formed by (lactic acid + glucose + water) have been employed. According to the authors, this separation technique based on eutectic solvents could be applied in olive mills to determine the amount of phenolic compounds in oils.

In 2019, Zullaikah et al. [44] applied several eutectic solvents to extract free fatty acids and a bioactive compound ( $\gamma$-oryzanol) from crude rice bran oil. In this work, four eutectic solvents formed by choline chloride + (ethylene glycol, glycerol, urea or oxalic acid) were studied and a natural eutectic 
solvent (NADES) formed by betaine monohydrate and glycerol in a mole ratio of 1:8 was also used. The highest value of recovery of $\gamma$-oryzanol was obtained using the NADES.

Finally, the eutectics solvents have been also proposed to be used in the deterpenation of citrus essential oils [45,46]. To this purpose, choline chloride + (glycerol, 1,3-butanediol, 2,3-butanediol, 1,2-propanediol or 1,3-propanediol) eutectic solvents have been tested in the separation of limonene from linalool and in the deterpenation of a crude orange essential oil. The eutectic solvents showed selectivities higher than those achieved using an ethanol aqueous solution and comparable to the values employing the 1-ethyl-3-methylimidazolium ethylsulfate ionic liquid. In addition, the distribution ratios of linalool were higher than those using ethylene glycol or the 1-ethyl-3-methylimidazolium methanesulfonate ionic liquid. Therefore, the tested eutectic solvents exhibited competitive extractive properties to be used in the deterpenation of essential oils.

\subsubsection{Separation of Aromatic, Sulfur or Nitrogen Hydrocarbons from Alkanes}

The separation of hydrocarbons with eutectic solvents is the most studied application until the date in liquid-liquid extraction, fundamentally seeking three objectives: to reduce the aromatic, sulfur or nitrogen contents in fuels. To analyze the evolution of the use of eutectic solvents in these applications, the published articles have been grouped according to the type of solutes extracted.

In Table 2, the articles that have studied the extraction of aromatic hydrocarbons (benzene, toluene, ethylbenzene and xylene) from $n$-alkanes using eutectic solvents are collected. As can be seen, the vast majority of works have studied the extraction of a single aromatic hydrocarbon from an $n$-alkane, despite the fact that liquid fuels are much more complex mixtures.

The first articles that studied the separation of aromatic hydrocarbons using eutectic solvents were published by Kareem et al. in 2012 and 2013 [50-52]. These authors studied the separation of benzene from $n$-hexane and the separation of toluene from $n$-heptane using mixtures of phosphonium salts with ethylene glycol or sulfolane as solvents. They studied the influence of the molar relationship between salt and hydrogen bond donor on the extractive capacity of the solvent, without working exactly at the eutectic point. The obtained benzene or toluene distribution ratios and the aromatic/aliphatic selectivities using eutectic solvents were lower than the reported using pyridinium-based ionic liquids in the same separation. A comparison with the extractive properties of sulfolane and $N$-formylmorpholine was also done, showing the eutectic solvents values close to those using the conventional solvents.

In 2013, the separation of aromatic hydrocarbons from $n$-alkanes using quaternary ammonium salts-based eutectic solvents was firstly studied [53]. Gonzalez et al. [53] tested the eutectic solvents formed by choline chloride + (lactic acid or glycerol) in the separation of benzene from $n$-hexane. The choline chloride-based eutectic solvents showed benzene distribution ratios lower than sulfolane and the obtained by Kareem et al. (2012) using the eutectic solvent formed by methyltriphenylphosphonium bromide and ethylene glycol in the molar ratio of 1:4 [50]. By contrast, the benzene $/ n$-hexane selectivities were substantially higher using the choline chloride + (lactic acid or glycerol) eutectic solvents than those for the sulfolane and the phosphonium-based eutectic solvent.

Therefore, choline chloride-based eutectic solvents could be applied to obtain aromatic hydrocarbons with high purity but a higher solvent-to-feed ratio than that using sulfolane should be needed. 
Table 2. Eutectic Solvents in the Liquid-liquid Extraction of Aromatic Hydrocarbons.

\begin{tabular}{|c|c|c|c|c|}
\hline Solute & Raffinate & Eutectic Solvent & Year & Ref. \\
\hline Benzene & $n$-Hexane & Methyltriphenylphosphonium bromide + ethylene glycol & 2012 & [50] \\
\hline Benzene and Ethylacetate & $n$-Hexane & $\begin{array}{l}\text { Choline chloride + lactic acid } \\
\text { Choline chloride + glycerol }\end{array}$ & 2013 & [53] \\
\hline $\begin{array}{l}\text { Benzene, Toluene, } \\
\text { Ethylbenzene and } \mathrm{m} \text {-Xylene }\end{array}$ & n-Octane & Tetrabutylammonium bromide + sulfolane & 2014 & [54] \\
\hline Benzene, Toluene or Pyridine & n-Hexane & $\begin{array}{l}\text { Choline chloride }+ \text { glucose } \\
\text { (Tetramethylammonium chloride, tetraethylammonium chloride, }\end{array}$ & 2016 & [55] \\
\hline Benzene & n-Hexane & $\begin{array}{c}\text { tetrabutylammonium chloride, } \\
\text { or tetrahexylammonium chloride) + } \\
\text { (ethylene glycol or glycerol) }\end{array}$ & 2017 & [56] \\
\hline Benzene & Cyclohexane & $\begin{array}{c}\text { Tetrabutylammonium bromide }+ \text { (sulfolane or triethylene glycol) } \\
\text { Methyltriphenylphosphonium bromide + (triethylene glycol or 1,2 propanediol) } \\
\text { Choline chloride + triethylene glycol }\end{array}$ & 2017 & [57] \\
\hline Benzene, Toluene & Cyclohexane, $n$-Heptane & $\begin{array}{c}\mathrm{N} \text {-ethylpyridinium bromide }+(\mathrm{N}-\text { formyl } \\
\text { morpholine or levulinic acid })\end{array}$ & 2019 & [58] \\
\hline Benzene, Cyclohexane & Thiophene, Hexadecane & $\begin{array}{l}\text { Choline chloride }+ \text { (monoethylene glycol, diethylene glycol, triethylene glycol, } \\
\text { monoethanolamine, diethanolamine; or triethanolamine) }\end{array}$ & 2019 & [59] \\
\hline Toluene & $n$-Heptane & Tetrabutylphosphonium bromide + (ethylene glycol or sulfolane) & 2012 & [51] \\
\hline Toluene & $n$-Heptane & Ethyltriphenylphosphonium iodide + (ethylene glycol or sulfolane) & 2013 & [52] \\
\hline Toluene & $n$-Heptane & $\begin{array}{l}\text { (Choline chloride, benzylcholinium chloride or tetrabutylammonium chloride) + } \\
\text { levulinic acid }\end{array}$ & 2016 & [60] \\
\hline Toluene, Quinoline & $n$-Heptane & Methyltriphenyl phosphonium bromide + (ethyleneglycol or glycerol) & 2016 & [61] \\
\hline Toluene & n-Octane & Choline chloride + malonic acid & 2018 & [62] \\
\hline Toluene & $\begin{array}{l}n \text {-Hexane, } \\
n \text {-Heptane }\end{array}$ & Choline chloride + Phenol & 2019 & [63] \\
\hline Ethylbenzene & $n$-Octane & Tetrabutylammonium bromide + (pyridine and/or ethylene glycol) & 2015 & [64] \\
\hline Ethylbenzene & Styrene & $\begin{array}{l}\text { Tetrabutyl ammonium bromide } \\
+ \text { (ethylene glycol diethylene glycol or triethylene glycol) }\end{array}$ & 2019 & {$[65]$} \\
\hline $\begin{array}{l}\text { Benzene, Toluene, Ethylbenzene, } \\
\text { Xylene }\end{array}$ & $\begin{array}{l}\text { Reformer and Pyrolysis } \\
\text { Gasolines }\end{array}$ & $\begin{array}{c}\text { Choline chloride + (ethylene glycol, glycerol, levulinic acid, phenylacetic acid, } \\
\text { malonic acid or urea) }\end{array}$ & 2018 & [66] \\
\hline
\end{tabular}


Mulyono et al. (2014) [54] studied the performance of the eutectic solvent formed by tetrabutylammonium bromide and sulfolane in the separation of benzene, toluene, ethylbenzene and $m$-xylene from $n$-octane. In this paper, a complete comparison between the distribution ratios and selectivities obtained with the eutectic solvent and those using sulfolane, propylene carbonate or ionic liquids was done. In the four separations of aromatics from $n$-octane, the eutectic solvent exhibited slightly lower distribution ratios than those for sulfolane or imidazolium and pyridinium-based ionic liquids and comparable selectivities.

Kurnia et al. (2016) [55] compared the performance of the choline chloride + glucose eutectic solvent in the separation of benzene and toluene from $n$-hexane with the sulfolane values, concluding that the distribution ratios for the conventional solvent were higher than those for the eutectic solvent, whereas the opposite trend was observed in the aromatic/aliphatic selectivity.

Naik et al. (2016) [61] also compared the extractive properties of the ethyltriphenyl phosphonium bromide + (ethyleneglycol or glycerol) eutectic solvents with those of sulfolane, obtaining lower toluene distribution ratios using the eutectic solvent. All these conclusions are in agreement with the comparison performed by Hadj-Kali et al. (2017) [67] between the extractive properties of a wide number of eutectic solvents and those for conventional solvents. They concluded that the use of eutectic solvents in the separation of aromatics from alkanes will enhance the selectivity but reduce the distribution ratio. This fact would imply that a greater flow rate of solvent in the extraction column would be necessary to achieve similar yields to those obtained with sulfolane.

As mentioned, the majority of works have been focused on the extraction process but the process of regeneration and reuse of the eutectic solvent has hardly been addressed. Salleh et al. (2017) [57] studied the separation of the extracted benzene from the tetrabutylammonium bromide + sulfolane eutectic solvent. This separation was performed in a rotary evaporator under 100 mbar vacuum and $40^{\circ} \mathrm{C}$. Four consecutive cycles of extraction and regeneration were done without observing a decrease in the extraction efficiency.

A similar approach was used by Larriba et al. (2018) [66] to regenerate the choline chloride + levulinic acid eutectic solvent after the extraction of benzene, toluene, ethylbenzene and $p$-xylene from reformer and pyrolysis gasoline models. The vapor-liquid equilibrium between the hydrocarbons and the eutectic solvents at 343.2, 353.2 and $363.2 \mathrm{~K}$ was determined using headspace gas chromatography, to optimize the solvent regeneration by flash distillation process. The used temperatures were selected after analyzing the thermal stability of the eutectic solvents obtained by thermogravimetrical analyses. According to the results obtained, the regenerated eutectic solvent with a purity greater than $99 \%$ could be recovered in a flash distillation operating at $363.2 \mathrm{~K}$ and $5 \mathrm{kPa}$. Therefore, the regeneration of eutectic solvents by distillation using vacuum in the separation of hydrocarbons seems to be technically viable.

As observed in Table 2, the simultaneous extraction of several aromatic hydrocarbons from complex mixtures has been little studied to date and the majority of works used binary mixtures formed by an aromatic and an alkane. Larriba et al. (2018) [66] used pyrolysis and reformer gasoline models formed by six and seven hydrocarbons, respectively. However, the extraction of aromatics from real gasoline has not been studied to date. This fact should be addressed to realistically assess the potential of eutectic solvents to be used at the industrial scale. Similarly, all the works have been carried out using single-stage extraction tests, so it would be necessary to use continuous extractors to evaluate the industrial applicability of these solvents in the separation of aromatics.

The application of eutectic solvents in the separation of sulfur-containing hydrocarbons has also been extensively studied, as shown in Table 3. Zhu et al. (2015) [68] proposed the use of eutectic solvents formed by choline chloride and several straight-chain monobasic acids in the removal of dibenzothiophene from cyclohexane and $p$-xylene. Combining the liquid-liquid extraction with photochemical oxidative desulfurization, the removal of dibenzothiophene reached $98.6 \%$. 
Table 3. Eutectic Solvents in the Extraction of Sulfur-Containing Aromatic Hydrocarbons.

\begin{tabular}{|c|c|c|c|c|}
\hline Solute & Raffinate & Eutectic Solvent & Year & Ref. \\
\hline Thiophene & n-Heptane & $\begin{array}{c}\text { Choline chloride }+ \text { phenol }+\mathrm{FeCl}_{4} \\
\text { Choline chloride + ethylene glycol }+\mathrm{FeCl}_{4}\end{array}$ & 2017 & [69] \\
\hline Thiophene & $\begin{array}{l}n \text {-Hexane } \\
n \text {-Octane }\end{array}$ & $\begin{array}{l}\text { Tetrahexylammonium bromide }+ \\
\text { (ethylene glycol or glycerol) }\end{array}$ & 2017 & [70] \\
\hline Thiophene & $n$-Hexane & $\begin{array}{c}\text { (Tetraethylammonium chloride or methyltriphenylphosphonium } \\
\text { bromide) + (ethylene glycol or glycerol) }\end{array}$ & 2018 & [71] \\
\hline Thiophene & $\begin{array}{l}n \text {-Hexane } \\
n \text {-Octane }\end{array}$ & $\begin{array}{l}\text { (Tetraethylammonium chloride, tetrahexylammonium bromide or } \\
\text { methyltriphenylphosphonium bromide) + (ethylene glycol or glycerol) }\end{array}$ & 2018 & {$[72]$} \\
\hline $\begin{array}{l}\text { Thiophene Benzothiophene } \\
\text { Dibenzothiophene } \\
\text { 4,6-dimethyl-dibenzothiophene }\end{array}$ & $\begin{array}{l}n \text {-Octane } \\
n \text {-Dodecane }\end{array}$ & $\begin{array}{l}\text { Choline chloride }+ \text { glycerol } \\
\text { Choline acetate }+ \text { glycerol }\end{array}$ & 2016 & [73] \\
\hline $\begin{array}{l}\text { Thiophene Benzothiophene } \\
\text { Dibenzothiophene }\end{array}$ & $n$-Decane & Choline chloride +1 ,5-pentandiol Choline chloride + glycerol & 2017 & [74] \\
\hline $\begin{array}{l}\text { Thiophene } \\
\text { Dibenzothiophene }\end{array}$ & Fuel & Tetrabutylammonium bromide + imidazole & & [75] \\
\hline Thiophene Benzothiazole & $n$-Heptane & $\begin{array}{l}\text { Tetrahexylammonium bromide }+ \\
\quad \text { (ethylene glycol or glycerol) }\end{array}$ & 2018 & [76] \\
\hline $\begin{array}{l}\text { Thiophene } \\
\text { Dibenzothiophene }\end{array}$ & Model Oil & $\begin{array}{l}\text { Tetrabutylammonium bromide }+ \\
\text { polyethylene glycol }\end{array}$ & 2019 & [77] \\
\hline Dibenzothiophene & $\begin{array}{l}\text { Cyclohexane } \\
\text { p-Xylene }\end{array}$ & Choline chloride $\left.+2 \mathrm{C}_{\mathrm{n}} \mathrm{H}_{2 \mathrm{n}+1} \mathrm{COOH}, \mathrm{n}=0,1,2,3,4\right)$ & 2015 & [68] \\
\hline Dibenzothiophene & Fuel & Tetrabutylammonium bromide + polyethylene glycol 200 & 2017 & [78] \\
\hline Dibenzothiophene & n-Octane & Screening with 49 eutectic solvents & 2018 & [79] \\
\hline $\begin{array}{l}\text { Dibenzothiophene } \\
\text { Benzothiophene }\end{array}$ & Fuel (Molecular Simulation) & $\begin{array}{l}\text { Choline chloride }+ \text { urea } \\
\text { Choline chloride + ethylene glycol }\end{array}$ & 2018 & [80] \\
\hline 2,3-Methylthiophene & $n$-Heptane & $\begin{array}{l}\text { Tetrahexylammonium bromide }+ \\
\text { (ethylene glycol or glycerol) }\end{array}$ & 2018 & {$[81]$} \\
\hline
\end{tabular}


In 2016, Zhao et al. [73] studied the extraction of thiophene, benzothiophene, dibenzothiophene and 4,6-dimethyl-dibenzothiophene from $n$-octane and $n$-dodecane using choline chloride + glycerol and choline acetate + glycerol eutectic solvents. In this paper, a comparison between the performance of both eutectic solvents and those using 71 ionic liquids was done.

The sulfur-containing hydrocarbon partition coefficients using the eutectic solvent were substantially lower than the results obtained for the majority of used ionic liquids. Therefore, the tested eutectic solvents were considered as solvents with low potential to be applied in the desulfurization of fuels.

A comparison between the extractive properties of tetrahexylammonium bromide + (ethylene glycol or glycerol) eutectic solvents and those for ionic liquids in desulfurization was also performed by Warrag et al. (2017) [70]. According to these authors, the distribution coefficients and the selectivities for the eutectic solvent were somewhat lower than those of all the studied ionic liquids. Warrag et al. (2018) [71] also compared the performance of the eutectic solvents formed by (tetraethylammonium chloride or methyltriphenylphosphonium bromide) and (ethylene glycol or glycerol) in the extraction of thiophene with the results showed by ionic liquids. The thiophene distribution ratios for all the tested eutectic solvents were lower than those using ionic liquids except for the 1-ethyl-3-methylimidazolium bis(trifluoromethylsulfonyl)imide ([emim][ $\left.\mathrm{NTf}_{2}\right]$ ). By contrast, the selectivity of the eutectic solvent formed by tetraethylammonium chloride and glycerol was the highest. Hence, eutectic solvents in sulfur-containing aromatic hydrocarbons extraction have shown low distribution coefficients but some of them may show higher selectivities than other alternative solvents, such as ionic liquids. This conclusion is similar to that previously discussed for the extraction of aromatics from alkanes.

The desulfurization of complex model fuels using eutectic solvents was first studied by Gano et al. (2017) [75]. In this work, a model fuel formed by $n$-decane, cyclohexane, iso-octane and toluene was used to extract $500 \mathrm{mg} / \mathrm{kg}$ of sulfur compounds (thiophene and dibenzothiophene) using the tetrabutylammonium bromide + imidazole eutectic solvent. In addition, two commercial fuels were also used, obtaining lower sulfur extraction yields in commercial fuels than in the simulated. The regeneration of the eutectic solvent was also studied in this work using back-extraction with water followed by evaporation under vacuum. Five consecutive extraction and regeneration cycles were done without a significant decrease in the sulfur removal efficiency of the eutectic solvent.

Therefore, eutectic solvents have shown lower extraction capacities than those of conventional organic solvents or ionic liquids in desulfurization of fuels but they have been successfully used and regenerated in extraction from real fuels. In the near future, large-scale and continuous extraction tests should be carried out with the solvents that have shown the best extraction properties in simple stage experiments, to evaluate the potential of these solvents to be applied in refineries.

The eutectic solvents have been also tested in the extraction of nitro-containing aromatic hydrocarbons and polycyclic aromatic hydrocarbons, as can be observed in Table 4 . The most studied solutes have been pyridine and quinoline. In 2016, Sander et al. [82] proposed the use of the eutectic solvents formed by choline chloride + (urea or glycerol) to separate pyridine from $n$-heptane. These authors compared the extractive properties of the eutectic solvents with literature values for ionic liquids. They found that the pyridine distribution ratios were higher using ionic liquids but the selectivity was higher for the tested eutectic solvents.

Warrag et al. (2019) [83] also compared the extractive properties of the ethyltriphenylphosphonium bromide + ethylene glycol eutectic solvent in the separation of pyridine from $n$-hexane and $n$-heptane with the literature value for ionic liquids. According to these authors, the eutectic solvent exhibited the highest values of pyridine distribution ratios and pyridine/ $n$-alkane selectivities higher than the majority of ionic liquids tested. Similar conclusions were recently published by Warrag et al. (2020) [84] in the extraction of pyridine from $n$-hexane and $n$-heptane using the methyltriphenylphosphonium bromide + glycerol eutectic solvent. This solvent showed selectivities substantially higher than those for ionic liquids and comparable pyridine distribution ratios. Therefore, the phosphonium-based eutectic solvents seem to be good candidates to be applied in the denitrogenation of fuels. 
However, analyzing the articles collected in Table 4, the denitrogenation of fuels using eutectic solvents has been only focused on the separation of nitro-containing aromatic hydrocarbons from model mixtures with alkanes. Real fuels should be also tested to confirm the applicability of these solvents at the industrial scale and the regeneration and reuse of the solvents should be also studied.

The eutectic solvents have been also proposed in the separation of polycyclic aromatic hydrocarbons from $n$-alkanes. Specifically, the separation of tetralin from $n$-dodecane has been recently studied using the eutectic solvents formed by tetrabutylphosphonium bromide (propionic acid, formic acid or levulinic acid) [85]. In this work, the regeneration of the eutectic solvent after the extraction of tetralin was studied. Due to the high boiling points of solutes, the solvent regeneration was done using back-extraction instead of distillation. In the back-extraction, water was used as a solvent to dissolve the hydrophilic eutectic solvent and to separate the hydrophobic tetralin. The subsequent separation of water and the eutectic solvents was done using flash distillation. Four cycles of extraction and regeneration were performed without observing a significant decrease in the values of selectivity and tetralin distribution ratio.

Table 4. Eutectic Solvents in the Extraction of Nitro-Containing Aromatic Hydrocarbons and Polycyclic Aromatic Hydrocarbons.

\begin{tabular}{|c|c|c|c|c|}
\hline Solute & Raffinate & Eutectic Solvent & Year & Ref. \\
\hline $\begin{array}{l}\text { Pyridine } \\
\text { Toluene }\end{array}$ & n-Hexane & $\begin{array}{l}\text { Choline chloride + urea } \\
\text { Choline chloride + glycerol }\end{array}$ & 2016 & [82] \\
\hline $\begin{array}{l}\text { Pyridine } \\
\text { Benzothiazole }\end{array}$ & $\begin{array}{l}n \text {-Hexane } \\
n \text {-Heptane }\end{array}$ & $\begin{array}{c}\text { Methyltriphenylphosphonium bromide + } \\
\text { ethylene glycol }\end{array}$ & 2019 & [83] \\
\hline Pyridine & $\begin{array}{l}\text { n-Hexane } \\
\text { n-Heptane } \\
\text { n-Octane }\end{array}$ & $\begin{array}{l}\text { Binary: (Methyltriphenylphosphonium } \\
\text { bromide + glycerol) } \\
\text { Ternary: (Methyltriphenylphosphonium } \\
\text { bromide + glycerol + ethylene glycol) }\end{array}$ & 2020 & [84] \\
\hline $\begin{array}{l}\text { Quinoline } \\
\text { Indoline }\end{array}$ & $\begin{array}{l}\text { n-Heptane } \\
\text { Toluene }\end{array}$ & $\begin{array}{l}\text { Methyltriphenylphosphonium } \\
\text { bromide + ethylene glycol }\end{array}$ & 2017 & [86] \\
\hline Quinoline & $\begin{array}{l}n \text {-Heptane } \\
\text { (Molecular } \\
\text { Simulation) }\end{array}$ & $\begin{array}{l}\text { Methyltriphenylphosphonium } \\
\text { bromide + ethylene glycol }\end{array}$ & 2018 & [87] \\
\hline Tetralin & n-Dodecane & $\begin{array}{l}\text { Tetrabutylphosphonium bromide }+ \\
\text { (Propionic Acid, Formic acid, or } \\
\text { Levulinic acid) }\end{array}$ & 2020 & [85] \\
\hline
\end{tabular}

\subsubsection{Separation of Alcohols from Hydrocarbons}

As seen in Table 5, the eutectic solvents formed by choline chloride as hydrogen bond acceptor has been widely used in the separation of linear alcohols (methanol, ethanol, $n$-propanol and $n$-butanol) from hydrocarbons due to the hydrophilic character of these solvents.

In 2013, Oliveira et al. [88] proposed the use of eutectic solvents to separate the azeotropic mixture of ethanol and $n$-heptane using the solvents formed by choline chloride with glycerol, levulinic acid or ethylene glycol. These authors compared the extractive properties of the eutectic solvents with those from literature for ionic liquids. The eutectic solvent formed by choline chloride and levulinic acid showed higher ethanol distribution ratios than ionic liquids, whereas the other two tested eutectic solvents exhibited distribution ratios comparable to the values for ionic liquids. In terms of ethanol $/ n$-heptane selectivities, the eutectic solvents achieved higher values than the majority of ionic liquids. In this work, the recovery and reuse of the eutectic solvents were also addressed. The separation of the extracted ethanol and $n$-heptane from the solvent was also successfully achieved by evaporation. Using NMR, these authors confirmed that the structure of the regenerated eutectic solvent was coincident with that for the fresh solvent.

The separation of ethanol from $n$-hexane and $n$-heptane was also studied by Rodríguez et al. (2015) using the eutectic solvents formed by choline chloride and glycolic acid or lactic acid [89]. A comparison 
with the extractive properties of ionic liquids was also done, concluding that the eutectic solvents exhibited ethanol $/ n$-alkane selectivities higher than the ionic solvents and comparable distribution ratios. In this work, the regeneration of the solvent was also achieved by evaporation of the solutes in a vacuum line.

Table 5. Eutectic Solvents in the Liquid-liquid Extraction of Alcohols from Hydrocarbons.

\begin{tabular}{|c|c|c|c|c|}
\hline Solute & Raffinate & Eutectic Solvent & Year & Ref. \\
\hline Methanol & $\begin{array}{l}\text { Toluene } \\
n \text {-Heptane }\end{array}$ & Choline chloride + malic acid & 2017 & {$[90]$} \\
\hline $\begin{array}{l}\text { Methanol } \\
\text { Ethanol }\end{array}$ & Benzene & $\begin{array}{c}\text { Choline chloride }+ \text { (ethylene glycol, levulinic acid or } \\
\text { 1,2-propanediol) }\end{array}$ & 2018 & {$[91]$} \\
\hline Ethanol & $n$-Heptane & $\begin{array}{c}\text { Choline chloride + (glycerol, levulinic acid or } \\
\text { ethylene glycol) }\end{array}$ & 2013 & {$[88]$} \\
\hline Ethanol & $\begin{array}{l}n \text {-Hexane } \\
n \text {-Heptane }\end{array}$ & Choline chloride + (glycolic acid or lactic acid) & 2015 & [89] \\
\hline Ethanol & Methyl ethyl ketone & $\begin{array}{l}\text { (Choline chloride or tetramethylammonium chloride) } \\
\qquad+ \text { glycerol }\end{array}$ & 2016 & {$[92]$} \\
\hline Ethanol & $\begin{array}{l}n \text {-Hexane } \\
n \text {-Heptane } \\
n \text {-Octane }\end{array}$ & $\begin{array}{l}\text { Choline chloride + (urea or 1,2-propanediol) } \\
\text { Tetrabutylammonium bromide + levulinic acid }\end{array}$ & 2017 & {$[93]$} \\
\hline Ethanol & $n$-Hexane & Choline chloride + (oxalic acid or malonic acid) & 2017 & {$[94]$} \\
\hline Ethanol & $\begin{array}{l}n \text {-Hexane } \\
n \text {-Heptane }\end{array}$ & $\begin{array}{l}\text { Binary: Choline chloride }+1 \text {,2-propanediol }) \\
\text { Ternary: Choline chloride }+(1,2 \text {-propanediol }+ \text { water })\end{array}$ & 2018 & {$[95]$} \\
\hline Ethanol & Dimethyl carbonate & $\begin{array}{c}\text { Choline chloride + } \\
\text { (glycerol, ethylene glycol, urea or } \\
\text { malonic acid) }\end{array}$ & 2019 & [96] \\
\hline $\begin{array}{l}\text { Ethanol } \\
n \text {-Propanol } \\
n \text {-Butanol }\end{array}$ & $\begin{array}{l}\text { Ethyl acetate } \\
n \text {-Propylacetate } \\
n \text {-Butylacetate }\end{array}$ & Choline chloride + malonic acid & 2018 & {$[97]$} \\
\hline $\begin{array}{l}\text { Ethanol } \\
n \text {-Propanol } \\
n \text {-Butanol }\end{array}$ & $\begin{array}{l}\text { (Ethyl, propyl or } \\
\text { butyl)acetate } \\
\text { (Ethyl, propyl or } \\
\text { butyl)propionate }\end{array}$ & Choline chloride + glutaric acid & 2019 & {$[98]$} \\
\hline $\begin{array}{l}\text { Phenol } \\
\text { Cresol }\end{array}$ & $\begin{array}{l}n \text {-Hexane, } \\
\text { Toluene } \\
p \text {-Xylene }\end{array}$ & $\begin{array}{l}\text { Choline chloride, } \\
\text { triethylamine hydrochloride or ethylamine hydrochloride } \\
\text { to form eutectic solvents }\end{array}$ & 2012 & [99] \\
\hline $\begin{array}{l}\text { Phenol, } \\
o, m, p \text {-Cresol }\end{array}$ & Coal tar & Imidazole to form eutectic solvents & 2015 & [100] \\
\hline Cresols & $n$-Hexane & Imidazole to form eutectic solvents & 2016 & {$[101]$} \\
\hline Phenol & Toluene & $\begin{array}{c}\text { Choline chloride, triethylethanaminium chloride or } \\
\text { trimethylmethanaminium chloride to form } \\
\text { eutectic solvents }\end{array}$ & 2016 & [102] \\
\hline
\end{tabular}

Samarov et al. (2017) [97] studied the application of the eutectic solvents formed by choline chloride and oxalic acid or malonic acid in the extraction of ethanol from $n$-hexane. A comparison with the literature values of ionic liquids and water was done. These authors concluded that the eutectic solvents exhibited better ethanol $/ n$-hexane selectivities than the ionic liquids. By contrast, water was revealed as a better agent to separate ethanol from $n$-hexane than the eutectic solvents considering distribution ratios and selectivities. This comparison shows the low real applicability of eutectic solvents in this application, as they showed worse extractive properties than water.

In addition to studying the separation of linear alcohols from linear or aromatic hydrocarbons, the extraction of ethanol from methyl ethyl ketone [92] and dimethyl carbonate [96] has been reported. In the separation from the ketone, the eutectic solvents composed of choline chloride or tetramethylammonium chloride and glycerol exhibited better extractive properties than those using pure glycerol [92]. In the separation of ethanol from dimethyl carbonate, selectivities higher than 400 were obtained using the (choline chloride + urea) [96]. Therefore, promising results have been obtained in both separations of ethanol. In the nearest future, solvent extraction and regeneration cycles should be also addressed and it is necessary a more complete comparison with other solvents.

The extraction of linear alcohols (ethanol, $n$-propanol and $n$-butanol) from acetates and propionates using eutectic solvents have also been studied by Samarov et al. $[97,98]$. These authors compared the selectivities obtained using the eutectic solvent formed by choline chloride and malonic acid with 
those for ionic liquids from literature. They concluded that the 1-ethyl-3-methylimidazolium hydrogen sulfate ([emim] $\left[\mathrm{HSO}_{4}\right]$ ) and 1-hexyl-3-methylimidazolium hydrogen sulfate ([hmim] $\left.\left[\mathrm{HSO}_{4}\right]\right)$ ionic liquids exhibited higher values of selectivity than the experimental for the eutectic solvents in the separation of ethanol from ethyl acetate, in the separation of $n$-propanol from $n$-propyl acetate and in the extraction of $n$-butanol from $n$-butyl acetate.

Finally, the separation of phenols and cresols from hydrocarbons has been studied using salts or imidazole to form a eutectic solvent. In 2012, Pang et al. [99] proposed the use of three salts (choline chloride, triethylamine hydrochloride or ethylamine hydrochloride) to separate phenol and cresol from hydrocarbons by forming eutectic solvents. To recover and reuse the choline chloride, diethyl ether was found to be an efficient solvent to recover the ammonium salt. Three consecutive cycles of separation and salt regeneration were done without affecting the phenol removal. A similar approach was used by Jiao et al. in the separation of phenols and cresols from coal tar and $n$-hexane using imidazole to form a eutectic solvent with the solutes [100,101]. In this case, water was used as an efficient solvent to recover the imidazole and three separation-regeneration cycles were successfully performed. Lin et al. (2016) [102] also studied the separation of phenol from toluene using choline chloride, triethylethanaminium chloride or trimethylmethanaminium chloride as salts to form eutectic solvents with the extracted phenol. According to these authors, the highest extraction yields were obtained using the choline chloride.

\subsubsection{Separation of Value-Added Compounds}

From 2017, several papers have been focused on the separation of value-added compounds using liquid-liquid extraction with eutectic solvents. As seen in Table 6, a wide variety of compounds has been separated: vitamins, amino acids, monosaccharides, pyrethroid or antibiotics. In some of these works, in addition to the eutectic solvent, a second phase formed by organic solvents has been used for the extraction or partitioning of the solutes.

Bezold et al. (2017) [103] studied the separation of $\alpha$-tocopherol from $\beta$-tocopherol using a biphasic system formed by the eutectic solvents of choline chloride + (levulinic acid or 1,4-butanediol) and other liquid phase composed of $n$-heptane and ethanol. The proportions of the solvents were optimized to maximize the separation yield of tocopherols. The system formed by $n$-heptane/ethanol/(choline chloride +1 ,4-butanediol) in the proportions 30/40/30 (wt./wt./wt.), was revealed as the most promising in partition chromatography experiments. In 2019, Bezold et al. [104] used a similar system in the partition of coumarin, $\beta$-ionone, $\beta$-carotene and $\alpha$-tocopherol. In this case, the eutectic solvents were formed by menthol and levulinic acid, whereas the other liquid phase was a mixture of $n$-heptane and methanol. The effect of modifying the proportions of solvents on the partition coefficient of solutes was studied, concluding that this system was a high potential to separate the studied solutes by centrifugal partition chromatography.

Table 6. Eutectic Solvents in the Separation of Value-added Compounds

\begin{tabular}{|c|c|c|c|c|}
\hline Solute & Raffinate & Eutectic Solvent & Year & Ref. \\
\hline$\alpha$-Tocopherol & $\beta$-Tocopherol & $\begin{array}{l}\text { Choline chloride }+ \text { (levulinic acid or 1,4-butanediol) with } \\
\text { other liquid phase formed by ( } n \text {-heptane }+ \text { ethanol) }\end{array}$ & 2017 & [103] \\
\hline $\begin{array}{l}\text { Chloromycetin } \\
\text { Thiamphenicol }\end{array}$ & Milk & $\begin{array}{l}\text { Choline chloride + glycerol with other liquid phase } \\
\text { formed by chloroform }\end{array}$ & 2017 & [105] \\
\hline Vitamin E & Red Palm Biodiesel & Potassium carbonate + glycerol & 2018 & [106] \\
\hline $\begin{array}{l}\text { Partition of: Couma } \\
\text { and } \alpha-\end{array}$ & $\begin{array}{l}\beta \text {-Ionone, } \beta \text {-Carotene } \\
\text { opherol }\end{array}$ & $\begin{array}{l}\text { Menthol + levulinic acid with other liquid phase formed } \\
\text { by ( } n \text {-heptane + methanol) }\end{array}$ & 2019 & [104] \\
\hline $\begin{array}{l}\text { Monosaccharides } \\
\text { and Amino Acids }\end{array}$ & Kelp & $\begin{array}{c}\text { Two phases using hydrophilic and hydrophobic } \\
\text { eutectic solvents. } \\
\text { Hydrophilic: Choline chloride + (caffeic acid } \\
\text { and/or glycerol) } \\
\text { Hydrophobic: Tetrabutylammonium chloride + (octanoic } \\
\text { acid and/or decanoic acid) }\end{array}$ & 2020 & [107] \\
\hline
\end{tabular}


The extraction of vitamin E from red palm biodiesel has been also addressed using eutectic solvents. Manurung et al. (2018) [106] used solvents formed by potassium carbonate and glycerol at salt:glycerol molar ratios of 1:5, 1:6 and 1:7. The highest extraction yields were achieved in the extraction of $\gamma$-tocotrienol, $\delta$-tocotrienol and $\alpha$-tocotrienol from biodiesel using the potassium carbonate + glycerol eutectic solvent with a molar ratio of 1:6.

The extraction of the antibiotics, chloromycetin and thiamphenicol from milk was studied by Li et al. (2017) [105] using the eutectic solvent formed by choline chloride and glycerol and a second liquid phase composed of chloroform. Using the ratio of 2:1 in volume for (the eutectic solvent: chloroform) system, the recoveries of chloromycetin and thiamphenicol achieved values of $87.23 \%$ and $83.17 \%$, respectively.

Finally, the use of systems formed by hydrophobic and hydrophilic eutectic solvents has recently been proposed for the recovery of monosaccharides and amino acids from kelp [107]. Li et al. (2020) have used air assisted dispersive liquid-liquid microextraction in a liquid-liquid system consisting of a hydrophilic eutectic solvent composed of choline chloride and (caffeic acid and/or glycerol) and a hydrophobic eutectic solvent formed by tetrabutylammonium chloride and (octanoic acid and/or decanoic acid). Using this innovative separation system, high values of recovery of galactose, fucose, tyrosine and valine from kelp were obtained.

As seen, the application of eutectic solvents in the separation of high added value compounds requires the addition of a second organic phase to achieve the partition of the solutes. This approach is similar to that used in the formation of aqueous biphasic systems that will be described below, in which the generation of two immiscible phases for the partition of solutes is sought.

\subsubsection{Aqueous Biphasic Systems (ABS) with Eutectic Solvents to Separate Organic Compounds}

Aqueous biphasic systems composed of polymers or salts have been widely used to selectively separate or purify bioactive compounds. From 2003, the application of ionic liquids in the formation of ABS has been increased, tending in recent years towards the use of biocompatible ionic liquids [108]. In 2014, Zeng et al. first proposed the use of eutectic solvents in the formation of ABS for protein partitioning [109]. In this work, extraction efficiencies of bovine serum albumin close to $100 \%$ were obtained using the eutectic solvent formed by choline chloride and urea and adding $\mathrm{K}_{2} \mathrm{HPO}_{4}$. Since this first article, 21 articles have been published on the use of eutectic solvents in the formation of ABS, as can be seen in Table 7 . 
Table 7. Formation of Aqueous Biphasic Systems (ABS) with Eutectic Solvents

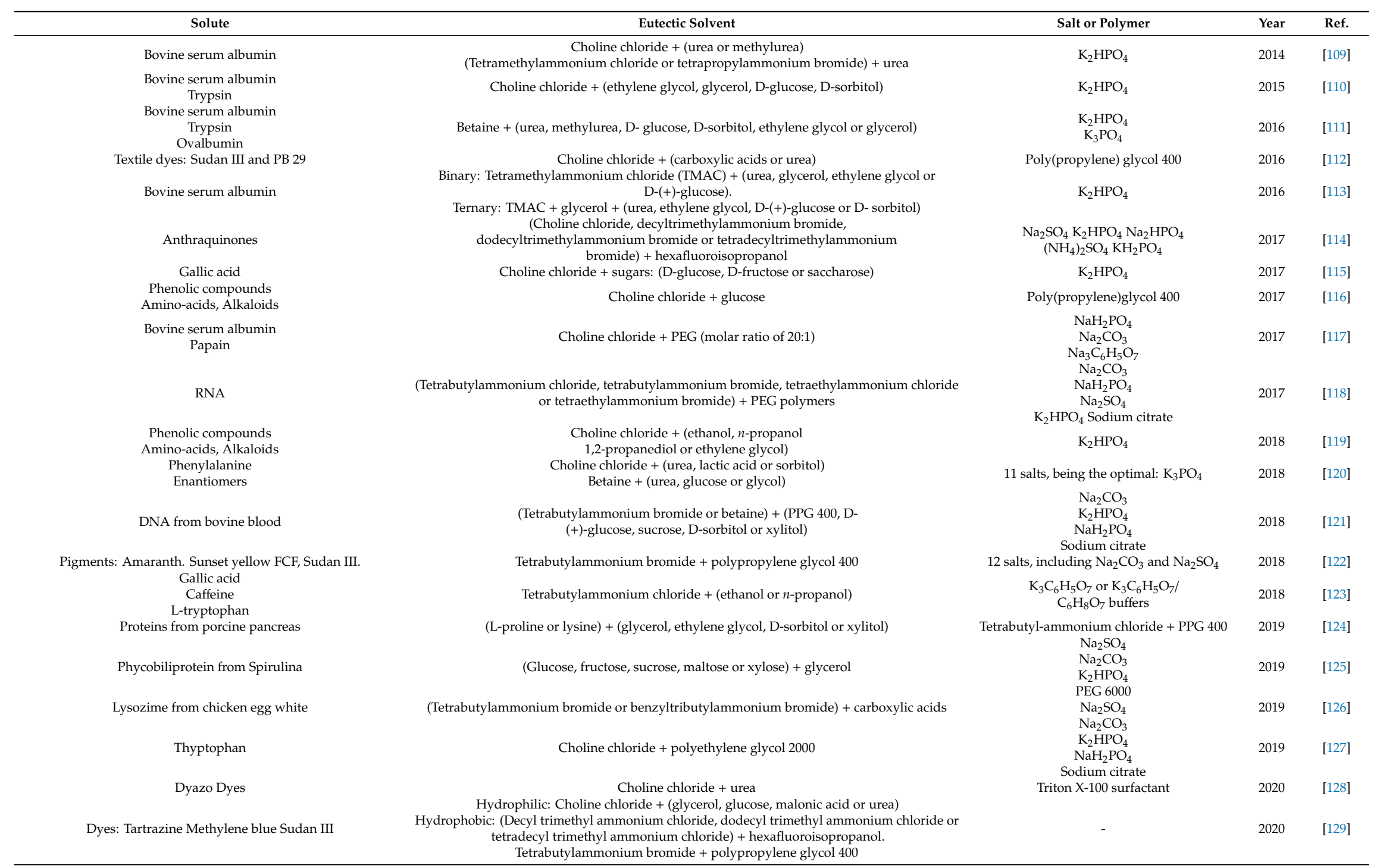


In 2015, the partitioning of bovine serum albumin and trypsin in ABS formed by choline chloride-based eutectic solvents was studied by Xu et al. [110]. In the optimal conditions, the extraction efficiencies for bovine serum albumin and trypsin achieved values of $98.16 \%$ and $94.36 \%$, respectively, confirming the great potential of ABS formed by eutectic solvents in the purification of proteins and enzymes.

In 2016, Passos et al. published a very relevant article on the application of eutectic solvents in the formation of ABS [112]. In this work, these authors demonstrated that the eutectic solvent integrity is destroyed in the ABS, because of the disruption of the eutectic solvent hydrogen-bond complex and the preferential solvation of the isolated components by water. In addition, a nonstoichiometric partition of the hydrogen bond donor and acceptor were found in the coexisting phases. Therefore, the eutectic solvent-based ABS must be considered as quaternary instead of ternary systems. Passos et al. also proposed in this paper the use of systems formed by choline chloride, (carboxylic acids or urea) and poly(propylene) glycol 400 in the separation of two textile dyes: Sudan III and PB 29. The application of eutectic solvent-based ABS in the separation of dyes has been subsequently studied in various articles. Zhang et al. (2018) [122] have applied the eutectic solvents formed by tetrabutylammonium bromide and polypropylene glycol 400 in the separation of three dyes: Amaranth, Sunset yellow FCF and Sudan III. The highest extraction efficiencies were above $98 \%$ and $\mathrm{Na}_{2} \mathrm{CO}_{3}$ was revealed as the most adequate salt to split two phases. Dyazo dyes has been also separated by Fernandez et al. (2020) using the eutectic solvent composed of choline chloride and urea [128]. In this work, the selective separation of dye mixtures and their complete removal from a polluted aqueous stream was successfully achieved.

The separation of three dyes: Tartrazine, Methylene blue and Sudan III has been also studied by $\mathrm{Xu}$ et al. (2020) [129]. In this paper, a system formed by a hydrophilic eutectic solvent and a hydrophobic eutectic solvent was proposed. In this system, the recoveries of Tartrazine and Methylene blue in the hydrophilic phase were $88.64 \%$ and $92.63 \%$, respectively, the recovery of Sudan III was close to $100 \%$ in the hydrophobic phase. Therefore, the ABS formed by immiscible eutectic solvents has been revealed as good systems to separate dyes with different hydrophobicity.

In addition to the separation of dyes, ABS formed with eutectic solvents have been widely used in the separation and purification of proteins and enzymes. As previously discussed, the first proteins and enzymes studied in ABS formed by eutectic solvents were the bovine serum albumin and trypsin $[109,110]$. In 2016, Li et al. [102] proposed the use of a betaine-based eutectic solvent to extract bovine serum albumin, trypsin and ovalbumin. At the optimal conditions, the protein extraction yields achieve a value of $99.82 \%$. In addition, in this work the back-extraction of proteins from the eutectic solvents was studied mixing the extract phase with an equal volume of fresh $\mathrm{K}_{3} \mathrm{PO}_{4}$ aqueous phase, obtaining back-extraction yields of $32.66 \%$.

Real biological samples have been recently used in the recovery of proteins using ABS formed by eutectic solvents. Meng et al. (2019) [124] studied the separation of proteins from porcine pancreas using eutectic solvents formed by L-proline or lysine as hydrogen bond acceptors and glycerol, ethylene glycol, D-sorbitol or xylitol as hydrogen bond donors. The highest yield was obtained for the extraction of chymotrypsin with a value of $97.30 \%$. The separation of phycobiliprotein from Spirulina has been reported by Rathnasamy et al. (2019) [125] using eutectic solvents formed by glucose, fructose, sucrose, maltose or xylose as hydrogen bond acceptors and glycerol as hydrogen bond donor. In this system, $5.8 \mathrm{mg}$ of phycocyanin was obtained for each gram of Spirulina. Finally, the extraction of lysozyme from chicken egg white has been also studied by Xu et al. (2019) [126] using eutectic solvents formed by tetrabutylammonium bromide or benzyltributylammonium bromide and carboxylic acids. The extraction yield of lysozyme was $98 \%$ and the activity of lysozyme after the process of extraction was $91.73 \%$ of initial activity.

The separation of amino acids has been also addressed using ABS formed by eutectic solvents. Farias et al. (2018) [119] studied the partition of L-tryptophan and L-phenylalanine, L-tyrosine and glycine using eutectic solvents formed by choline chloride as hydrogen bond acceptor and ethanol, n-propanol 1,2-propanediol or ethylene glycol as hydrogen bond donors. The highest values of partition 
coefficients were obtained for the L-tryptophan: 180, followed by L-phenylalanine: 23, L-tyrosine: 7 and glycine: 0.35 . The $\mathrm{pH}$ effect on the partition of L-tryptophan in ABS formed by choline chloride based-eutectic solvents was also studied by Farias et al., obtaining a higher partition coefficient at pH 9 than at $\mathrm{pH} 5$ [123]. The separation of phenylalanine enantiomers have been also researched using ABS formed by choline chloride or betaine as hydrogen bond acceptors and urea, lactic acid, glucose or sorbitol as hydrogen bond donors [120]. Among the tested eutectic solvent-based ABS, the highest separation factor was obtained by the (choline chloride + lactic acid) with a value of 1.2.

The application of ABS formed with eutectic solvents in the extraction and purification of nucleic acids has recently been proposed. Zhang et al. (2017) [118] studied the extraction and back-extraction of RNA using ABS formed by eutectic solvents composed of quaternary ammonium salts and PEG polymers. Extraction efficiencies for RNA close to 100\% were obtained, whereas the RNA back-extraction using $\mathrm{Na}_{2} \mathrm{SO}_{4}$ solution achieved yields higher than $90 \%$. The extraction of DNA from bovine blood has also studied using ABS composed of ionic liquids and eutectic solvents [121]. The extracted DNA was analyzed by agarose gel electrophoresis and the results indicated that the proposed method could be applied to effectively extract DNA from real blood samples.

As described, the application of ABS formed with eutectic solvents has shown high extraction yields in the separation of organic compounds of different types (dyes, proteins, enzymes, amino acids or nucleic acids). The vast majority of papers have studied the partitioning of solutes in the two aqueous phases but it would be necessary in the future to study in greater depth the process of back-extraction and the reuse of ABS. Some of the works have already used real biological samples achieving good separation yields, so it is expected that for the future the application of eutectic solvent-based ABS will continue towards a larger scale application.

\subsubsection{Extraction of Organic Compounds with Hydrophobic Eutectic Solvents (HES)}

In 2015, van Osch et al. [130] published the first work on the use of hydrophobic eutectic solvents (HES). In this publication, six HES formed by decanoic acid as hydrogen bond donor and quaternary ammonium salts were described and used in the extraction of acetic, propionic and butyric acids from water. These innovative solvents showed extractive yields higher than those using trioctylamine. Since this first work, a large number of articles have focused on the use of HES in the extraction of different types of solutes, such as organic acids, alcohols, pesticides, antibiotics or dyes from aqueous solutions, as can be seen in Table 8 .

The extraction of organic acids from water using HES has been addressed in several papers. Rodríguez-Llorente et al. (2019) studied the extraction of acetic, propionic, butyric and valeric acids using HES formed by DL-menthol or thymol and octanoic acid [26]. The performance of both HES in the extraction was compared with the results obtaining using three terpenoids: geraniol, eugenol and citral. The HES showed extractive properties similar to those using terpenoids but the recovery of the extracted acids from the HES using alkali solutions was not technically viable because of the formation of the octanoate ion. By contrast, the back-extraction of extracted organic acids was successfully done using geraniol. Therefore, the terpenoids seem to be more adequate to this purpose than the tested HES.

Van den Bruinhorst et al. (2019) also studied the extraction of volatile acids from water using the HES formed by trioctylphosphine oxide (TOPO) and dodecanoic acid or dihexylthiourea [131]. The HES composed of TOPO and dihexylthiourea showed good extraction performance at low acid concentrations and small S/F ratios. Therefore, this HES has great potential to be used in the volatile fatty acid extraction from fermentation broths. HES formed by TOPO and decanoic acid or dodecanoic acids have been recently used by Riveiro et al. [132] in the extraction of adipic, levulinic and succinic acid from water. The extraction efficiencies of the HES were compared with the results obtained using pure TOPO. According to the authors, the extraction capacity of TOPO was higher than those for the tested HES in the separation of the three acids. 
Another very relevant application of HES has been the extraction of pollutants or biomolecules from aqueous effluents. Riveiro et al. (2015) proposed the use of HES formed by L-menthol and pyruvic, acetic, L-lactic or lauric acids in the recovery of caffeine, tryptophan, isophthalic acid and vanillin [14]. In this work, the partition of these biomolecules was studied and extensively compared with the partition obtained using organic solvents, ABS or ionic liquids from literature, obtaining competitive results using the HES.

Florindo et al. (2017) proposed the use of HES to separate pesticides from water [133]. In this work, HES formed by natural organic acids as hydrogen bond donors and DL-menthol or tetrabutylammonium chloride as hydrogen bond acceptors were employed. The extraction efficiencies of these HES were comparable to those obtained using hydrophobic imidazolium-based ionic liquids. In addition, the HES were used in four consecutive extraction cycles without regeneration, showing a decrease in the efficiency in each cycle. The extraction of five pesticides (bifenthrin, deltamethrin, fenpropathrin, permethrin, tetramethrin) from water has been recently studied by Mat Hussin et al. (2020) using HES formed by DL-menthol and thymol, 3-hydroxybenzoic acid or sesamol [134]. The highest extraction yields were obtained for the HES composed of DL-menthol and sesamol using a mole ratio of 1:1.

Table 8. Extraction of Organic Compounds Using Hydrophobic Eutectic Solvents.

\begin{tabular}{|c|c|c|c|c|}
\hline Solute & Raffinate & Hydrophobic Eutectic Solvent & Year & Ref. \\
\hline $\begin{array}{l}\text { Volatile fatty } \\
\text { acids }\end{array}$ & Water & Quaternary ammonium salts + decanoic acid & 2015 & [130] \\
\hline $\begin{array}{c}\text { Caffeine } \\
\text { Tryptophan } \\
\text { Isophthalic acid Vanillin }\end{array}$ & Water & $\begin{array}{c}\text { DL-Menthol + (pyruvic acid, acetic acid, L-lactic acid or } \\
\text { lauric acid) }\end{array}$ & 2015 & [14] \\
\hline Pesticides & Water & $\begin{array}{l}\text { DL-Menthol + natural organic acids } \\
\text { Tetrabutylammonium chloride + natural organic acids }\end{array}$ & 2017 & [133] \\
\hline Bisphenol A & Water & $\begin{array}{l}\text { Fatty acids combined: octanoic acid, nonanoic acid, } \\
\text { decanoic acid and dodecanoic acid }\end{array}$ & 2018 & [135] \\
\hline Levofloxacin, Ciprofloxacin & Water & $\begin{array}{l}\text { Quaternary ammonium salts + (hexanoic acid, octanoic } \\
\text { acid, decanoic acid, n-butyl alcohol, cyclohexanol, } \\
\text { 1-octanol, 1-dodecanol or 1-dodecanol) }\end{array}$ & 2018 & [136] \\
\hline $\begin{array}{l}\text { Ethanol } \\
\text { 1-Propanol } \\
\text { 1-Butanol } \\
\text { Ethanol }\end{array}$ & Water & DL-Menthol + dodecanoic acid & 2018 & [137] \\
\hline $\begin{array}{l}\text { 1-Propanol } \\
\text { 1-Butanol }\end{array}$ & Water & DL-Menthol + (decanoic acid or dodecanoic acid) & 2018 & [138] \\
\hline $\begin{array}{l}\text { Tyrosol } \\
\text { Phenols }\end{array}$ & $\begin{array}{l}\text { Olive oil mill } \\
\text { wastewater }\end{array}$ & DL-Menthol + (octanoic acid or dodecanoic acid) & 2019 & [139] \\
\hline $\begin{array}{l}N, N \text {-Diethyl-4-nitroaniline } \\
\text { Chloranilic acid } \\
\text { Dyes }\end{array}$ & Water & $\begin{array}{l}10 \text { Binary eutectic solvents formed by: menthol, } \\
\text { camphor, borneol, thymol and trans-sobrerol }\end{array}$ & 2019 & [16] \\
\hline Pyrethroids & $\begin{array}{l}\text { Tea beverages and } \\
\text { fruit juices }\end{array}$ & $\begin{array}{l}\text { Hexafluoroisopropanol as hydrogen-bond donor and } \\
\text { L-carnitine or } \\
\text { betaine as hydrogen-bond acceptor }\end{array}$ & 2019 & [140] \\
\hline $\begin{array}{l}\text { Acetic acid } \\
\text { Propionic acid } \\
\text { Butyric acid } \\
\text { Valeric acid }\end{array}$ & Water & (DL-Menthol or thymol) + octanoic acid & 2019 & [26] \\
\hline $\begin{array}{l}\text { Volatile fatty } \\
\text { acids }\end{array}$ & Water & $\begin{array}{c}\text { Trioctylphosphine oxide (TOPO) }+(\text { dodecanoic acid or } \\
\text { dihexylthiourea) }\end{array}$ & 2019 & [131] \\
\hline $\begin{array}{l}\text { 2-Chlorophenol } \\
o \text {-Cresol } \\
\text { Phenol }\end{array}$ & Water & $\begin{array}{c}\text { (DL-Menthol, Thymol or dodecanoic acid) }+ \text { (octanoic } \\
\text { acid or decanoic acid) }\end{array}$ & 2019 & [141] \\
\hline Trace phenolic compounds & $\begin{array}{l}\text { Large volume } \\
\quad \text { water }\end{array}$ & $\begin{array}{l}\text { Binary or ternary mixtures of carboxylic acids }\left(C_{8}, C_{9}\right. \\
\left.\qquad C_{10}, C_{11} \text { and } C_{12}\right) .\end{array}$ & 2019 & [142] \\
\hline Bisphenol A & Water & $\begin{array}{c}\text { Menthol or quaternary ammonium salts }+ \text { (octanoic } \\
\text { acid or decanoic acid) }\end{array}$ & 2020 & [143] \\
\hline Carbamazepine & Water & Menthol + (formic acid or acetic acid) & 2020 & [144] \\
\hline $\begin{array}{l}\text { Pesticides: Bifenthrin, Deltamethrin, } \\
\text { Fenpropathrin } \\
\text { Permethrin Tetramethrin }\end{array}$ & Water & $\begin{array}{c}\text { DL-Menthol + } \\
\text { (thymol, 3-hydroxybenzoic acid or sesamol) }\end{array}$ & 2020 & [134] \\
\hline Adipic acid Levulinic acid Succinic acid & Water & $\begin{array}{c}\text { Trioctylphosphine oxide }(\text { TOPO })+(\text { decanoic acid or } \\
\text { dodecanoic acid })\end{array}$ & 2020 & [132] \\
\hline Phenolic Compounds & Beverage samples & $\begin{array}{l}\text { DL-Menthol }+ \\
\text { carboxylic acids }\left(\mathrm{C}_{8}, \mathrm{C}_{9}, \mathrm{C}_{10}, \mathrm{C}_{11} \text { and } \mathrm{C}_{12}\right) .\end{array}$ & 2020 & [145] \\
\hline $\begin{array}{l}\text { Phenol } \\
\text { 2-Chlorophenol } \\
\text { 2-Nitrophenol }\end{array}$ & Water & $\begin{array}{c}\text { Menthol + (thymol or octanoic acid }) \\
\text { Thymol + octanoic acid }\end{array}$ & 2020 & [27] \\
\hline
\end{tabular}


The use of HES in the extraction of pharmaceuticals from aqueous streams has been also studied. Tang et al. (2018) applied HES composed of quaternary ammonium salts and acids or alcohols in the extraction of two antibiotics: levofloxacin and ciprofloxacin [136]. The eutectic solvent formed by trioctylammonium chloride and 1-octanol exhibited extraction efficiencies of both antibiotics around 80-90\%, being these values higher than those obtained using halogenated conventional solvents: $\mathrm{CHCl}_{3}, \mathrm{CH}_{2} \mathrm{Cl}_{2}, \mathrm{C}_{2} \mathrm{H}_{2} \mathrm{Cl}_{4}$ and $\mathrm{C}_{6} \mathrm{H}_{5} \mathrm{Cl}$.

The extraction of carbamazepine has recently studied using HES composed of menthol and formic or acetic acid [144]. In this work, Pekel et al. used diethyl succinate as the diluent, obtaining extraction efficiencies higher than $90 \%$ in 30 min using the HES formed by menthol and acetic acid with 1:1 of molar ratio. Martins et al. (2019) proposed the use of HES formed by two terpenes, studying the solid-liquid equilibrium of 10 HES composed of: menthol, camphor, borneol, thymol and trans-sobrerol [16]. In this work, the effect of terpene proportion in the HES on the extraction efficiency of the selective separation of two dyes: $N, N$-diethyl-4-nitroaniline and chloranilic acid was studied. The maximum value of the separation factor of both dyes was 600, demonstrating the great capacity of these HES in the selective separation of dyes.

The extraction of linear and aromatic alcohols from water using HES has been also extensively studied. Verma et al. proposed the use of the HES formed by DL-menthol and dodecanoic acid to extract ethanol, 1-propanol and 1-butanol from water [137]. The HES exhibited substantially higher alcohol/water selectivities than the literature values for hydrophobic ionic liquids, whereas the alcohol distribution ratios for the HES were comparable to those of ionic liquids. These authors have proposed the recovery of the extracted alcohols from the HES by distillation, successfully simulating this process in Aspen Plus [138]. Florindo et al. have studied the extraction of bisphenol A from water using HES formed by binary mixtures of fatty acids [135] and mixtures of menthol or quaternary ammonium salts with octanoic or decanoic acid [143]. The mixture formed by octanoic and dodecanoic acids in a molar ratio of 3:1 showed a bisphenol A extraction efficiency of $88.32 \%$. Better results were obtained using the HES formed by menthol or quaternary ammonium salts, achieving extraction efficiencies of bisphenol A close to $99 \%$ with the HES formed by tetraoctylammonium bromide and decanoic acid. In addition, this HES was used in five consecutive cycles with fresh feed without decreasing the extractive capacity.

Several papers have been focused on the extraction of phenols from aqueous solutions. Buldo et al. (2019) [139] applied the HES formed by DL-menthol and octanoic acid or dodecanoic acid, in the recovery of tyrosol and phenol from olive oil mill wastewater. Sas et al. (2019) also used the HES formed by DL-menthol, thymol or dodecanoic acid as hydrogen bond acceptors and octanoic acid or decanoic acid as hydrogen bond donors in the extraction of phenol, 2-chlorophenol and $o$-cresol from water [141]. Using the menthol-based HES, extraction yields higher than $80 \%$ for 2-chlorophenol and $o$-cresol were obtained and yields higher than $70 \%$ for the separation of phenol were achieved. Yang et al. (2019) have applied the binary and ternary HES formed by mixtures of $C_{8}-C_{12}$ carboxylic acids to extract trace phenolic compounds from real samples from the tap, lake and river waters [145]. Using the ternary HES formed by $\mathrm{C}_{8}: \mathrm{C}_{9}: \mathrm{C}_{12}$ carboxylic acids in molar ratio 3:2:1, extraction efficiency higher than $91.0 \%$ of phenolic compounds was achieved. Recently, Rodríguez-Llorente et al. (2020) have used the HES formed by thymol, menthol and octanoic acid to extract phenol, 2-chlorophenol and 2-nitrophenol from aqueous solutions [27]. These HES showed extraction efficiencies lower than those for three terpenoids: geraniol, linalool and citral and a conventional solvent: methyl isobutyl ketone. Because of this, the tested HES were discarded as potential solvents to be used in the extraction of phenols from industrial wastewater.

Finally, the HES has been used in the recovery of pollutants from beverages. The recovery of pyrethroids from tea beverages and fruit juices using eutectic solvents was proposed by Deng et al. (2019) [140]. In this work, new hydrophobic eutectic solvents composed of hexafluoroisopropanol as a hydrogen-bond donor and L-carnitine or betaine as hydrogen-bond acceptor was used. The obtained extraction efficiencies (85-109\%) were similar to those using literature methods based on chlorobenzene or chloroform. Yang et al. (2020) [145] also used HES in the extraction of phenolic compounds from 
beverage samples of fruit juice, tea drink and soda. Recoveries of bisphenol A higher than 95\% were achieved using the HES formed by menthol and undecanoic acid in a molar ratio of 3:1 in the three studied beverages. Therefore, the HES has been revealed as very promising solvents to determine pollutants in beverages.

As described, the HES has been applied in the extraction of a wide variety of organic compounds from 2015. The majority of the works have used synthetic solutions of the compounds in water and real aqueous streams should be used to evaluate the potential of the HES to be applied in industrial applications. Studies on regeneration and reuse of HES are still very scarce and the fatty acid-based HES have been chemically unstable in solvent regeneration with alkalis. Hence, further studies should be conducted in the future with real streams and extraction and regeneration cycles to assess the performance of HES in the extraction of organic compounds from aqueous streams.

\subsubsection{Extraction of Metals with Hydrophobic Eutectic Solvents (HES)}

In 2016, Van Osch et al. proposed for the first time the use of hydrophobic eutectic solvents in the separation of metals from aqueous solutions [146]. Since this first work, several articles on the use of HES in the extraction of a large number of metals from aqueous solutions have been published, as can be seen in Table 9.

Table 9. Extraction of Metals using Hydrophobic Eutectic Solvents (HES).

\begin{tabular}{|c|c|c|c|c|}
\hline Metals Extracted & Raffinate & Hydrophobic Eutectic Solvent & Year & Ref. \\
\hline $\begin{array}{l}\mathrm{Li}, \mathrm{Na}, \mathrm{K}, \mathrm{Co}, \mathrm{Ni}, \mathrm{Mn}, \\
\mathrm{Zn} \text { and } \mathrm{Cu} \text { chlorides }\end{array}$ & Water & $\begin{array}{c}\text { Decanoic acid + lidocaine in a 2:1, 3:1 and } \\
4: 1 \text { molar ratio. }\end{array}$ & 2016 & [146] \\
\hline $\begin{array}{l}\mathrm{Cu}, \mathrm{Fe}, \mathrm{Mg}, \mathrm{Ca}, \mathrm{Cr}, \mathrm{Mn}, \\
\mathrm{Co} \text { and } \mathrm{Ni}\end{array}$ & $\begin{array}{l}\text { Mildly acidic } \\
\text { solutions }\end{array}$ & $\begin{array}{l}\text { (Menthol or thymol) }+\left(\mathrm{C}_{8}, \mathrm{C}_{10}, \mathrm{C}_{12}, \mathrm{C}_{14}, \mathrm{C}_{16}\right. \\
\left.\text { and } \mathrm{C}_{18}\right) \text { carboxylic acids }\end{array}$ & 2018 & [147] \\
\hline Uranyl nitrate & Aqueous acid & Trioctylphosphine oxide (TOPO) + Phenol & 2018 & [148] \\
\hline $\begin{array}{l}\mathrm{Pd}, \mathrm{Pt}, \mathrm{Cu}, \mathrm{Co}, \mathrm{Ni}, \mathrm{Cr} \\
\text { and } \mathrm{Fe}\end{array}$ & $\mathrm{HCl}$ media & $\begin{array}{l}\text { Thymol + trioctylphosphine oxide } \\
\text { Trioctylphosphine oxide + capric acid } \\
\text { Hydrocinnamic acid + capric acid }\end{array}$ & 2020 & [149] \\
\hline Co and $\mathrm{Zn}$ & Water & 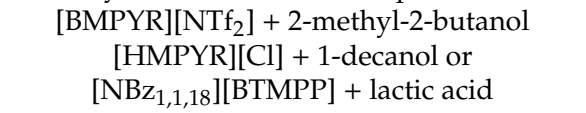 & 2020 & [150] \\
\hline
\end{tabular}

The HES formed by lidocaine and decanoic acid in three molar ratios was used in the extraction of $\mathrm{Li}, \mathrm{Na}, \mathrm{K}, \mathrm{Co}, \mathrm{Ni}, \mathrm{Mn}, \mathrm{Zn}$ and $\mathrm{Cu}$ from water. Van Osch et al. (2016) [146] concluded that the metal extraction occurs via an ion-exchange mechanism, transferring the protonated lidocaine to the water phase. In this work, high distribution coefficients were obtained for all tested metals, even for high $\mathrm{Co}^{2+}$ concentrations and low mass fractions of HES. In addition, the HES with a higher decanoic to lidocaine ratio (3:1 and 4:1) were successfully regenerated using sodium oxalate $0.1 \mathrm{M}$ solutions.

Schaeffer et al. (2018) proposed the use of menthol and thymol-based HES in the selective extraction of $\mathrm{Cu}$ from $\mathrm{Fe}, \mathrm{Mg}, \mathrm{Ca}, \mathrm{Cr}, \mathrm{Mn}, \mathrm{Co}$ and $\mathrm{Ni}$ in mildly acidic solutions [147]. Analyzing the metal distribution ratios obtained using the HES, authors concluded that $\mathrm{Cu}$ (II) and Fe(III) could be successfully extracted, whilst extraction of $\mathrm{Mg}(\mathrm{II}), \mathrm{Ca}(\mathrm{II}), \mathrm{Cr}$ (III), $\mathrm{Mn}$ (II), $\mathrm{Co}(\mathrm{II})$ and $\mathrm{Ni}$ (II) was negligible at the tested conditions. Because of this, the HES formed by thymol and decanoic acid was successfully used in the highly selective separation of $\mathrm{Cu}(\mathrm{II})$ from concentrated solutions containing other transition metals. In addition, this HES was used in five consecutive extraction and stripping cycles with constant extraction efficiency, using a $0.1 \mathrm{M} \mathrm{H}_{2} \mathrm{SO}_{4}$ solution as a stripping agent. Therefore, the HES based on terpenes (menthol or thymol) were revealed as a non-toxic and biodegradable alternative to conventional solvents in the extraction of $\mathrm{Cu}$.

In 2018, Gilmore et al. proposed the use of HES formed by trioctylphosphine oxide (TOPO) and phenol in the extraction of uranyl nitrate from acidic solutions [148]. Using this HES, the distribution ratio was 500 using 250 ppm uranyl solutions and 5000 for the 2350 ppm solution, being these values similar to those reported for the commercial TRPO extraction process. 
Schaeffer et al. (2020) have also used the HES formed by trioctylphosphine oxide and thymol or capric acid and the HES composed of hydrocinnamic and capric acids in the recovery and separation of platinum group and transition metals in $\mathrm{HCl}$ media [149]. The TOPO-based HES showed high values of selectivity towards $\mathrm{Pt}^{4+}, \mathrm{Pd}^{2+}$ and $\mathrm{Fe}^{3+}$, being promising solvents in the selective recovery of platinum-group metals from complex mixtures. Moreover, the tested HES showed selectivities and distribution ratios higher than literature values for TOPO in diluents or ionic liquids. The regeneration of the HES was studied using an acidic $0.1 \mathrm{M}$ thiourea solution, obtaining a regeneration efficiency of $96 \%$. After the extraction using HES, a $0.1 \mathrm{M} \mathrm{NaCH}_{3} \mathrm{COO}$ aqueous solution was also used to form palladium nanoparticles with an average size of $5.7 \pm 1.3 \mathrm{~nm}$.

Finally, Lukomska et al. have recently studied the liquid-liquid extraction of Co(II) and $\mathrm{Zn}$ (II) from aqueous solutions using hydrophobic ionic liquids and HES formed by three ionic liquids: 1-butyl-1-methylpyrrolidinium bis\{(trifluoromethyl)sulfonyl\}imide ([BMPYR][NTf 2$]$ ), 1-hexyl-1-methylpyrrolidinium chloride ([HMPYR][Cl]) or benzyldimethyloctadecylammonium bis(2,4,4-trimethylpentyl)phosphinate ([NBz $1,1,18][\mathrm{BTMPP}])$ and three hydrogen bond donors: 2-methyl-2-butanol, 1-decanol or lactic acid [150]. The Co and Zn extraction efficiencies showed by the tested HES were substantially lower than those obtained for hydrophobic ionic liquids under the same conditions.

In summary, although the extraction of metals with HES has still been studied only in a few articles, the results obtained in the selective separation of metals is very promising, having studied the extraction under different operating conditions and having successfully reused HES with various stripping agents. It is expected that in the next few years the hydrophobic eutectic solvents will be applied in the separation of metals from real mixtures from the industry.

\subsubsection{Predictive Methods in Liquid-liquid Extraction with Eutectic Solvents}

Due to the great variety of eutectic solvents that have already been proposed in the literature, the use of predictive methods in the selection of the most suitable eutectic solvent in each application becomes increasingly necessary. Furthermore, to optimize and verify the viability of future processes using eutectic solvents, it is necessary to use thermodynamic models to correlate the liquid-liquid equilibrium data obtained experimentally and process simulators. For this reason, the following three sections review the predictive models, the thermodynamic correlation models and the simulators used to date in the literature on eutectic solvents.

Among the articles described in the previous categories, 25 articles were found in which predictive models have been used, with COSMO-based methods being the most widely used, followed by Perturbed-Chain Statistical Associating Fluid Theory (PC-SAFT) and molecular dynamics.

The use of predictive methods in the application of eutectic solvents in the separation of hydrocarbons has been widely studied. The quantum chemical method conductor-like screening model for real solvents (COSMO-RS) has been successfully employed in the prediction of ternary liquid-liquid equilibria in the separation of toluene from $n$-heptane [60], ethylbenzene from $n$-octane [64], ethylbenzene from styrene [65], BTEX aromatics from $n$-octane [54], quinoline or indoline from toluene and $n$-heptane [86], pyridine from $n$-hexane and $n$-heptane and $n$-octane [84] using eutectic solvents. The prediction of solute distribution ratios and selectivities has been also done with the COSMO-RS method in the separation of benzene from $n$-hexane [56], benzene from cyclohexane [57] and dibenzothiophene from $n$-octane [79]. In addition, the COSMO-RS method was used to understand the interactions between the eutectic solvents and thiophene [71] and to predict the toluene solubility in eutectic solvents [66]. Naik et al. (2018) used classical molecular dynamic simulation techniques to understand and predict the phase behavior of ternary systems composed of quinoline, $n$-heptane and eutectic solvents, obtaining predictions with low deviations from the experimental ternary liquid-liquid equilibria [87]. Finally, Warrag et al. (2018) used PC-SAFT theory to successfully predict the distribution coefficients and thiophene/alkane selectivities in the separation of thiophene from $n$-hexane and $n$-octane [72]. 
Predictive methods have been also used in the extraction of alcohols from hydrocarbons using eutectic solvents. The COSMO-RS method was applied to predict the liquid-liquid equilibria in the separation of ethanol from $n$-hexane, $n$-heptane or $n$-octane and the separation of methanol and ethanol from benzene [91,93]. The COSMO-SAC model was also used in the selection of choline chloride-based eutectic solvents to separate dimethylcarbonate from ethanol [96]. PC-SAFT was also applied in the separation of ethanol, propanol and butanol from acetates and propionates using the choline chloride + glutaric acid eutectic solvents, correctly describing the phase equilibria of binary and ternary systems [98].

In the selective separation of $\beta$-tocopherol from $\alpha$-tocopherol, Bezold et al. (2017) used the COSMO-RS methodology to predict the partition coefficients of solutes in eutectic solvents [103]. This predictive method overestimated the partition coefficient of $\alpha$-tocopherol but the predicted trend of the tocopherol distribution was reproduced for the experimental values. The COSMO-RS successfully predicted key thermodynamic parameters (selectivities, solute distribution ratios, mixing excess enthalpies and activity coefficients at infinite dilutions) in the separation process of the deterpenation of essential oils $[45,46]$.

Finally, predictive models have been also applied in the use of hydrophobic eutectic solvents in liquid-liquid extraction. Verma et al. (2018) used the COSMO-SAC model to predict the solid-liquid equilibria of the HES formed by lauric acid and DL-menthol and the ternary liquid-liquid equilibria in the separation of ethanol, 1-propanol and 1-butanol from water using the cited HES [137]. The liquid-liquid equilibria of ternary systems formed by linear alcohols and water using HES with menthol were also successfully predicted by COSMO-based calculations in Aspen Plus and molecular dynamics simulations [138]. Martins et al. (2019) applied the COSMO-RS method to accurately predict the solid-liquid equilibria of HES composed of terpenes [16]. Rodríguez-Llorente et al. (2019) [26] used the COSMO-RS method to select the most adequate HES and terpenoids to be used in the extraction of volatile fatty acids from water, by calculating the infinite dilution activity coefficients of the solutes in a wide number of HES, terpenes and terpenoids. The same methodology has been applied in the solvent screening to select the most promising solvents for the separation of phenols from industrial wastewater using HES, terpenes and terpenoids [27]. Finally, the COSMO-SAC model has been recently used in the solvent screening for 1-butanol dehydration, estimating distribution coefficients and selectivities [151].

Therefore, different predictive methods have been used to date to predict thermodynamic equilibria in ternary systems containing eutectic solvents and they have also been used in solvent screening. To date, the most widely used predictive methods have been those based on COSMO calculations, obtaining predictions with high reliability. The use of these methods in future investigations may reduce the experimental efforts, using those eutectic solvents that have a greater potential for the studied application.

\subsubsection{Correlation of Liquid-Liquid Equilibrium Using Eutectic Solvents}

To simulate and optimize a liquid-liquid extraction process on an industrial scale, the correlation of experimental data is essential, since commercial process simulators can thus be used. Among the described papers on the use of eutectic solvents in liquid-liquid extraction processes, 33 papers have used thermodynamic models to correlate the obtained liquid-liquid equilibria, being the most applied the Non-random two liquids (NRTL) model followed by the Universal quasichemical (UNIQUAC) model.

In the separation of hydrocarbons, the NRTL thermodynamic model has been successfully used in the correlation of the ternary liquid-liquid equilibria obtained in the separation with eutectic solvents of benzene and toluene from cyclohexane [57,58], BTEX from $n$-octane [54], toluene from $n$-hexane, $n$-heptane or $n$-octane [51,52,62,63], ethylbenzene from $n$-octane [64], ethylbenzene from styrene [65], thiophene from $n$-hexane and $n$-octane, pyridine and toluene from $n$-hexane [82], pyridine or benzothiazole from $n$-hexane, $n$-heptane and $n$-octane [83,84] and tetralin from dodecane [85]. On the other hand, the UNIQUAC model was simultaneously used with the NRTL model in the correlation 
of equilibria in the separation of toluene, quinoline and iodine from $n$-heptane $[61,86]$ and in the extraction of benzene from thiophene and cyclohexane from hexadecane [59]. In these publications, the deviations between experimental and predicted data were similar using both thermodynamic models, being lower than $1 \%$. Since the UNIQUAC model requires more complex mathematical modeling than the NRTL model and the results obtained are comparable, the NRTL model has been more widely used in the literature for the correlation of liquid-liquid equilibrium data of systems containing hydrocarbons and eutectic solvents.

In the extraction of alcohols, the NRTL model has adequately correlated the liquid-liquid equilibria in the extraction of methanol and ethanol from benzene [91], ethanol from $n$-hexane, $n$-heptane and n-octane [89,93,94], ethanol from dimethyl carbonate [96], ethanol from methyl ethyl ketone [92] and ethanol, propanol and butanol from ethyl, propyl and butyl acetates and propionates [97,98]. The UNIQUAC model was used together with the NRTL thermodynamic model in the separation of methanol from toluene or $n$-heptane [90], ethanol from $n$-hexane and $n$-heptane [95] and in the extraction of cresols from $n$-hexane [101]. In the separation of methanol or ethanol from $n$-alkanes, the deviations between experimental and fitted data of UNIQUAC model were slightly lower than those for the NRTL model $[90,95]$, whereas the deviations of UNIQUAC model were almost double than those for the NRTL model in the extraction of cresols from $n$-hexane [101]. Therefore, in the extraction of alcohols from hydrocarbons both thermodynamic methods have shown similar reliability to be used in the correlation of ternary liquid-liquid equilibrium data using eutectic solvents.

The NRTL model has been also employed to correlate the thermodynamic equilibrium data obtained in the separation of alcohols from water using eutectic solvents. Verma et al. (2018) used the NRTL model in the extraction of ethanol, 1-propanol and 1-butanol from water using HES and Song et al. (2020) in the dehydration of 1-butanol using hydrophilic eutectic solvents [137,151]. Finally, the experimental tie-lines of the equilibrium obtained in the use of ABS formed by eutectic solvents were adequately correlated with the NRTL model, showing deviations lower than $1.7 \%$ using eutectic solvents formed by choline chloride and sugars (glucose, fructose or saccharose) [115] and deviations below $1.2 \%$ in the ABS formed by eutectic solvents composed of choline chloride and ethanol, $n$-propanol, 1,2-propanediol or ethylene glycol [119]. In both papers, potassium phosphate was used to form the ABS previously described, showing the NRTL model a high reliability to be used in the correlation of liquid-liquid equilibria in ABS formed by eutectic solvents.

Hence, the NRTL model has also demonstrated its applicability in liquid-liquid extraction using hydrophobic eutectic solvents and aqueous biphasic systems formed by eutectic solvents and, therefore, this model can be used in the simulations of extraction processes with eutectic solvents.

\subsubsection{Simulation of Liquid-Liquid Extraction Processes with Eutectic Solvents}

The vast majority of industrial liquid-liquid extraction processes use counter-current extractors with multiple equilibrium stages. On the contrary, experimental liquid-liquid extraction studies with eutectic solvents have been focused on obtaining equilibrium data in a single stage. Because of this, the simulation of liquid-liquid extraction processes is essential to determine the potential of these solvents to be used on an industrial scale and to optimize the extraction processes. However, a very small number have been published to date on simulating liquid-liquid extraction processes with eutectic solvents.

Jiao et al. (2016) use the Aspen Plus simulator to optimize the extractor in the separation of cresols from $n$-hexane via eutectic solvents formation using imidazole [101]. In these simulations, the parameters of the NRTL model obtained from the correlation of experimental data obtained in the same work were used. In the optimization, the number of equilibrium stages in the extractor and the mass flow of imidazole were varied to maximize the recovery of $o$-cresol. 
Verma et al. (2018) also used Aspen Plus simulation software to optimize the whole process to separate 1-butanol from water using hydrophobic eutectic solvents [138]. In this work, the eutectic solvents were introduced to Aspen Plus as pseudo components using COSMO-based calculations. In the simulations, the extraction of 1-butanol from water with the HES formed by menthol and decanoic or dodecanoic acids and the subsequent solvent regeneration were optimized. A complete comparison of the proposed process using HES with the results and costs for a conventional process using mesitylene as solvent was also done using Aspen Plus simulations, concluding that the alternative process using HES is economically and technically competitive with the currently used process in the industry.

Aspen Plus simulator has been also used to simulate the dehydration of 1-butanol using the eutectic solvent formed by choline chloride and urea [151]. In the simulations done by Song et al., the parameters of the NRTL model obtained from the experimental data were used to optimize the extraction and the solvent recovery by flash distillation. In the extractor, the equilibrium stages and the mass flow of the solvent were optimized to maximize the extraction yield of 1-butanol and its purity, whereas pressure and temperature of flash distillation were optimized to regenerate the eutectic solvent.

A similar approach using Aspen Plus and NRTL thermodynamic model has been applied by Wu et al. (2020) in the simulation of the whole process of extraction of tetralin from dodecane [85]. In this work, the extractor was simulated to optimize the number of equilibrium stages and the solvent-to-feed ratio. In addition, the solvent recovery was simulated using back-extraction with water followed by a flash distillation to separate the eutectic solvent formed by tetrabutylphosphonium bromide and levulinic acid from water.

Therefore, the application of process simulation in liquid-liquid extraction with eutectic solvents has been little studied to date. However, very valuable results have been obtained using process simulators since it allows the optimization of the whole extraction and solvent regeneration processes. In addition, a comparison between the extraction processes using eutectic solvents with those already used in the industry could be done using simulators to evaluate the technical and economic potential to be employed at the industrial scale.

\subsection{General Overview of the Use of Eutectic Solvents in the Development of Analytical Methods by Liquid-Liquid Extraction}

As previously discussed, eutectic solvents are currently being used in the development of a large number of analytical methods based on liquid-liquid microextraction processes. This review is focused on the application of eutectic solvents, terpenes and terpenoids in liquid-liquid extraction processes that can be used at the industrial scale. For this reason, a general review of the applications of eutectic solvents in analytics will be carried out without analyzing the specific variables of each of the analytical methods. Recently, several reviews have been published on the application of eutectic solvents in analytical methods, detailing the analytical procedures [28-30].

The analytical methods based on extraction processes with eutectic solvents that are being developed are focused on the determination of organic compounds and metals in water, food and biological samples. In Figure 4, the percentage distribution of the published papers is shown in six categories as a function of the application. 


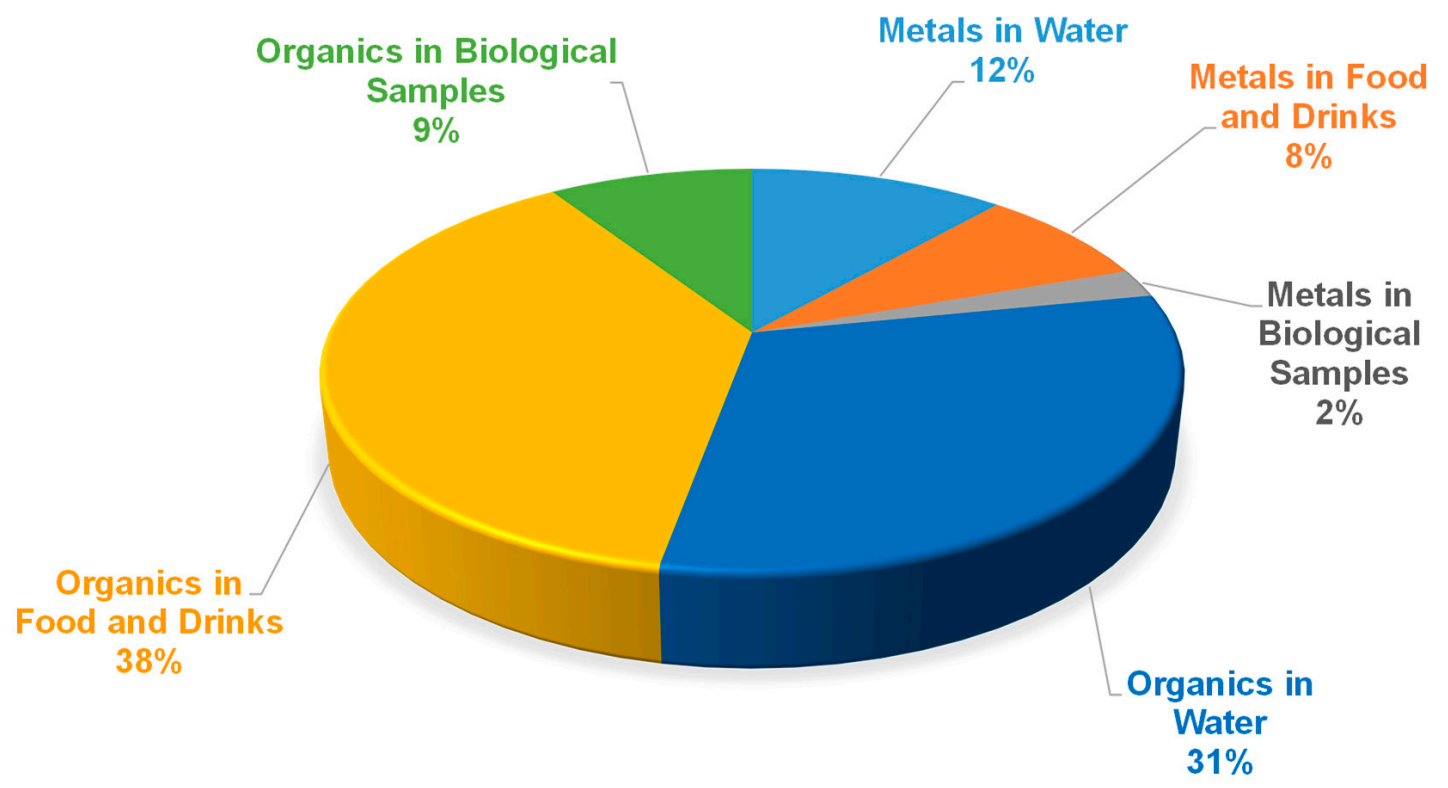

Figure 4. Percentage distribution of the published papers (2010-2020) on eutectic solvents in the development of analytical methods as a function of the application.

As seen, the determination of organic compounds in food is the most relevant application of eutectic solvents in the development of analytical methods. Specifically in the analysis of oils, the eutectic solvents have been used in the quantification of hexanal and heptanal [152], alkyl gallated [153], oxyprenylated phenylpropanoids [154], ferulic, caffeic and cinnamic acids [155], sesamol [156], tert-butylhydroquinone [157-159], chlorophenol, 2,3-dihydroxybenzoic acid, $p$-cresol, 4-chlorophenol, 2,4-dichlorophenol and 2,4,6-trichlorophenol [160] and bisphenol A [161].

The eutectic solvents have been also applied in analytical methods to quantify organic compounds in tea, fruit juices and milk. The organic compounds analyzed in drinks have been: antibiotics [162], curcumin $[163,164]$, diazinon and fenitrothion [165], auxins [166], pesticides [167-169], $\beta$-carotene and lycopene [170], phthalates [171], bisphenol-A [172], caffeine [173] and synthetic pigments [174]. Pesticides and insecticides have been also quantified using eutectic solvent-based analytical methods in cucumber [175], tomato [176], honey [177] and cabbage leaves [178]. Finally, meats have been also analyzed to quantify polycyclic aromatic hydrocarbons [179] and antibiotics [180].

A wide variety of organic compounds in water have been analyzed using analytical methods based on microextraction using eutectic solvents, being the second most studied application. Some of the organic compounds analyzed have been: antibiotics [181], chlorophenols [182], microcystins [183], anti-inflammatory drugs [184], malachite green and crystal violet $[185,186]$, polycyclic aromatic hydrocarbons [187,188], ultraviolet filters [189-191], parabens [192], steroids [193], benzene, toluene and ethylbenzene [194], benzylureas [195,196], methadone [197], sulfonamides [198-200], ciprofloxacin [201], agonists [202], organic acids [203] and pesticides [204,205].

Organic compounds have been also quantified in biological samples using eutectic solvent-based analytical procedures. These methods have been used to determine pesticides in urine and plasma [206], polycyclic aromatic hydrocarbons in urine and saliva of tobacco smokers [179], warfarin in urine and plasma [207], procainamide in human saliva [208], ketoprofen and diclofenac in liver [209] and nitrite in saliva and human urine [210].

Analytical methods based on microextraction with eutectic solvents have also been used to quantify metals. In water samples, the following metals were analyzed: arsenic [211], cadmium [212], cobalt [213], copper [214], chromium [215-217], nickel [213,218], palladium [219] and selenium [220]. In the analysis of food and drinks, the eutectic solvents have been applied in the quantification of copper, cadmium and lead in honey and milk [221,222], copper in vegetables [223], chromium (VI) 
in beverages [224], cadmium and zinc in fruit juices [225], vanadium in tomato, cucumber, banana and apple [226] and a wide variety of heavy metals in vegetables irrigated with treated municipal wastewaters [227]. Finally, the eutectic solvents have been also used in the quantification of metals in biological samples, analyzing the chromium content in fishes and mushrooms species [228] and the cadmium, nickel and lead content in urine samples [229].

In all the analytical methods previously enumerated, the eutectic solvents have been used in microextraction processes to concentrate the solutes to be quantified. Once the solutes have been extracted, different conventional analytical techniques have been used. Figure 5 shows the percentage distribution of the analytical techniques used in the different articles described. As seen, the vast majority of articles have used high-performance liquid chromatography (HPLC), a technique especially used in articles focused on the quantification of organic compounds. The second most used technique has been atomic absorption, corresponding to articles in which the content of metals has been quantified in water, food and drinks or biological samples. The gas chromatography (GC) has been used to quantify volatile hydrocarbons in water and food and drinks, using flame ionization (FID) or mass spectrometry (MS) detectors. Ultraviolet-visible spectroscopy (UV-VIS) has been applied in the quantification of organic compounds in drinks and biological samples and to quantify the metal content in water and drinks. Finally, other more complex techniques, such as ion mobility spectrometry [180] and the electroanalysis [201] have been used together with eutectic solvents in analytical methods.

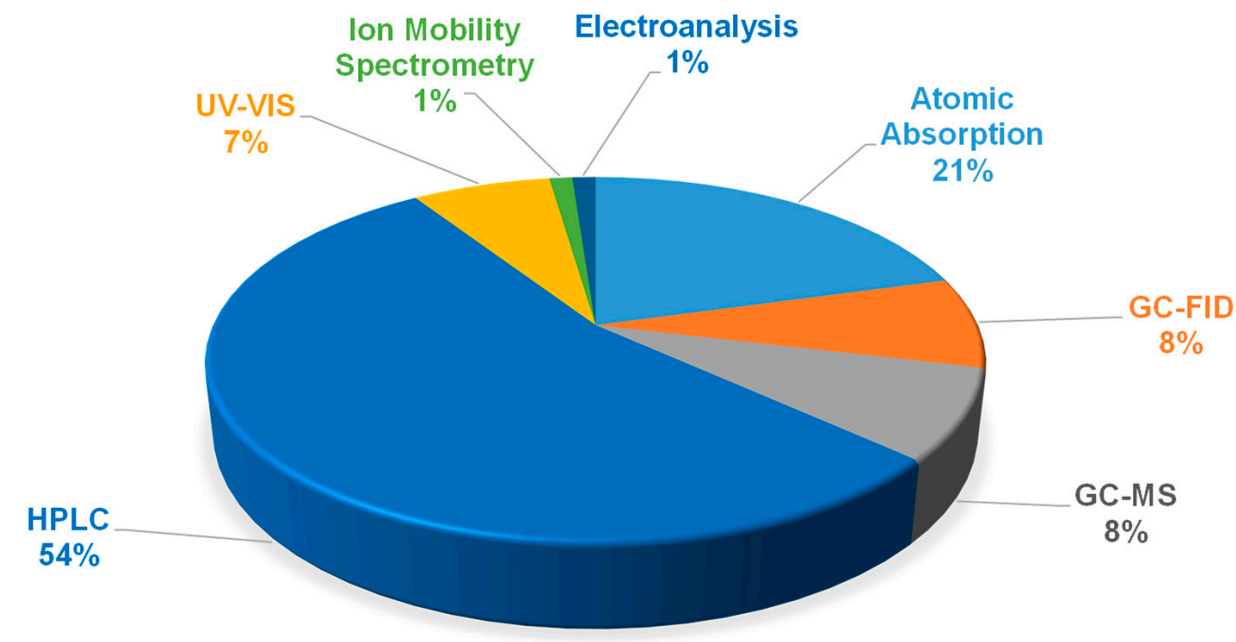

Figure 5. Percentage distribution of the published papers (2010-2020) on eutectic solvents in the development of analytical methods as function of the analytical method used after the extraction.

In this general review of the applications of eutectic solvents in the development of analytical methodologies using liquid-liquid microextraction processes, a large number of published works and a great variety of solutes analyzed have been revealed. Although these applications are not oriented to the development of industrial processes of separation by liquid-liquid extraction, some of the solutes that have been extracted in the described analytical methods could be carried out on a larger scale.

\section{Application of Terpenes and Terpenoids in Extraction Processes}

This section focuses on the use of terpenes and terpenoids as solvents in extraction processes. The use of terpenes and terpenoids has previously appeared in this paper in the formulation of hydrophobic eutectic solvents using menthol, thymol, camphor, borneol and sesamol as hydrogen bond donors or acceptors. In this section, it will be discussed the extraction processes using pure terpenes and terpenoids as solvents. According to the search performed, only 46 articles were found that study their application in extraction processes. Figure 6 shows the appearance of terpenes and terpenoids as solvents in the collected articles. Notably, limonene is the most studied followed by $\alpha$-pinene, citral, 
geraniol and $p$-cymene. Limonene is very widespread in nature and is also an agricultural by-product of the citric industry [18]. Its applications are mainly based on the substitution of conventional $n$-hexane. The rest of the terpenes with application in extraction processes that have been found are $\beta$-pinene, eucalyptol, linalool, $\beta$-citronellol, eugenol, pinane (and hydrogenated pinenes), carvone, menthol and $p$-menthane.

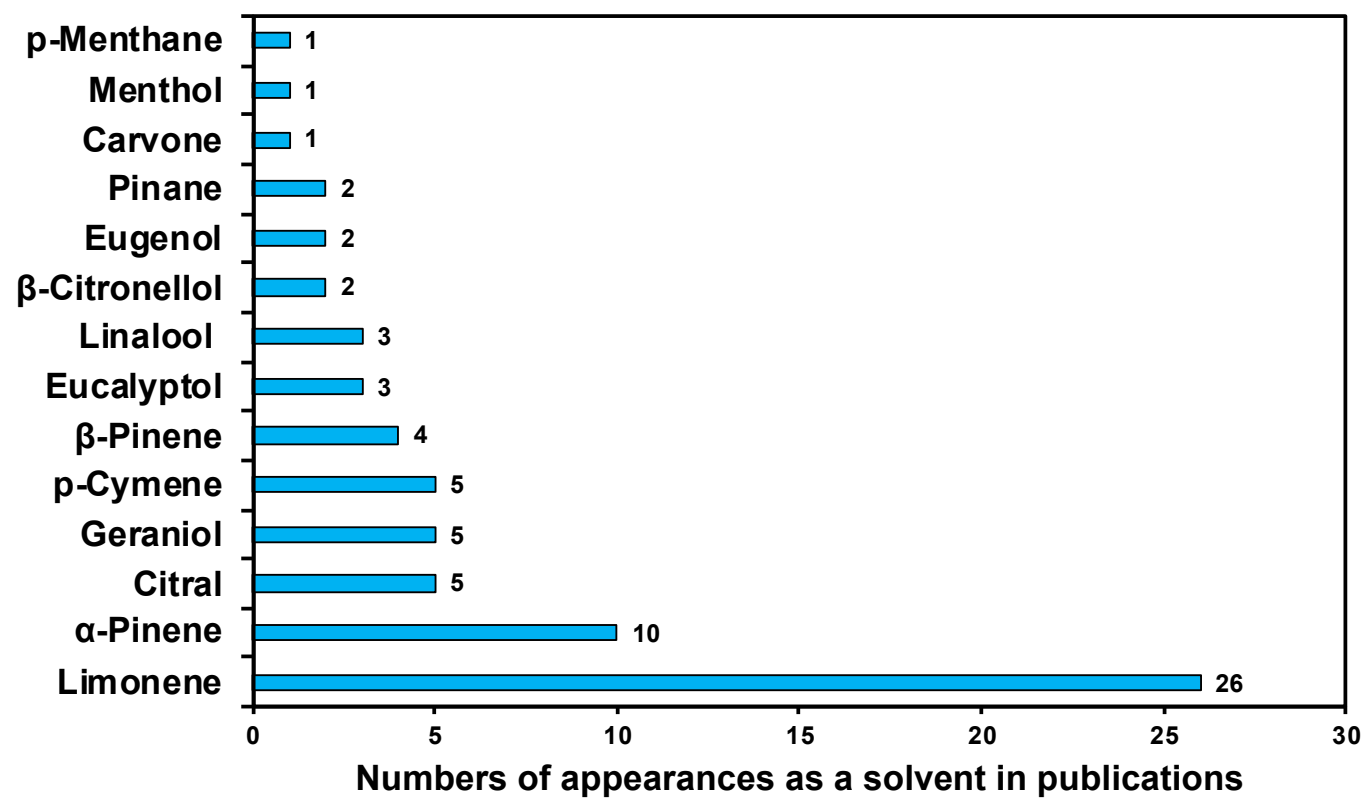

Figure 6. Numbers of appearances in the published papers of terpenes and terpenoids as solvents.

To analyze the different extraction processes with terpenes and terpenoids, the articles found were divided into 4 categories depending on the matrix to which solvents were applied. The selected matrices are the following:

1. Agricultural products

2. Microalgae

3. Aqueous streams

4. Others

As with eutectics solvents, a critical review of published articles on the application of terpenes and terpenoids as solvents has been made. A description of the uses and main results of the different articles has been performed, emphasizing the comparison with conventional solvents. Besides, the regeneration and reuse processes of the terpenes and terpenoids used by the different authors have been analyzed. At the end of the section, a review of the different predictive methods, the thermodynamic models used in the correlation of the liquid-liquid equilibria and the simulation methods of the separation processes with terpenes and terpenoids are described.

\subsection{Extraction from Agricultural Products with Terpenes and Terpenoids}

First applications of terpenoids as solvents were performed in the extraction of compounds from food products, specifically in lipid extraction. The most employed solvent is $n$-hexane, though for its hazardousness and being a petroleum-based compound, other solvents have been sought.

In 2004 and 2005, Mamidipally and Liu used limonene for the extraction of lipids from rice bran [230,231]. Limonene obtained almost equivalent yields of lipid extraction compared to the conventional solvent $n$-hexane. Also, the quality of crude oil was comparable. The optimal conditions for lipid extraction obtained were a solvent-to-bran ratio (wt./wt.) of 5:1 and an extraction time of $1 \mathrm{~h}$. 
Besides, a limonene recovery step was done through vacuum evaporation. Compared to the fresh solvent, oxidation products in the recovered limonene was $<1 \%$ (wt.), thus allowing the limonene to be recycled. After obtaining these results with limonene in lipid extraction, other works were published with other matrices for substitution of $n$-hexane and other conventional solvents. The research papers concerning the extraction from agricultural products are collected in Table 10.

Table 10. Extraction Processes from Agricultural Products Using Terpenes and Terpenoids.

\begin{tabular}{|c|c|c|c|c|}
\hline Solute Extracted & Agricultural Product & $\begin{array}{c}\text { Terpene/Terpenoid as } \\
\text { Solvent }\end{array}$ & Year & Ref. \\
\hline Lipids & Rice bran & Limonene & 2004 & [230] \\
\hline Lipids & Rice bran & Limonene & 2005 & [231] \\
\hline Lipids & Olive seeds & Limonene & 2008 & {$[232,233]$} \\
\hline Lipids & $\begin{array}{l}\text { Peanuts, soy and sunflower } \\
\text { seeds }\end{array}$ & $\alpha$-Pinene & 2013 & [234] \\
\hline Lipids & Rapeseed & $\begin{array}{c}\text { Limonene, } \alpha \text {-pinene, } \\
p \text {-cymene }\end{array}$ & 2014 & [235] \\
\hline Lipids & Rapeseed & Limonene, $p$-cymene & 2015 & [236] \\
\hline $\begin{array}{l}\text { Lipids, aromas, } \\
\text { carotenoids }\end{array}$ & Caraway seed, carrot, rapeseed & Pinane & 2016 & [237] \\
\hline $\begin{array}{l}\text { Lipids, aromas, } \\
\text { carotenoids, } \\
\text { water }\end{array}$ & Caraway seed, carrot, rapeseed & $p$-Menthane & 2019 & [238] \\
\hline Carotenoids & Tomato & Limonene & 2010 & [239] \\
\hline Aromas & Blackcurrant bud & $\alpha$-Pinene & 2014 & [240] \\
\hline Aromas & Caraway seed & $\alpha$-Pinene & 2015 & [241] \\
\hline Aromas & Thyme & Limonene & 2015 & [242] \\
\hline $\begin{array}{l}\text { Water (Moisture } \\
\text { determination) }\end{array}$ & $\begin{array}{l}\text { Onion, garlic, minced meat, } \\
\text { carrots, rosemary, mozzarella, } \\
\text { mint, leeks and sage leaves }\end{array}$ & Limonene & 2010 & [243] \\
\hline $\begin{array}{l}\text { Water (Moisture } \\
\text { determination) }\end{array}$ & $\begin{array}{c}\text { Onion, garlic, carrot, leeks, } \\
\text { olive, caraway and } \\
\text { coriander seeds }\end{array}$ & $\alpha$-Pinene & 2012 & [244] \\
\hline Betulin & Birch bark & $\begin{array}{l}\text { Limonene, pinane and } \\
\text { turpentine }\end{array}$ & 2018 & [245] \\
\hline
\end{tabular}

In 2008 Virot et al. also reported a method for lipid extraction with limonene from olive seeds [232,233]. Soxhlet extraction and microwave-integrated Soxhlet extraction techniques were applied in lipid extractions. No differences in using $n$-hexane were obtained in terms of the quantity and quality of the extracts. Also, a regeneration stage was performed with Clevenger and microwave Clevenger distillation procedures. In Clevenger distillation almost $90 \%$ of limonene was recycled, surpassing $50 \%$ reached with $n$-hexane.

Other terpenes have been applied as solvents from the lipid extraction from oilseeds. Bertouche et al. in 2013 employed $\alpha$-pinene for oil extraction from peanuts, soy and sunflower seeds with Soxhlet extraction [234]. As with previously published articles using limonene, the results achieved with $\alpha$-pinene were comparable to $n$-hexane. Additionally, recycling rates of $90 \%$ were reached with $\alpha$-pinene employing Clevenger distillation, obtaining also almost negligible degradation of the solvent. The terpenes limonene, $\alpha$-pinene, $p$-cymene were used also in lipid extraction from rapeseed, in the work conducted by Li et al. in 2014 [235]. Soxhlet extraction and Clevenger distillation techniques were also applied. The highest oil extraction yield was obtained with $p$-cymene and limonene, surpassing isopropanol, butanol, $n$-hexane and ethanol solvents. Also, extraction yields with $\alpha$-pinene outnumbered those obtained with $n$-hexane. On the other hand, in the work published by Sicaire et al. in 2015 [236], also applying p-cymene and limonene in oil extraction from rapeseeds with conventional Soxhlet, resulted in lower extraction yields for the terpenes than $n$-hexane. $n$-Hexane enabled $47 \mathrm{~g}$ 
lipids $/ 100 \mathrm{~g}$ dry matter and terpenes reached $80 \%$ of this quantity. Sicaire et al. highlighted the relevance of solvent diffusivity into the matrix in the results obtained.

Otherwise, valuable compounds as carotenoids have been extracted using terpenes and terpenoids. In 2010, Chemat-Djenni et al. applied limonene as solvent by the first time for the extraction of lycopene from tomato [239]. The limonene was obtained through steam distillation and deterpenation process from orange peels, thus remarking the valorization of this agricultural by-product. The results with limonene were also comparable with the use of conventional solvent dichloromethane.

Pure terpenes have also been applied in the extraction of aromas. Filly et al. conducted experimental and theorical studies in the extraction of aromas from blackcurrant buds in 2014 [240] and caraway seeds in 2015 [241] with alternative solvents including $\alpha$-pinene, for substitution of $n$-hexane. Besides, in 2015 Villanueva Bermejo et al. published a research work for the extraction of thymol from thyme using limonene and pressurized liquid extraction [242]. From Thymus vulgaris at $10 \mathrm{MPa}$, thymol recoveries obtained were $7-11 \mathrm{mg} / \mathrm{g}$ and the highest thymol concentrations were obtained with limonene compared with ethanol and ethyl lactate.

In 2016, Yara-Varón et al. investigated the use of pinane in the Soxhlet extraction of lipids, carotenoids and aromas from rapeseeds, carrots and caraway seeds, respectively [237]. A mixture of cis and trans pinanes was obtained through catalytic hydrogenation of pinenes and turpentine oils. Pinanes were compared to $n$-hexane performance, obtaining similar extraction yields and lipids profiles in rapeseeds extraction. A maximum of $95.4 \%$ carotenoids extraction yield from carrots was reached with pinanes, while $n$-hexane extracted a maximum of $78.1 \%$. Concerning aromas extraction, both extract compositions were similar using the two solvents. Continuing with this research, in 2019 Madji et al. studied the same solutes and matrices but with the employment of $p$-menthane. Analogously to the previous work, $p$-menthane was originated by catalytic hydrogenation of limonene. Mass yields in lipid extractions from rapeseeds were comparable using $p$-menthane $(40.5 \%)$ and $n$-hexane $(39.5 \%)$. In the extraction of aromas and carotenoids, similar yields and composition profiles were obtained with both solvents.

Terpenes have also been in water determination by Dean-Stark distillation for the substitution of toluene. In 2010 Veillet et al. [243] proposed the use of limonene instead of toluene for moisture determination of different food matrices (onion, garlic, minced meat, carrots, rosemary, mozzarella, mint, leeks and sage leaves). Comparable results were obtained using both solvents. Bertouche et al. in 2012 [244] also applied $\alpha$-pinene in water extraction of food samples (onion, garlic, carrot, leeks, olive, caraway and coriander seeds). Analogously with the results obtained with limonene, performance with $\alpha$-pinene was comparable to toluene. Besides, the use of $p$-menthane in the Dean-Stark procedure was performed by Madji et al. in 2019 [238]. Water extractions yields were similar with $p$-menthane and toluene, thus with $p$-menthane time needed to reach $100 \%$ water recovery was $55 \%$ lower than using toluene.

Finally, in 2018, Grazhdannikov et al. employed limonene, pinanes and hydrogenated turpentine in the extraction of betulin from birch bark [245]. The terpenes were proposed as green solvents in the purification of betulin. A separation of pure betulin of $95-97 \%$ and high yields of $75-82 \%$ were obtained.

Due to all the research that has been carried limonene, $\alpha$-pinene, $p$-cymene and pinanes are promising candidates for the substitution of $n$-hexane in lipid extraction from oilseeds. Limonene has surpassed or matched $n$-hexane performance in lipid extraction, being able to replace it in this process. Though more studies must be done in fields of economic scope and solvent regeneration processes. Besides, more terpenes and terpenoids could be applied in this field. In the same way, the extraction of aromas and carotenoids research works could be expanded as there are no many studies, despite the results achieved. In Dean-Stark distillation, terpenes showed great performance comparable to toluene, being also good candidates in this technique. 


\subsection{Extraction from Microalgae with Terpenes and Terpenoids}

In the same way that the extraction of lipids from oilseeds, terpenes have been applied in the extraction of oil from microalgae. Lately more applications have been developed. The research articles are collected in Table 11. In 2012, Dejoye Tanzi et al. applied for the first time terpenes in the extraction of lipids from microalgae (Chlorella vulgaris), using limonene, $\alpha$-pinene and $p$-cymene [246]. Soxhlet extraction and solvent regeneration through Clevenger distillation were performed. The extraction yields of crude oil with terpenes resulted higher than those obtained $n$-hexane.

Continuing with this application of terpenes, in 2013, Dejoye Tanzi et al. also applied limonene, $\alpha$-pinene and $p$-cymene in lipid extraction from Nannochloropsis oculata and Dunaliella salina [247]. A simultaneous distillation and extraction process with terpenes, Soxhlet extraction using $n$-hexane and Bligh \& Dyer method employing a chloroform/methanol solvent mixture [248] were compared. Oil extraction yields of both microalgae using terpenes were slightly lower than those obtained from Bligh \& Dyer method but higher than Soxhlet extraction with $n$-hexane. In 2015, Golmakani et al. [249] tested limonene in lipid extraction from Spirulina, Phormidium sp., Anabaena planctonica and Stigeoclonium sp. employed pressurized liquid extraction. They optimized the extraction process at $200{ }^{\circ} \mathrm{C}$ and $15 \mathrm{~min}$. In agreement with the results obtained with Dejoye Tanzi et al. [247], lipid extraction yields with limonene were higher than those obtained with $n$-hexane from Spirulina. This phenomenon reported for several authors and also in lipid extraction from oilseeds could be related to a major polarity and higher density of limonene compared to $n$-hexane.

Castro-Puyana et al. in 2013 also proposed an alternative source of carotenoids using Neochloris oleoabundans, instead of focusing on lipid extraction [250]. The authors optimized the use of a limonene/ethanol mixture and pure solvents employing pressurized liquid extraction. The optimum conditions predicted by the statistical analysis were at $112{ }^{\circ} \mathrm{C}$ and using pure ethanol. Therefore, limonene was not a more suitable solvent than ethanol from carotenoid extraction.

Table 11. Extraction Processes from Microalgae using Terpenes and Terpenoids.

\begin{tabular}{|c|c|c|c|c|}
\hline Solute Extracted & Microalgae & $\begin{array}{c}\text { Terpene/Terpenoid } \\
\text { as Solvent }\end{array}$ & Year & Ref. \\
\hline Lipids & Chlorella vulgaris & $\begin{array}{l}\text { Limonene, } \\
\alpha \text {-pinene, } \\
p \text {-cymene }\end{array}$ & 2012 & [246] \\
\hline Lipids & $\begin{array}{l}\text { Nannochloropsis oculata } \\
\text { and Dunaliella salina }\end{array}$ & $\begin{array}{l}\text { Limonene, } \\
\alpha \text {-pinene, } \\
p \text {-cymene }\end{array}$ & 2013 & [247] \\
\hline Lipids & $\begin{array}{l}\text { Spirulina, Phormidium sp., } \\
\text { Anabaena planctonica and } \\
\text { Stigeoclonium sp. }\end{array}$ & Limonene & 2014 & [249] \\
\hline Carotenoids & Neochloris oleoabundans & Limonene & 2013 & [250] \\
\hline Phenolic compounds & Zonaria tournefortii & Eucalyptol & 2018 & [251] \\
\hline
\end{tabular}

In 2018, Hamiche et al. [251] presented for the first time eucalyptol (1,8-cineole) as a candidate for the extraction of phenolic compounds from Zonaria tournefortii. The authors used a multistep liquid-liquid extraction with distilled water followed by the elimination of the aqueous phase after centrifugation and terpenoid recovery by steam distillation. The extraction yield with eucalyptol was ( $0.45 \%$ wt./vol.) notably lower than using a conventional solvent of a chloroform/methanol solvent mixture (2.16\% wt./vol.). Nevertheless, solvent regeneration with steam distillation was successful as FTIR analysis showed no degradation of eucalyptol. Lastly, Hamiche et al. [251] recommended the use of more polar terpenoids for improving extraction performance. 
As described, the lipid extraction of microalgae with limonene seems to be feasible and to be able to replace the use of $n$-hexane, as well as the previous extraction proposals in oilseeds. In the field of carotenoids and phenolic compounds using limonene and eucalyptol, they do not seem the most suitable solvents. However, these studies are still preliminary and scarce and it is necessary to investigate the use of different terpenes and terpenoids in order to optimize these processes.

\subsection{Extraction from Aqueous Solutions with Terpenes and Terpenoids}

Published papers about extraction using terpenes and terpenoids from aqueous solutions are collected in Table 12. Most of the studies determined the liquid-liquid equilibria of alcohols, terpenes or terpenoids and water. Subsequently, more studies have studied the extraction of other solutes.

Table 12. Extraction Processes from Aqueous Solutions with Terpenes and Terpenoids.

\begin{tabular}{|c|c|c|c|c|}
\hline Solute & Raffinate & $\begin{array}{c}\text { Terpene/Terpenoid } \\
\text { as Solvent }\end{array}$ & Year & Ref. \\
\hline Ethanol & Water & Limonene, citral & 1995 & [252] \\
\hline Ethanol & Water & Limonene & 2004 & [253] \\
\hline Ethanol & Water & Linalool & 2005 & [254] \\
\hline Ethanol & Water & Citral & 2007 & [255] \\
\hline Methanol & Water & $\begin{array}{l}\text { Limonene, } \alpha \text {-pinene, } \\
\beta \text {-pinene }\end{array}$ & 2005 & [256] \\
\hline Ethanol & Water & $\begin{array}{l}\text { Limonene, } \alpha \text {-pinene, } \\
\beta \text {-pinene }\end{array}$ & 2005 & [257] \\
\hline 1-Butanol, 1-propanol & Water & $\begin{array}{l}\text { Limonene, } \alpha \text {-pinene, } \\
\beta \text {-pinene }\end{array}$ & 2008 & [258] \\
\hline Acetone & Water & $\begin{array}{l}\text { Limonene, } \alpha \text {-pinene, } \\
\beta \text {-pinene }\end{array}$ & 2010 & [259] \\
\hline Ethanol, methanol & Water & Geraniol & 2012 & [260] \\
\hline Ethanol, methanol & Water & $\beta$-Citronellol & 2012 & [261] \\
\hline Ethanol, methanol & Water & Linalool & 2013 & [262] \\
\hline Ethanol & Water & Limonene, carvone & 2013 & [263] \\
\hline Methanol & Water & Citral & 2013 & [264] \\
\hline Acetone, 1-propanol & Water & $\beta$-Citronellol & 2015 & [265] \\
\hline $\begin{array}{l}\text { 1-Butanol, ethanol, } \\
\text { methanol, 1-propanol }\end{array}$ & Water & Eucalyptol & 2016 & [266] \\
\hline 1-Propanol & Water & Linalool, geraniol & 2016 & [267] \\
\hline Phenol, $p$-cresol & Water & Eucalyptol & 2016 & [268] \\
\hline$\beta$-Cyclodextrin & $\begin{array}{c}\text { Pharmaceutical } \\
\text { wastewaters }\end{array}$ & Limonene & 2016 & [269] \\
\hline $\begin{array}{l}\text { Acetic, propionic, butyric } \\
\text { and valeric acids }\end{array}$ & Water & $\begin{array}{l}\text { Citral, eugenol, } \\
\text { geraniol }\end{array}$ & 2019 & [26] \\
\hline $\begin{array}{l}\text { Phenol, 2-chlorophenol, } \\
\text { 2-nitrophenol }\end{array}$ & Water & $\begin{array}{l}\text { Citral, eugenol, } \\
\text { geraniol linalool }\end{array}$ & 2020 & [27] \\
\hline
\end{tabular}

Gironi et al. in 1995 [252] started to study binary systems (water + limonene) and (water + citral) and also the ternary systems (water + ethanol + limonene) and (water + ethanol + citral) at $293 \mathrm{~K}$. Complete miscibility was observed with ethanol mass fraction greater than 0.73 for limonene system and 0.45 for citral system. Besides, Cháfer et al. in 2004 also studied the (water + ethanol + limonene) ternary system at temperatures 293.15 from 323.15 K [253]. In 2005 [254], Cháfer et al. published an article with the same temperatures for the (water + ethanol + linalool) ternary system. Lastly, in 2007 Gramajo de Doz et al. [255] also studied (water + ethanol + citral) ternary system at $303.15 \mathrm{~K}$.

Tamura and Li published in 2005 [256] liquid equilibrium data of alcohols in ternary systems (water + methanol + limonene or $\alpha$-pinene or $\beta$-pinene) and quaternary system (water + methanol + limonene $+\alpha$-pinene) at $293.15 \mathrm{~K}$. Analogously, the same year they presented a study [257] of (water + ethanol + limonene or $\alpha$-pinene or $\beta$-pinene) and quaternary system (water + ethanol + limonene $+\alpha$-pinene) at $293.15 \mathrm{~K}$. Continuing with this work, in 2008 Tamura et al. [258] studied the ternary 
systems (water + (1-butanol or 1-propanol) + limonene or $\alpha$-pinene or $\beta$-pinene) at $293.15 \mathrm{~K}$. Also, $\mathrm{Li}$ and Tamura published in 2010 [259] the equilibrium data of ternary system (water + acetone + $\alpha$-pinene) at $288.15,298.15$ at $308.15 \mathrm{~K}$ and (water + acetone + limonene or $\beta$-pinene) at $298.15 \mathrm{~K}$.

In 2012, Li et al. [260] published liquid-liquid equilibrium data of ternary systems (water + ethanol + citral) and (water + methanol + citral) at 283.15, 298.15 and $313.15 \mathrm{~K}$. In the same year, Tianfie et al. [261] presented the data of the same systems but replacing citral with $\beta$-citronellol. Besides, Li et al. [262] published equilibrium data from (water + ethanol + linalool) and (water + methanol + linalool) ternary systems at $298.15 \mathrm{~K}$. Also, in 2013 Huang et al. [264] studied ternary system (water + methanol + citral) at 283.15 and $313.15 \mathrm{~K}$ and Oliveira et al. [263] the quaternary system (water + ethanol + limonene + carvone) at $298.2 \mathrm{~K}$.

More liquid-liquid equilibrium data with alcohols were published by Li et al. in 2015 [265] of (water +1 -propanol $+\beta$-citronellol) and (water + acetone $+\beta$-citronellol) systems at $283.15,298.15$ and $313.15 \mathrm{~K}$. Also in 2016, Li et al. [266] presented the study of four alcohol systems with eucalyptol, (water + methanol or ethanol or 1-propanol or 1-butanol + eucalyptol) at $298.15 \mathrm{~K}$. Lastly in 2016, Wan et al. [267] presented data from (water + 1-propanol + linalool) and (water + 1-propanol + geraniol) systems at $283.15,298.15$ and $313.15 \mathrm{~K}$.

Another application of terpenes and terpenoids as solvents in liquid-liquid extraction is focused on the analytical field. Pourreza et al. published a research article in 2016 [269] applying limonene in dispersive liquid-liquid microextraction for the determination of cyclodextrin from pharmaceutical wastewater samples. In the same way that eutectic solvents are currently being used in the development of analytical methodologies to determine organic compounds in water, it is expected that terpenes and terpenoids can be applied in this field in the nearest future.

The extraction of phenolic compound from aqueous solutions using terpenes and terpenoids has been also studied. In 2017, Li et al. [268] studied the ternary liquid-liquid equilibria of (water + phenol + eucalyptol) and (water + p-cresol + eucalyptol) systems at 283.15, 298.15 and $313.15 \mathrm{~K}$, showing phenol extraction efficiencies higher than $90 \%$.

Recently, Rodríguez-Llorente et al. [27] have applied terpenoids in the extraction of phenol, 2-chlorophenol and 2-nitrophenol from aqueous solutions. Citral, eugenol, geraniol and linalool were applied in the multicomponent extraction of phenols and compared with the results obtained using eutectic solvents and conventional solvents such as toluene, diisopropyl ether (DIPE) and methyl isobutyl ketone (MIBK). Citral and geraniol archived higher extraction yields than DIPE, toluene and eutectic solvents and similar values to those using MIBK. Linalool also obtained high phenols extraction yield higher than DIPE and the eutectic solvents but lower than MIBK. Besides, a regeneration process was addressed with alkali back-extraction. Geraniol and linalool could be fully regenerated but back-extraction yields and FTIR analysis showed that citral and eugenol were not suitable for this process. Also, this regeneration capacity was tested through 3 cycles of extraction-regeneration, being the extraction yields higher to $94 \%$. In addition, geraniol and linalool were applied in a parallel packed column extraction at different solvent-feed ratios obtaining similar yields than in vial. Lastly, Rodríguez-Llorente et al. also conducted countercurrent column simulations with Kremser and COSMO-based/Aspen Plus methodologies.

Rodríguez-Llorente et al. [26] also proposed the use of geraniol, citral and eugenol in the extraction of volatile fatty acids (acetic, propionic, butyric and valeric acids) from aqueous solutions, obtaining high yields of extraction. In this work, geraniol and eugenol showed extraction yields of volatile fatty acids greater than those reached experimentally by eutectic solvents formed by octanoic acid, thymol and menthol. Also, a back-extraction with $\mathrm{NaOH}$ and $\mathrm{Na}_{2} \mathrm{CO}_{3}$ for solvent regeneration was performed. As described for the extraction of phenols [27], consecutive cycles of extraction-regeneration were done, showing no decrease in extraction capacity after back-extraction. In addition, through experiments in parallel packed column extraction with geraniol, distribution coefficients were obtained and applied in countercurrent extraction by Kremser method simulations. 
To summarize, liquid-liquid equilibria from alcohol-water-terpene systems have been extensively determined, though the studies are limited to some terpenes and terpenoids. Besides, alternative applications of terpenes and terpenoids in the extraction of different compounds as phenols or organic acids have been done, obtaining very promising results. In several cases, the results obtained using terpenoids have been higher to those using eutectic solvents and showing greater chemical stability. It is expected that studies on a greater scale could be performed for checking the feasibility of this extraction process. Also, research is still scarce, it could be amplified searching for new matrices and solutes for the extraction process.

\subsection{Other Applications in Extraction of Terpenes and Terpenoids}

This section includes works that use terpenes and terpenoids as solvents in other applications than those described in the three previous sections. In the development of novel analytical methodologies, some research articles have been focused on the use of terpenes and terpenoids. In 2013, Farajzadeh et al. [270] used menthol in dispersive liquid-liquid microextraction for extraction and concentration of phthalate esters in pharmaceutical samples. Through the solidification of menthol, analytes could be separated from water samples and concentrated. Faure et al. [271] in the same year proposed the use of limonene as a substitute of $n$-heptane in counter-current chromatography. Lastly, Medvedovici et al. in 2013 [272] published the use of limonene for the extraction of simvastatin, lovastatin and their metabolites from human plasma.

Moreover, Nikakhtari et al. in 2013 [273] applied limonene in the extraction of bitumen from oil sands. Different solvents were tested as cycloalkanes and aromatics solvents. Nevertheless, limonene showed the lowest results of the 13 solvents and mixtures employed.

\subsection{Predictive Methods in Extraction with Terpenes and Terpenoids}

Among the tools available for prediction of the most suitable solvents in extraction processes using terpenes and terpenoids, Hansen Solubility Parameters (HSP) and COSMO-based methods have been the most used. A total of 11 articles have been applied these methodologies in extraction processes with terpenes and terpenoids.

HSP can describe solvents in terms non-polar, polar and hydrogen bonding properties and can be a tool of selection and comparison of solvents. Dejoye Tanzi et al. [246] compared HSP parameters of limonene, $\alpha$-pinene and $p$-cymene to $n$-hexane concluding that by their similar values, their behavior in the extraction of oil from microalgae likely also had to be similar. Besides, Li et al. [235] used HSP of limonene, $\alpha$-pinene and $p$-cymene in the extraction of lipids from rapeseeds and predicted the differences in the extraction of the fatty acids, tocopherol and sterols. Also, HSP parameters have been used for prediction in the extraction of aromas using terpenes and terpenoids from blackcurrant buds [240], food [241] and caraway seeds [237].

COSMO-RS (Conductor-like Screening Model for Real Solvents) has served as a method for solvent screening in various applications of terpenes and terpenoids in extraction. Filly et al. [241] calculated sigma potential similarities of solvents and solutes for the comparison of the solvents in lipid extraction for caraway seeds, being the values in agreement with experimental results [241]. In addition, relative solubilities have been calculated and applied in prediction of the extraction of lipids from rapeseeds [236-238], carotenoids from carrots [237,238], aromas from caraway seeds [237,238] and betulin from bitch bark [245] using terpenes. Lastly, as it was previously mentioned, Rodríguez-Llorente et al. applied the COSMO-RS method for calculating the infinite dilution activity coefficients as solvent screening of terpenes and terpenoids in extraction of volatile fatty acids from water [26] and separation of phenols from industrial wastewater [27], obtaining very similar trends in predictions and experimental data using various terpenes and terpenoids. 


\subsection{Correlation of Liquid-Liquid Equilibrium Using Terpenes and Terpenoids}

Thermodynamic models as Non-random two liquids (NRTL) and UNIQUAC have been applied in the correlation of liquid-liquid equilibria of systems composed of water, alcohols, acetone or phenols and using terpenes and terpenoids as solvents. Between both models, UNIQUAC has been more extensively employed.

NRTL and UNIQUAC models have been applied satisfactorily in the correlation of the ternary systems formed by water, ethanol and terpenes as limonene [253] and linalool [254]. The quaternary system (ethanol + water + limonene + carvone) [263] was also fitted by NTRL and UNIQUAC models obtaining lower deviation using the NTRL model. In the correlation of equilibria of 1-propanol and water with linalool and geraniol, calculated root mean square deviations (RMSDs) were $0.97 \%$ and $1.07 \%$ for NRTL and UNIQUAC models, respectively [267]. Besides, RMSDs obtained values for NRTL and UNIQUAC were $0.59 \%$ and $0.54 \%$ in ethanol, 1-propanol and 1-butanol with eucalyptol systems [266]. On the other hand, eucalyptol equilibria data with water and phenol or $p$-cresol obtained RMSDs of $0.32 \%$ for both models [268]. Therefore, NTRL and UNIQUAC models can satisfactorily correlate liquid-liquid equilibria of systems formed by water, alcohols and terpenes.

The extended UNIQUAC model has been applied in correlation for equilibria of water, methanol and citral system, obtaining RMSDs lower than 1.12\% [263]. Also, in the system of linalool with methanol and ethanol a satisfactory correlation was obtained with RMSDs lower than $1.35 \%$ [262]. On the other hand, a modified UNIQUAC model was applied by Li and Tamura in the correlation of liquid-liquid equilibria of limonene, $\alpha$-pinene and $\beta$-pinene with acetone [259] and ethanol [257], obtaining a good agreement between experimental results and calculated values.

Extended and modified UNIQUAC models has been also employed simultaneously in the correlation of systems with alcohols. Both models could correlate satisfactorily limonene, $\alpha$-pinene and $\beta$-pinene with 1-propanol and 1-butanol systems [258]. In the correlation of $\beta$-citronellol with methanol and ethanol with extended UNIQUAC and modified UNIQUAC mean RMSDs were $0.69 \%$ and $0.76 \%$, respectively [261]. Also, in the $\beta$-citronellol with acetone and 1-propanol systems, equilibrium data with both models obtained mean RMSDs minor to $0.86 \%$ [265]. Lastly, Li et al. studied geraniol with methanol and ethanol systems obtaining mean deviations of $0.66 \%$ and $0.77 \%$ with the extended and modified UNIQUAC models, respectively [260].

Therefore, both the NRTL and UNIQUAC thermodynamic models have been used successfully in the correlation of liquid-liquid equilibrium data in systems that use terpenes or terpenoids as solvents. Both models could be used to simulate liquid-liquid extraction processes on an industrial scale with these solvents.

\subsection{Simulation of Liquid-Liquid Extraction Processes with Terpenes and Terpenoids}

Papers that address simulations in liquid-liquid extraction processes using terpenes and terpenoids are scarce and very recent. Firstly, Rodríguez-Llorente et al. in 2019 [26] applied the Kremser method in countercurrent extraction column simulations for the separation of volatile fatty acids from aqueous streams. The extraction $\left(E_{\mathrm{i}}\right)$ and reciprocal $\left(U_{\mathrm{i}}\right)$ factors of the Kremser method were obtained from experimental distribution ratios obtained in packed column extraction. Simulations showed that with 10 extraction stages in the extractor, a global acid extraction yield of $98 \%$ could be achieved using geraniol as solvent.

A similar approach was applied in the extraction of phenols from wastewaters by Rodríguez-Llorente et al. [27]. First, simulations using the Kremser method were performed using experimental data. These simulations served to compare and validate simulations using the predictive COSMO-based/Aspen Plus methodology. In this approach, terpenoids were described as pseudocomponents and the activity coefficients were calculated using the COSMOSAC model in Aspen Plus. Kremser and COSMO-based/Aspen Plus simulations showed close results validating this last methodology. According to the results obtained in the simulations, a complete separation of phenols 
could be achieved using linalool and geraniol with a solvent-to-feed ratio of 0.5 and 10 equilibrium stages in the extractor.

The application of terpenes and terpenoids in liquid-liquid extraction processes as solvents is still very scarce. For this reason, the number of articles in which process simulation has been used is also very low. Taking into account the promising results recently obtained in the extraction of volatile fatty acids or phenols from aqueous streams, the applications of terpenes and terpenoids in extraction processes will be expanded in the nearest future.

\section{Conclusions and Future Outlook of the Use of Eutectic Solvents, Terpenes and Terpenoids in Liquid-Liquid Extraction Processes}

In 2007, the first article on the use of eutectic solvents in liquid-liquid extraction was published. In the early years, these solvents were used mainly in the extraction of organic compounds from oils and biodiesel and in the separation of hydrocarbons. Afterward, a wide variety of hydrophilic eutectic solvents were applied in the separation of alcohols from hydrocarbons and in the extraction of high added-value compounds. From 2014, aqueous biphasic systems based on eutectic solvents have been used in the separation of biomolecules and bioactive compounds. Another important novelty was the preparation of hydrophobic eutectic solvents (HES) in 2015. These HES are being currently studied in the extraction of organic compounds from aqueous streams and in the selective separation of metals.

In the extraction of glycerol from biodiesel using eutectic solvents, real biodiesel samples have been used and the solvents were successfully regenerated and reused. Also, the proposed processes achieved the requirements of international standards of biodiesel. Therefore, the degree of development of the process of extraction of glycerol from biodiesel with eutectic solvents is high and it would be necessary to increase the scale of the processes to develop a continuous process.

The extraction of hydrocarbons using eutectic solvent has been widely studied, being focused on the reduction of aromatic, nitrogen and sulfur contents in fuels. However, the extraction of hydrocarbons from real fuels has hardly been studied and few articles have studied the simultaneous extraction of hydrocarbons from multicomponent streams. To assess the feasibility of an extraction process of hydrocarbons using eutectic solvents, larger-scale extraction tests should be carried out and continuous extraction processes should be developed.

The eutectic solvents tested in the extraction of alcohols from alkanes have shown low extraction capacities compared to those of conventional solvents and ionic liquids. By contrast, higher alcohol/hydrocarbon selectivities were obtained using eutectic solvents than conventional solvents. Hence, these eutectic solvents could be used to remove alcohols with high purity from their mixtures with hydrocarbons. In the extraction of phenols from hydrocarbons, various salts have been tested to form eutectic solvents with the extracted phenols. In these applications, several extraction and regeneration cycles have been performed satisfactorily and larger scale extraction experiments will be required to confirm the technical viability of the processes.

One of the most promising applications of eutectic solvents in liquid-liquid separation processes is the formation of aqueous biphasic systems. Although the use of eutectic solvents in ABS is a recent application, significant results have been published to date. High extraction yields have been obtained using these systems in the separation of a wide variety of compounds: proteins, enzymes, dyes, amino acids and nucleic acids. To ensure the viability of these purification processes on the industrial scale, the back-extraction process of the solutes should be studied and technologies should be developed on a larger scale. Furthermore, the use of real biological samples and the comparison with other conventional or alternative technologies for the purification of these biomolecules will be essential in the future. In the application of eutectic solvents in the formation of ABS, the eutectic solvent integrity is destroyed and a nonstoichiometric partition of the hydrogen bond donor and acceptor can be found in the coexisting phases. Therefore, the distribution of the eutectic solvent on both phases must be checked to ensure their recovery and reuse. 
The application of hydrophobic eutectic solvents in the extraction of organic molecules from water has also been widely studied in recent years. However, the vast majority of works have used synthetic mixtures formed by organic compounds and ultrapure water. The influence of the matrix of industrial aqueous streams or wastewaters should be studied in greater depth to confirm the viability of these solvents in the different proposed applications. Besides, continuous extraction and back-extraction processes should be carried out, studying the chemical stability of hydrophobic eutectic solvents, especially those formed by middle chain fatty acids that have shown low chemical stability. In the separation of metals with hydrophobic eutectic solvents, very promising results have been obtained, despite being a very recent application. Soon it is expected that real mixtures will be used to confirm the application of these solvents in the selective recovery of metals from waste.

To evaluate the application of eutectic solvents in liquid-liquid extraction processes on an industrial scale, it is essential to address the simulation of these processes. Using process simulators, the technical and economic feasibility of these alternative processes can be demonstrated and costs can be compared with conventional extraction processes. For this, it is essential to use both predictive methods and thermodynamic adjustment models that have shown high reliability. Until now, the NRTL and UNIQUAC thermodynamic models are suitable models for fitting ternary equilibrium thermodynamic data in systems composed of eutectic solvents. In addition, the COSMO-based calculations have been successfully used in solvent screenings and in predictions of liquid-liquid equilibria. PC-SAFT theory has been also successfully applied in the prediction of liquid-liquid equilibria of systems formed by eutectic solvents. These predictive and thermodynamic models should be applied to more realistic multi-component mixtures to adequately simulate and optimize complete extraction processes using eutectic solvents.

In the case of terpenes and terpenoids, their application in extraction processes is still scarce, even though they have proven to be competitive solvents with conventional solvents in some uses. Most of the articles on the application of terpenes and terpenoids in extraction have been focused on the separation of lipids and aromas from agricultural products and on the extraction of lipids from microalgae. Due to their hydrophobic character, terpenes and terpenoids have also recently been used as solvents in the liquid-liquid extraction of organic compounds from aqueous solutions.

In the extraction of lipids and aromas from agricultural products, terpenes have achieved results similar to those obtained with conventional solvents such as toluene and $n$-hexane. In addition, the regeneration and reuse of these solvents and their chemical stability have been confirmed. Similar results have been obtained in the extraction of liquids from microalgae, showing the terpenes extraction yields comparable to those of $n$-hexane.

In the application of terpenes and terpenoids in liquid-liquid extraction processes, these solvents have shown extraction performances superior to those of eutectic solvents in the extraction of volatile fatty acids and phenolic compounds from aqueous streams. Taking these preliminary results into account, terpenes and terpenoids have emerged as solvents with potential for the separation of organic compounds from aqueous streams due to their great ability to solubilize organic compounds and their hydrophobic nature. To confirm this potential as alternative solvents, terpenes and terpenoids should be used in the liquid-liquid extraction of contaminants from real aqueous streams, carrying out extraction experiments on a larger scale and developing continuous extraction and back-extraction processes.

Author Contributions: Conceptualization, M.L.; literature search, D.R.-L. and M.L.; writing—original draft preparation, D.R.-L., A.C.-B. and M.L.; writing-review and editing, S.Á.-T., J.G., V.I.Á. and M.L. supervision, S.Á.-T., J.G. and V.I.Á.; project administration, V.I.Á., J.G. and M.L. All authors have read and agreed to the published version of the manuscript.

Funding: The research was funded by Comunidad Autónoma de Madrid, Project P2018/EMT-4341 and Project PR65/19-22441 and Ministerio de Ciencia, Innovación y Universidades, Project CTM2017-84033-R. Diego Rodríguez-Llorente and Andrés Cañada-Barcala thank Ministerio de Ciencia, Innovación y Universidades for awarding them two FPU grants (FPU18/01536 and FPU19/01451).

Conflicts of Interest: The authors declare no conflict of interest. 


\section{References}

1. Smith, E.L.; Abbott, A.P.; Ryder, K.S. Deep Eutectic Solvents (DESs) and Their Applications. Chem. Rev. 2014, 114, 11060-11082. [CrossRef]

2. Abbott, A.P.; Capper, G.; Davies, D.L.; Rasheed, R.K.; Tambyrajah, V. Novel solvent properties of choline chloride/urea mixtures. Chem. Commun. 2003, 70-71. [CrossRef] [PubMed]

3. Alkhatib, I.I.I.; Bahamon, D.; Llovell, F.; Abu-Zahra, M.R.M.; Vega, L.F. Perspectives and guidelines on thermodynamic modelling of deep eutectic solvents. J. Mol. Liq. 2020, 298, 112183. [CrossRef]

4. Abranches, D.O.; Martins, M.A.R.; Silva, L.P.; Schaeffer, N.; Pinho, S.P.; Coutinho, J.A.P. Phenolic hydrogen bond donors in the formation of non-ionic deep eutectic solvents: The quest for type V DES. Chem. Commun. 2019, 55, 10253-10256. [CrossRef] [PubMed]

5. Martins, M.A.R.; Pinho, S.P.; Coutinho, J.A.P. Insights into the Nature of Eutectic and Deep Eutectic Mixtures. J. Solut. Chem. 2019, 48, 962-982. [CrossRef]

6. Alonso, D.A.; Baeza, A.; Chinchilla, R.; Guillena, G.; Pastor, I.M.; Ramón, D.J. Deep Eutectic Solvents: The Organic Reaction Medium of the Century. Eur. J. Org. Chem. 2016, 2016, 612-632. [CrossRef]

7. Ruß, C.; König, B. Low melting mixtures in organic synthesis-An alternative to ionic liquids? Green Chem. 2012, 14, 2969-2982. [CrossRef]

8. Francisco, M.; Van Den Bruinhorst, A.; Kroon, M.C. Low-transition-temperature mixtures (LTTMs): A new generation of designer solvents. Angew. Chem. Int. Ed. 2013, 52, 3074-3085. [CrossRef]

9. Zainal-Abidin, M.H.; Hayyan, M.; Hayyan, A.; Jayakumar, N.S. New horizons in the extraction of bioactive compounds using deep eutectic solvents: A review. Anal. Chim. Acta 2017, 979, 1-23. [CrossRef]

10. Dai, Y.; van Spronsen, J.; Witkamp, G.-J.J.; Verpoorte, R.; Choi, Y.H. Natural deep eutectic solvents as new potential media for green technology. Anal. Chim. Acta 2013, 766, 61-68. [CrossRef]

11. Liu, Y.; Friesen, J.B.; McAlpine, J.B.; Lankin, D.C.; Chen, S.N.; Pauli, G.F. Natural Deep Eutectic Solvents: Properties, Applications and Perspectives. J. Nat. Prod. 2018, 81, 679-690. [CrossRef] [PubMed]

12. Paiva, A.; Craveiro, R.; Aroso, I.; Martins, M.; Reis, R.L.; Duarte, A.R.C. Natural Deep Eutectic Solvents-Solvents for the 21st Century. ACS Sustain. Chem. Eng. 2014, 2, 1063-1071. [CrossRef]

13. van Osch, D.J.G.P.; Dietz, C.H.J.T.; van Spronsen, J.; Kroon, M.C.; Gallucci, F.; van Sint Annaland, M.; Tuinier, R. A Search for Natural Hydrophobic Deep Eutectic Solvents Based on Natural Components. ACS Sustain. Chem. Eng. 2019, 7, 2933-2942. [CrossRef]

14. Ribeiro, B.D.; Florindo, C.; Iff, L.C.; Coelho, M.A.Z.Z.; Marrucho, I.M. Menthol-based Eutectic Mixtures: Hydrophobic Low Viscosity Solvents. ACS Sustain. Chem. Eng. 2015, 3, 2469-2477. [CrossRef]

15. Martins, M.A.R.; Crespo, E.A.; Pontes, P.V.A.; Silva, L.P.; Bülow, M.; Maximo, G.J.; Batista, E.A.C.; Held, C.; Pinho, S.P.; Coutinho, J.A.P. Tunable Hydrophobic Eutectic Solvents Based on Terpenes and Monocarboxylic Acids. ACS Sustain. Chem. Eng. 2018, 6, 8836-8846. [CrossRef]

16. Martins, M.A.R.; Silva, L.P.; Schaeffer, N.; Abranches, D.O.; Maximo, G.J.; Pinho, S.P.; Coutinho, J.A.P. Greener Terpene-Terpene Eutectic Mixtures as Hydrophobic Solvents. ACS Sustain. Chem. Eng. 2019, 7, 17414-17423. [CrossRef]

17. Zwenger Chhandak Basu, S.; Zwenger, S.; Basu, C. Plant Terpenoids: Applications and Future Potentials. Biotechnol. Mol. Biol. Rev. 2008, 3, 1-007.

18. Kirk-Othmer. Chemical Technology of Cosmetics; John Wiley \& Sons: Hoboken, NJ, USA, 2013.

19. Boutekedjiret, C.; Vian, M.A.; Chemat, F. Terpenes as Green Solvents for Natural Products Extraction. In Alternative Solvents for Natural Products Extraction. Green Chemistry and Sustainable Technology; Springer: Berlin/Heidelberg, Germany, 2014; pp. 205-219.

20. Vovers, J.; Smith, K.H.; Stevens, G.W. Bio-Based Molecular Solvents; Elsevier Inc.: Amsterdam, The Netherlands, 2017; ISBN 9780128054437.

21. Li, Y.; Kunz, W.; Chemat, F. From Petroleum to Bio-Based Solvents: From Academia to Industry. In Green Chemistry and Sustainable Technology; Li, Y., Chemat, F., Eds.; Green Chemistry and Sustainable Technology; Springer: Singapore, 2019; pp. 51-87. ISBN 978-981-13-3809-0.

22. Espino, M.; de los Ángeles Fernández, M.; Gomez, F.J.V.; Silva, M.F. Natural designer solvents for greening analytical chemistry. TrAC Trends Anal. Chem. 2016, 76, 126-136. [CrossRef] 
23. Tomé, L.I.N.; Baião, V.; da Silva, W.; Brett, C.M.A. Deep eutectic solvents for the production and application of new materials. Appl. Mater. Today 2018, 10, 30-50. [CrossRef]

24. Li, X.; Row, K.H. Development of deep eutectic solvents applied in extraction and separation. J. Sep. Sci. 2016, 39, 3505-3520. [CrossRef]

25. Ruesgas-Ramón, M.; Figueroa-Espinoza, M.C.; Durand, E. Application of Deep Eutectic Solvents (DES) for Phenolic Compounds Extraction: Overview, Challenges and Opportunities. J. Agric. Food Chem. 2017, 65, 3591-3601. [CrossRef] [PubMed]

26. Rodríguez-Llorente, D.; Bengoa, A.; Pascual-Muñoz, G.; Navarro, P.; Águeda, V.I.; Delgado, J.A.; Álvarez-Torrellas, S.; García, J.; Larriba, M. Sustainable Recovery of Volatile Fatty Acids from Aqueous Solutions Using Terpenoids and Eutectic Solvents. ACS Sustain. Chem. Eng. 2019, 7, 16786-16794. [CrossRef]

27. Rodríguez-Llorente, D.; Cañada-Barcala, A.; Muñoz, C.; Pascual-Muñoz, G.; Navarro, P.; Santiago, R.; Ismael Águeda, V.; Álvarez-Torrellas, S.; García, J.; Larriba, M. Separation of phenols from aqueous streams using terpenoids and hydrophobic eutectic solvents. Sep. Purif. Technol. 2020, 251, 117379. [CrossRef]

28. Cunha, S.C.; Fernandes, J.O. Extraction techniques with deep eutectic solvents. TrAC Trends Anal. Chem. 2018, 105, 225-239. [CrossRef]

29. Lee, J.; Jung, D.; Park, K. Hydrophobic deep eutectic solvents for the extraction of organic and inorganic analytes from aqueous environments. TrAC Trends Anal. Chem. 2019, 118, 853-868. [CrossRef]

30. Makoś, P.; Słupek, E.; Gębicki, J. Hydrophobic deep eutectic solvents in microextraction techniques-A review. Microchem. J. 2020, 152, 104384. [CrossRef]

31. Abbott, A.P.; Cullis, P.M.; Gibson, M.J.; Harris, R.C.; Raven, E. Extraction of glycerol from biodiesel into a eutectic based ionic liquid. Green Chem. 2007, 9, 868-872. [CrossRef]

32. Shahbaz, K.; Mjalli, F.S.; Hashim, M.A.; ALNashef, I.M. Using Deep Eutectic Solvents for the Removal of Glycerol from Palm Oil-Based Biodiesel. J. Appl. Sci. 2010, 10, 3349-3354. [CrossRef]

33. Hayyan, M.; Mjalli, F.S.; Hashim, M.A.; AlNashef, I.M. A novel technique for separating glycerine from palm oil-based biodiesel using ionic liquids. Fuel Process. Technol. 2010, 91, 116-120. [CrossRef]

34. Shahbaz, K.; Mjalli, F.S.; Hashim, M.A.; AlNashef, I.M. Using Deep Eutectic Solvents Based on Methyl Triphenyl Phosphunium Bromide for the Removal of Glycerol from Palm-Oil-Based Biodiesel. Energy Fuels 2011, 25, 2671-2678. [CrossRef]

35. Ho, K.C.; Shahbaz, K.; Rashmi, W.; Mjalli, F.S.; Hashim, M.A.; Alnashef, I.M. Removal of glycerol from palm oil-based biodiesel using new ionic liquids analogues. J. Eng. Sci. Technol. 2015, 10, 98-111.

36. Shahbaz, K.; Mjalli, F.S.; Hashim, M.A.; AlNashef, I.M. Eutectic solvents for the removal of residual palm oil-based biodiesel catalyst. Sep. Purif. Technol. 2011, 81, 216-222. [CrossRef]

37. Israyandi, Z.; Mulia, K. Optimization process condition for deacidification of palm oil by liquid-liquid extraction using NADES (Natural Deep Eutectic Solvent). AIP Conf. Proc. 2017, 1823, 020107.

38. Zahrina, I.; Nasikin, M.; Krisanti, E.; Mulia, K. Deacidification of palm oil using betaine monohydrate-based natural deep eutectic solvents. Food Chem. 2018, 240, 490-495. [CrossRef] [PubMed]

39. Mulia, K.; Nasikin, M.; Krisanti, E.A.; Zahrina, I. Deacidification of Palm Oil Using Betaine Monohydrate-Carboxylic Acid Deep Eutectic Solvents: Combined Extraction and Simple Solvent Recovery. Processes 2020, 8, 543. [CrossRef]

40. Abdul Hadi, N.; Ng, M.H.; Choo, Y.M.; Hashim, M.A.; Jayakumar, N.S. Performance of Choline-Based Deep Eutectic Solvents in the Extraction of Tocols from Crude Palm Oil. J. Am. Oil Chem. Soc. 2015, 92, 1709-1716. [CrossRef]

41. Gu, T.; Zhang, M.; Tan, T.; Chen, J.; Li, Z.; Zhang, Q.; Qiu, H. Deep eutectic solvents as novel extraction media for phenolic compounds from model oil. Chem. Commun. 2014, 50, 11749-11752. [CrossRef]

42. Paradiso, V.M.; Clemente, A.; Summo, C.; Pasqualone, A.; Caponio, F. Towards green analysis of virgin olive oil phenolic compounds: Extraction by a natural deep eutectic solvent and direct spectrophotometric detection. Food Chem. 2016, 212, 43-47. [CrossRef] [PubMed]

43. Paradiso, V.M.; Squeo, G.; Pasqualone, A.; Caponio, F.; Summo, C. An easy and green tool for olive oils labelling according to the contents of hydroxytyrosol and tyrosol derivatives: Extraction with a natural deep eutectic solvent and direct spectrophotometric analysis. Food Chem. 2019, 291, 1-6. [CrossRef] 
44. Zullaikah, S.; Wibowo, N.D.; Wahyudi, I.M.G.E.D.; Rachimoellah, M. Deacidification of Crude Rice Bran Oil (CRBO) to Remove FFA and Preserve $\gamma$-Oryzanol Using Deep Eutectic Solvents (DES). Mater. Sci. Forum. 2019, 964, 109-114. [CrossRef]

45. Ozturk, B.; Esteban, J.; Gonzalez-Miquel, M. Deterpenation of Citrus Essential Oils Using Glycerol-Based Deep Eutectic Solvents. J. Chem. Eng. Data 2018, 63, 2384-2393. [CrossRef]

46. Ozturk, B.; Gonzalez-Miquel, M. Alkanediol-based deep eutectic solvents for isolation of terpenoids from citrus essential oil: Experimental evaluation and COSMO-RS studies. Sep. Purif. Technol. 2019, 227, 115707. [CrossRef]

47. Pan, Y.; Alam, M.A.; Wang, Z.; Huang, D.; Hu, K.; Chen, H.; Yuan, Z. One-step production of biodiesel from wet and unbroken microalgae biomass using deep eutectic solvent. Bioresour. Technol. 2017, 238, 157-163. [CrossRef]

48. Sander, A.; Antonije Košćak, M.; Kosir, D.; Milosavljević, N.; Parlov Vuković, J.; Magić, L. The influence of animal fat type and purification conditions on biodiesel quality. Renew. Energy 2018, 118, 752-760. [CrossRef]

49. Sander, A.; Petračić, A.; Parlov Vuković, J.; Husinec, L. From Coffee to Biodiesel-Deep Eutectic Solvents for Feedstock and Biodiesel Purification. Separations 2020, 7, 22. [CrossRef]

50. Kareem, M.A.; Mjalli, F.S.; Hashim, M.A.; AlNashef, I.M. Liquid-liquid equilibria for the ternary system (phosphonium based deep eutectic solvent-benzene-hexane) at different temperatures: A new solvent introduced. Fluid Phase Equilib. 2012, 314, 52-59. [CrossRef]

51. Kareem, M.A.; Mjalli, F.S.; Hashim, M.A.; Hadj-Kali, M.K.O.; Bagh, F.S.G.; Alnashef, I.M. Phase equilibria of toluene/heptane with tetrabutylphosphonium bromide based deep eutectic solvents for the potential use in the separation of aromatics from naphtha. Fluid Phase Equilib. 2012, 333, 47-54. [CrossRef]

52. Kareem, M.A.; Mjalli, F.S.; Hashim, M.A.; Hadj-Kali, M.K.O.; Ghareh Bagh, F.S.; Alnashef, I.M. Phase equilibria of toluene/heptane with deep eutectic solvents based on ethyltriphenylphosphonium iodide for the potential use in the separation of aromatics from naphtha. J. Chem. Thermodyn. 2013, 65, 138-149. [CrossRef]

53. Gonzalez, A.S.B.; Francisco, M.; Jimeno, G.; de Dios, S.L.G.; Kroon, M.C. Liquid-liquid equilibrium data for the systems $\{$ LTTM + benzene + hexane $\}$ and $\{$ LTTM+ethyl acetate+hexane $\}$ at different temperatures and atmospheric pressure. Fluid Phase Equilib. 2013, 360, 54-62. [CrossRef]

54. Mulyono, S.; Hizaddin, H.F.; Alnashef, I.M.; Hashim, M.A.; Fakeeha, A.H.; Hadj-Kali, M.K. Separation of BTEX aromatics from n-octane using a (tetrabutylammonium bromide + sulfolane) deep eutectic solvent-experiments and COSMO-RS prediction. RSC Adv. 2014, 4, 17597-17606. [CrossRef]

55. Kurnia, K.A.; Athirah, N.A.; Candieiro, F.J.M.; Lal, B. Phase Behavior of Ternary Mixtures \{Aliphatic Hydrocarbon + Aromatic Hydrocarbon + Deep Eutectic Solvent\}: A Step Forward toward "Greener" Extraction Process. Procedia Eng. 2016, 148, 1340-1345. [CrossRef]

56. Rodriguez, N.R.; Gerlach, T.; Scheepers, D.; Kroon, M.C.; Smirnova, I. Experimental determination of the LLE data of systems consisting of \{hexane + benzene + deep eutectic solvent\} and prediction using the Conductor-like Screening Model for Real Solvents. J. Chem. Thermodyn. 2017, 104, 128-137. [CrossRef]

57. Salleh, Z.; Wazeer, I.; Mulyono, S.; El-blidi, L.; Hashim, M.A.; Hadj-Kali, M.K. Efficient removal of benzene from cyclohexane-benzene mixtures using deep eutectic solvents-COSMO-RS screening and experimental validation. J. Chem. Thermodyn. 2017, 104, 33-44. [CrossRef]

58. Feng, S.; Sun, J.; Ren, Z.; Zhou, Z.; Zhang, F.; Liu, W. Effective separation of aromatic hydrocarbons by pyridine-based deep eutectic solvents. Can. J. Chem. Eng. 2019, 97, 3138-3147. [CrossRef]

59. Shekaari, H.; Zafarani-Moattar, M.T.; Mohammadi, B. Liquid-Liquid Equilibria for Benzene/Thiophene + Cyclohexane/Hexadecane + Deep Eutectic Solvents: Data and Correlation. J. Chem. Eng. Data 2019, 64, 3904-3918. [CrossRef]

60. Gouveia, A.S.L.; Oliveira, F.S.; Kurnia, K.A.; Marrucho, I.M. Deep Eutectic Solvents as Azeotrope Breakers: Liquid-Liquid Extraction and COSMO-RS Prediction. ACS Sustain. Chem. Eng. 2016, 4, 5640-5650. [CrossRef]

61. Naik, P.K.; Dehury, P.; Paul, S.; Banerjee, T. Evaluation of Deep Eutectic Solvent for the selective extraction of toluene and quinoline at $\mathrm{T}=308.15 \mathrm{~K}$ and $\mathrm{p}=1$ bar. Fluid Phase Equilib. 2016, 423, 146-155. [CrossRef]

62. Samarov, A.A.; Smirnov, M.A.; Sokolova, M.P.; Toikka, A.M. Liquid-liquid Equilibrium Data for the System N-Octane + Toluene + DES at 293.15 and 313.15 K and Atmospheric Pressure. Theor. Found. Chem. Eng. 2018, 52, 258-263. [CrossRef] 
63. Hosseini, A.; Haghbakhsh, R.; Raeissi, S. Experimental Investigation of Liquid-Liquid Extraction of Toluene + Heptane or Toluene + Hexane Using Deep Eutectic Solvents. J. Chem. Eng. Data 2019, 64, 3811-3820. [CrossRef]

64. Hizaddin, H.F.; Sarwono, M.; Hashim, M.A.; Alnashef, I.M.; Hadj-Kali, M.K. Coupling the capabilities of different complexing agents into deep eutectic solvents to enhance the separation of aromatics from aliphatics. J. Chem. Thermodyn. 2015, 84, 67-75. [CrossRef]

65. Mulyono, S.; Hizaddin, H.F.; Wazeer, I.; Alqusair, O.; Ali, E.; Ali Hashim, M.; Hadj-Kali, M.K. Liquid-liquid equilibria data for the separation of ethylbenzene/styrene mixtures using ammonium-based deep eutectic solvents. J. Chem. Thermodyn. 2019, 135, 296-304. [CrossRef]

66. Larriba, M.; Ayuso, M.; Navarro, P.; Delgado-Mellado, N.; Gonzalez-Miquel, M.; García, J.; Rodríguez, F. Choline Chloride-Based Deep Eutectic Solvents in the Dearomatization of Gasolines. ACS Sustain. Chem. Eng. 2018, 6, 1039-1047. [CrossRef]

67. Hadj-Kali, M.K.; Salleh, Z.; Ali, E.; Khan, R.; Hashim, M.A. Separation of aromatic and aliphatic hydrocarbons using deep eutectic solvents: A critical review. Fluid Phase Equilib. 2017, 448, 152-167. [CrossRef]

68. Zhu, W.; Wang, C.; Li, H.; Wu, P.; Xun, S.; Jiang, W.; Chen, Z.; Zhao, Z.; Li, H. One-pot extraction combined with metal-free photochemical aerobic oxidative desulfurization in deep eutectic solvent. Green Chem. 2015, 17, 2464-2472. [CrossRef]

69. Khezeli, T.; Daneshfar, A. Synthesis and application of magnetic deep eutectic solvents: Novel solvents for ultrasound assisted liquid-liquid microextraction of thiophene. Ultrason. Sonochem. 2017, 38, 590-597. [CrossRef]

70. Warrag, S.E.E.; Rodriguez, N.R.; Nashef, I.M.; van Sint Annaland, M.; Siepmann, J.I.; Kroon, M.C.; Peters, C.J. Separation of Thiophene from Aliphatic Hydrocarbons Using Tetrahexylammonium-Based Deep Eutectic Solvents as Extracting Agents. J. Chem. Eng. Data 2017, 62, 2911-2919. [CrossRef]

71. Warrag, S.E.E.; Adeyemi, I.; Rodriguez, N.R.; Nashef, I.M.; van Sint Annaland, M.; Kroon, M.C.; Peters, C.J. Effect of the Type of Ammonium Salt on the Extractive Desulfurization of Fuels Using Deep Eutectic Solvents. J. Chem. Eng. Data 2018, 63, 1088-1095. [CrossRef]

72. Warrag, S.E.E.; Pototzki, C.; Rodriguez, N.R.; van Sint Annaland, M.; Kroon, M.C.; Held, C.; Sadowski, G.; Peters, C.J. Oil desulfurization using deep eutectic solvents as sustainable and economical extractants via liquid-liquid extraction: Experimental and PC-SAFT predictions. Fluid Phase Equilib. 2018, 467, $33-44$. [CrossRef]

73. Zhao, H.; Baker, G.A.; Wagle, D.V.; Ravula, S.; Zhang, Q. Tuning Task-Specific Ionic Liquids for the Extractive Desulfurization of Liquid Fuel. ACS Sustain. Chem. Eng. 2016, 4, 4771-4780. [CrossRef]

74. Abbott, A.P.; Al-Murshedi, A.Y.M.; Alshammari, O.A.O.; Harris, R.C.; Kareem, J.H.; Qader, I.B.; Ryder, K. Thermodynamics of phase transfer for polar molecules from alkanes to deep eutectic solvents. Fluid Phase Equilib. 2017, 448, 99-104. [CrossRef]

75. Gano, Z.S.; Mjalli, F.S.; Al-Wahaibi, T.; Al-Wahaibi, Y.; AlNashef, I.M. Desulfurization of liquid fuel via extraction with imidazole-containing deep eutectic solvent. Green Process. Synth. 2017, 6, 511-521. [CrossRef]

76. Alli, R.D.; Kroon, M.C. Extraction of benzothiazole and thiophene from their mixtures with n-heptane using tetrahexylammonium bromide-based deep eutectic solvents as extractive denitrogenation and desulfurization agents. Fluid Phase Equilib. 2018, 477, 1-11. [CrossRef]

77. Mjalli, F.S.; Ahmed Rahma, W.S.; Al-Wahaibi, T.; Al-Hashmi, A.A. Superior liquid fuel desulfurization through emulsification solvent extraction using polymeric-based eutectic solvents. Chin. J. Chem. Eng. 2019. [CrossRef]

78. Al Ani, Z.; Al Wahaibi, T.; Mjalli, F.S.; Al Hashmi, A.; Abu-Jdayil, B. Flow of deep eutectic solvent-simulated fuel in circular channels: Part II-Extraction of dibenzothiophene. Chem. Eng. Res. Des. 2017, 119, 294-300. [CrossRef]

79. Cheng, H.; Liu, C.; Zhang, J.; Chen, L.; Zhang, B.; Qi, Z. Screening deep eutectic solvents for extractive desulfurization of fuel based on COSMO-RS model. Chem. Eng. Process. Process Intensif. 2018, 125, $246-252$. [CrossRef]

80. Wagle, D.V.; Zhao, H.; Deakyne, C.A.; Baker, G.A. Quantum Chemical Evaluation of Deep Eutectic Solvents for the Extractive Desulfurization of Fuel. ACS Sustain. Chem. Eng. 2018, 6, 7525-7531. [CrossRef] 
81. Alli, R.D.; AlNashef, I.M.; Kroon, M.C. Removal of 2-and 3-methylthiophene from their mixtures with n-heptane using tetrahexylammonium bromide-based deep eutectic solvents as extractive desulfurization agents. J. Chem. Thermodyn. 2018, 125, 172-179. [CrossRef]

82. Sander, A.; Rogošić, M.; Slivar, A.; Žuteg, B. Separation of Hydrocarbons by Means of Liquid-liquid Extraction with Deep Eutectic Solvents. Solvent Extr. Ion Exch. 2016, 34, 86-98. [CrossRef]

83. Warrag, S.E.E.; Alli, R.D.; Kroon, M.C. Liquid-Liquid Equilibrium Measurements for the Extraction of Pyridine and Benzothiazole from n-Alkanes Using Deep Eutectic Solvents. J. Chem. Eng. Data 2019, 64, 4882-4890. [CrossRef]

84. Warrag, S.E.E.; Darwish, A.S.; Adeyemi, I.A.; Hadj-Kali, M.K.; Kroon, M.C.; AlNashef, I.M. Extraction of pyridine from n-alkane mixtures using methyltriphenylphosphonium bromide-based deep eutectic solvents as extractive denitrogenation agents. Fluid Phase Equilib. 2020, 517, 112622. [CrossRef]

85. Wu, Z.; Zeng, Q.; Cheng, H.; Chen, L.; Qi, Z. Extractive separation of tetralin-dodecane mixture using tetrabutylphosphonium bromide-based deep eutectic solvent. Chem. Eng. Process.-Process Intensif. 2020, 149, 107822. [CrossRef]

86. Naik, P.K.; Paul, S.; Banerjee, T. Liquid Liquid Equilibria measurements for the extraction of poly aromatic nitrogen hydrocarbons with a low cost Deep Eutectic Solvent: Experimental and theoretical insights. J. Mol. Liq. 2017, 243, 542-552. [CrossRef]

87. Naik, P.K.; Mohan, M.; Banerjee, T.; Paul, S.; Goud, V.V. Molecular Dynamic Simulations for the Extraction of Quinoline from Heptane in the Presence of a Low-Cost Phosphonium-Based Deep Eutectic Solvent. J. Phys. Chem. B 2018, 122, 4006-4015. [CrossRef] [PubMed]

88. Oliveira, F.S.; Pereiro, A.B.; Rebelo, L.P.N.; Marrucho, I.M. Deep eutectic solvents as extraction media for azeotropic mixtures. Green Chem. 2013, 15, 1326-1330. [CrossRef]

89. Rodriguez, N.R.; Molina, B.S.; Kroon, M.C. Aliphatic+ethanol separation via liquid-liquid extraction using low transition temperature mixtures as extracting agents. Fluid Phase Equilib. 2015, 394, 71-82. [CrossRef]

90. Vuksanović, J.; Todorović, N.M.; Kijevčanin, M.L.; Šerbanović, S.P.; Radović, I.R. Experimental investigation and modeling of thermophysical and extraction properties of choline chloride + DL-malic acid based deep eutectic solvent. J. Serb. Chem. Soc. 2017, 82, 1287-1302. [CrossRef]

91. Wazeer, I.; Hizaddin, H.F.; El Blidi, L.; Ali, E.; Hashim, M.A.; Hadj-Kali, M.K. Liquid-Liquid Equilibria for Binary Azeotrope Mixtures of Benzene and Alcohols Using Choline Chloride-Based Deep Eutectic Solvents. J. Chem. Eng. Data 2018, 63, 613-624. [CrossRef]

92. Rodriguez, N.R.; Ferre Guell, J.; Kroon, M.C. Glycerol-Based Deep Eutectic Solvents as Extractants for the Separation of MEK and Ethanol via Liquid-Liquid Extraction. J. Chem. Eng. Data 2016, 61, 865-872. [CrossRef]

93. Hadj-Kali, M.K.; Hizaddin, H.F.; Wazeer, I.; El blidi, L.; Mulyono, S.; Hashim, M.A. Liquid-liquid separation of azeotropic mixtures of ethanol/alkanes using deep eutectic solvents: COSMO-RS prediction and experimental validation. Fluid Phase Equilib. 2017, 448, 105-115. [CrossRef]

94. Samarov, A.A.; Smirnov, M.A.; Sokolova, M.P.; Popova, E.N.; Toikka, A.M. Choline chloride based deep eutectic solvents as extraction media for separation of n-hexane-ethanol mixture. Fluid Phase Equilib. 2017, 448, 123-127. [CrossRef]

95. Vuksanović, J.; Kijevčanin, M.L.; Radović, I.R. Effect of water addition on extraction ability of eutectic solvent choline chloride+ 1,2-propanediol for separation of hexane/heptane+ethanol systems. Korean J. Chem. Eng. 2018, 35, 1477-1487. [CrossRef]

96. Liu, X.; Xu, D.; Diao, B.; Zhang, L.; Gao, J.; Liu, D.; Wang, Y. Choline chloride based deep eutectic solvents selection and liquid-liquid equilibrium for separation of dimethyl carbonate and ethanol. J. Mol. Liq. 2019, 275, 347-353. [CrossRef]

97. Samarov, A.A.; Smirnov, M.A.; Toikka, A.M.; Prikhodko, I.V. Study of Deep Eutectic Solvent on the Base Choline Chloride as Entrainer for the Separation Alcohol-Ester Systems. J. Chem. Eng. Data 2018, 63, 1877-1884. [CrossRef]

98. Samarov, A.; Prikhodko, I.; Shner, N.; Sadowski, G.; Held, C.; Toikka, A. Liquid-Liquid Equilibria for Separation of Alcohols from Esters Using Deep Eutectic Solvents Based on Choline Chloride: Experimental Study and Thermodynamic Modeling. J. Chem. Eng. Data 2019, 64, 6049-6059. [CrossRef] 
99. Pang, K.; Hou, Y.; Wu, W.; Guo, W.; Peng, W.; Marsh, K.N. Efficient separation of phenols from oils via forming deep eutectic solvents. Green Chem. 2012, 14, 2398-2401. [CrossRef]

100. Jiao, T.; Li, C.; Zhuang, X.; Cao, S.; Chen, H.; Zhang, S. The new liquid-liquid extraction method for separation of phenolic compounds from coal tar. Chem. Eng. J. 2015, 266, 148-155. [CrossRef]

101. Jiao, T.; Wang, H.; Dai, F.; Li, C.; Zhang, S. Thermodynamics Study on the Separation Process of Cresols from Hexane via Deep Eutectic Solvent Formation. Ind. Eng. Chem. Res. 2016, 55, 8848-8857. [CrossRef]

102. Lin, Z.; Hou, Y.; Ren, S.; Ji, Y.; Yao, C.; Niu, M.; Wu, W. Phase equilibria of phenol + toluene + quaternary ammonium salts for the separation of phenols from oil with forming deep eutectic solvents. Fluid Phase Equilib. 2016, 429, 67-75. [CrossRef]

103. Bezold, F.; Weinberger, M.E.; Minceva, M. Computational solvent system screening for the separation of tocopherols with centrifugal partition chromatography using deep eutectic solvent-based biphasic systems. J. Chromatogr. A 2017, 1491, 153-158. [CrossRef]

104. Bezold, F.; Minceva, M. A water-free solvent system containing an L-menthol-based deep eutectic solvent for centrifugal partition chromatography applications. J. Chromatogr. A 2019, 1587, 166-171. [CrossRef]

105. Li, G.; Zhu, T.; Row, K.H. Deep eutectic solvents for the purification of chloromycetin and thiamphenicol from milk. J. Sep. Sci. 2017, 40, 625-634. [CrossRef] [PubMed]

106. Manurung, R.; Hutauruk, G.R.; Arief, A. Vitamin E extraction from red palm biodiesel by using $\mathrm{K}_{2} \mathrm{CO}_{3}$ based deep eutectic solvent with glycerol as hydrogen bond donor. AIP Conf. Proc. 2018, 1977, 020011.

107. Li, G.; Row, K.H. Air Assisted Dispersive Liquid-Liquid Microextraction (AA-DLLME) Using Hydrophilic-Hydrophobic Deep Eutectic Solvents for the Isolation of Monosaccharides and Amino Acids from Kelp. Anal. Lett. 2020, 53, 188-202. [CrossRef]

108. Freire, M.G.; Cláudio, A.F.M.; Araújo, J.M.M.; Coutinho, J.A.P.; Marrucho, I.M.; Lopes, J.N.C.; Rebelo, L.P.N. Aqueous biphasic systems: A boost brought about by using ionic liquids. Chem. Soc. Rev. 2012, 41, 4966-4995. [CrossRef]

109. Zeng, Q.; Wang, Y.; Huang, Y.; Ding, X.; Chen, J.; Xu, K. Deep eutectic solvents as novel extraction media for protein partitioning. Analyst 2014, 139, 2565-2573. [CrossRef] [PubMed]

110. Xu, K.; Wang, Y.; Huang, Y.; Li, N.; Wen, Q. A green deep eutectic solvent-based aqueous two-phase system for protein extracting. Anal. Chim. Acta 2015, 864, 9-20. [CrossRef] [PubMed]

111. Li, N.; Wang, Y.; Xu, K.; Huang, Y.; Wen, Q.; Ding, X. Development of green betaine-based deep eutectic solvent aqueous two-phase system for the extraction of protein. Talanta 2016, 152, 23-32. [CrossRef] [PubMed]

112. Passos, H.; Tavares, D.J.P.; Ferreira, A.M.; Freire, M.G.; Coutinho, J.A.P. Are Aqueous Biphasic Systems Composed of Deep Eutectic Solvents Ternary or Quaternary Systems? ACS Sustain. Chem. Eng. 2016, 4, 2881-2886. [CrossRef]

113. Zhang, H.; Wang, Y.; Xu, K.; Li, N.; Wen, Q.; Yang, Q.; Zhou, Y. Ternary and binary deep eutectic solvents as a novel extraction medium for protein partitioning. Anal. Methods 2016, 8, 8196-8207. [CrossRef]

114. Deng, W.-W.; Zong, Y.; Xiao, Y.-X. Hexafluoroisopropanol-Based Deep Eutectic Solvent/Salt Aqueous Two-Phase Systems for Extraction of Anthraquinones from Rhei Radix et Rhizoma Samples. ACS Sustain. Chem. Eng. 2017, 5, 4267-4275. [CrossRef]

115. Farias, F.O.; Sosa, F.H.B.; Igarashi-Mafra, L.; Coutinho, J.A.P.; Mafra, M.R. Study of the pseudo-ternary aqueous two-phase systems of deep eutectic solvent (choline chloride:sugars) $+\mathrm{K}_{2} \mathrm{HPO}_{4}+$ water. Fluid Phase Equilib. 2017, 448, 143-151. [CrossRef]

116. Farias, F.O.; Passos, H.; Lima, Á.S.; Mafra, M.R.; Coutinho, J.A.P. Is It Possible To Create Ternary-like Aqueous Biphasic Systems with Deep Eutectic Solvents? ACS Sustain. Chem. Eng. 2017, 5, 9402-9411. [CrossRef]

117. Pang, J.; Sha, X.; Chao, Y.; Chen, G.; Han, C.; Zhu, W.; Li, H.; Zhang, Q. Green aqueous biphasic systems containing deep eutectic solvents and sodium salts for the extraction of protein. RSC Adv. 2017, 7, 49361-49367. [CrossRef]

118. Zhang, H.; Wang, Y.; Zhou, Y.; Xu, K.; Li, N.; Wen, Q.; Yang, Q. Aqueous biphasic systems containing PEG-based deep eutectic solvents for high-performance partitioning of RNA. Talanta 2017, 170, 266-274. [CrossRef] [PubMed]

119. Farias, F.O.; Passos, H.; Sanglard, M.G.; Igarashi-Mafra, L.; Coutinho, J.A.P.; Mafra, M.R. Designer solvent ability of alcohols in aqueous biphasic systems composed of deep eutectic solvents and potassium phosphate. Sep. Purif. Technol. 2018, 200, 84-93. [CrossRef] 
120. Sun, D.; Wang, R.; Li, F.; Liu, L.; Tan, Z. Enantioselective Extraction of Phenylalanine Enantiomers Using Environmentally Friendly Aqueous Two-Phase Systems. Processes 2018, 6, 212. [CrossRef]

121. Xu, P.; Wang, Y.; Chen, J.; Wei, X.; Xu, W.; Ni, R.; Meng, J.; Zhou, Y. A novel aqueous biphasic system formed by deep eutectic solvent and ionic liquid for DNA partitioning. Talanta 2018, 189, 467-479. [CrossRef]

122. Zhang, H.; Wang, Y.; Zhou, Y.; Chen, J.; Wei, X.; Xu, P. Aqueous biphasic systems formed by deep eutectic solvent and new-type salts for the high-performance extraction of pigments. Talanta 2018, 181, 210-216. [CrossRef]

123. Farias, F.O.; Passos, H.; Coutinho, J.A.P.; Mafra, M.R. pH Effect on the Formation of Deep-EutecticSolvent-Based Aqueous Two-Phase Systems. Ind. Eng. Chem. Res. 2018, 57, 16917-16924. [CrossRef]

124. Meng, J.; Wang, Y.; Zhou, Y.; Chen, J.; Wei, X.; Ni, R.; Liu, Z.; Xu, F. Development of different deep eutectic solvent aqueous biphasic systems for the separation of proteins. RSC Adv. 2019, 9, 14116-14125. [CrossRef]

125. Rathnasamy, S.K.; Rajendran, D.S.; Balaraman, H.B.; Viswanathan, G. Functional deep eutectic solvent-based chaotic extraction of phycobiliprotein using microwave-assisted liquid-liquid micro-extraction from Spirulina (Arthrospira platensis) and its biological activity determination. Algal Res. 2019, 44, 101709. [CrossRef]

126. Xu, P.; Wang, Y.; Chen, J.; Wei, X.; Xu, W.; Ni, R.; Meng, J.; Zhou, Y. Development of deep eutectic solvent-based aqueous biphasic system for the extraction of lysozyme. Talanta 2019, 202, 1-10. [CrossRef] [PubMed]

127. Chao, Y.; Ding, H.; Peng, J.; Jin, Y.; Li, X.; Chang, H.; Jiang, W.; Chen, G.; Han, C.; Zhu, W. High Efficient Extraction of Tryptophan Using Deep Eutectic Solvent-based Aqueous Biphasic Systems. Indian J. Pharm. Sci. 2019, 81, 448-455. [CrossRef]

128. Fernández, A.; Deive, F.J.; Rodríguez, A.; Álvarez, M.S. Towards the use of eco-friendly solvents as adjuvants in remediation processes. J. Mol. Liq. 2020, 305, 112824. [CrossRef]

129. Xu, K.; Xu, P.; Wang, Y. Aqueous biphasic systems formed by hydrophilic and hydrophobic deep eutectic solvents for the partitioning of dyes. Talanta 2020, 213, 120839. [CrossRef] [PubMed]

130. van Osch, D.J.G.P.; Zubeir, L.F.; van den Bruinhorst, A.; Rocha, M.A.A.; Kroon, M.C. Hydrophobic deep eutectic solvents as water-immiscible extractants. Green Chem. 2015, 17, 4518-4521. [CrossRef]

131. van den Bruinhorst, A.; Raes, S.; Maesara, S.A.; Kroon, M.C.; Esteves, A.C.C.; Meuldijk, J. Hydrophobic eutectic mixtures as volatile fatty acid extractants. Sep. Purif. Technol. 2019, 216, 147-157. [CrossRef]

132. Riveiro, E.; González, B.; Domínguez, Á. Extraction of adipic, levulinic and succinic acids from water using TOPO-based deep eutectic solvents. Sep. Purif. Technol. 2020, 241, 116692. [CrossRef]

133. Florindo, C.; Branco, L.C.C.; Marrucho, I.M.M. Development of hydrophobic deep eutectic solvents for extraction of pesticides from aqueous environments. Fluid Phase Equilib. 2017, 448, 135-142. [CrossRef]

134. Mat Hussin, S.A.; Varanusupakul, P.; Shahabuddin, S.; Yih Hui, B.; Mohamad, S. Synthesis and characterization of green menthol-based low transition temperature mixture with tunable thermophysical properties as hydrophobic low viscosity solvent. J. Mol. Liq. 2020, 308, 113015. [CrossRef]

135. Florindo, C.; Romero, L.; Rintoul, I.; Branco, L.C.; Marrucho, I.M. From Phase Change Materials to Green Solvents: Hydrophobic Low Viscous Fatty Acid-Based Deep Eutectic Solvents. ACS Sustain. Chem. Eng. 2018, 6, 3888-3895. [CrossRef]

136. Tang, W.; Dai, Y.; Row, K.H. Evaluation of fatty acid/alcohol-based hydrophobic deep eutectic solvents as media for extracting antibiotics from environmental water. Anal. Bioanal. Chem. 2018, 410, 7325-7336. [CrossRef] [PubMed]

137. Verma, R.; Banerjee, T. Liquid-Liquid Extraction of Lower Alcohols Using Menthol-Based Hydrophobic Deep Eutectic Solvent: Experiments and COSMO-SAC Predictions. Ind. Eng. Chem. Res. 2018, 57, 3371-3381. [CrossRef]

138. Verma, R.; Mohan, M.; Goud, V.V.; Banerjee, T. Operational Strategies and Comprehensive Evaluation of Menthol Based Deep Eutectic Solvent for the Extraction of Lower Alcohols from Aqueous Media. ACS Sustain. Chem. Eng. 2018, 6, 16920-16932. [CrossRef]

139. Buldo, M.; Cicci, A.; Sed, G.; Sapone, V.; Bravi, M. Detoxification of Olive Mill Wastewaters by Liquid-liquid Extraction with Natural Deep Eutectic Solvents. Chem. Eng. Trans. 2019, 74, 1495-1500.

140. Deng, W.; Yu, L.; Li, X.; Chen, J.; Wang, X.; Deng, Z.; Xiao, Y. Hexafluoroisopropanol-based hydrophobic deep eutectic solvents for dispersive liquid-liquid microextraction of pyrethroids in tea beverages and fruit juices. Food Chem. 2019, 274, 891-899. [CrossRef] [PubMed] 
141. Sas, O.G.; Castro, M.; Domínguez, Á.; González, B. Removing phenolic pollutants using Deep Eutectic Solvents. Sep. Purif. Technol. 2019, 227, 115703. [CrossRef]

142. Yang, D.; Wang, Y.; Peng, J.; Xun, C.; Yang, Y. A green deep eutectic solvents microextraction coupled with acid-base induction for extraction of trace phenolic compounds in large volume water samples. Ecotoxicol. Environ. Saf. 2019, 178, 130-136. [CrossRef]

143. Florindo, C.; Monteiro, N.V.; Ribeiro, B.D.; Branco, L.C.C.; Marrucho, I.M.M. Hydrophobic deep eutectic solvents for purification of water contaminated with Bisphenol-A. J. Mol. Liq. 2020, 297, 111841. [CrossRef]

144. Pekel, A.G.; Kurtulbaş, E.; Toprakçı, İ; Şahin, S. Menthol-based deep eutectic solvent for the separation of carbamazepine: Reactive liquid-liquid extraction. Biomass Convers. Biorefinery 2020. [CrossRef]

145. Yang, D.; Wang, Y.; Li, H.; Yang, Y. Acid-base-governed deep eutectic solvent-based microextraction combined with magnetic solid-phase extraction for determination of phenolic compounds. Microchim. Acta 2020, 187, 124. [CrossRef]

146. van Osch, D.J.G.P.; Parmentier, D.; Dietz, C.H.J.T.; van den Bruinhorst, A.; Tuinier, R.; Kroon, M.C. Removal of alkali and transition metal ions from water with hydrophobic deep eutectic solvents. Chem. Commun. 2016, 52, 11987-11990. [CrossRef] [PubMed]

147. Schaeffer, N.; Martins, M.; Neves, C.; Pinho, S.P.; Coutinho, J. Sustainable hydrophobic terpene-based eutectic solvents for the extraction and separation of metals. Chem. Commun. 2018, 54, 8104-8107. [CrossRef] [PubMed]

148. Gilmore, M.; McCourt, É.N.; Connolly, F.; Nockemann, P.; Swadźba-Kwaśny, M.; Holbrey, J.D. Hydrophobic Deep Eutectic Solvents Incorporating Trioctylphosphine Oxide: Advanced Liquid Extractants. ACS Sustain. Chem. Eng. 2018, 6, 17323-17332. [CrossRef]

149. Schaeffer, N.; Conceica\&cedil, J.H.; Martins, M.A.; Neves, M.C.; Pérez-Sánchez, G.; Gomes, J.R.B.; Papaiconomou, N.; Coutinho, J.A. Non-ionic hydrophobic eutectics-Versatile solvents for tailored metal separation and valorisation. Green Chem. 2020, 22, 2810-2820. [CrossRef]

150. Łukomska, A.; Wiśniewska, A.; Dabrowski, Z.; Domańska, U. Liquid-liquid extraction of cobalt(II) and zinc(II) from aqueous solutions using novel ionic liquids as an extractants. J. Mol. Liq. 2020, 307, 112955. [CrossRef]

151. Song, Y.; Wang, R.; Liu, R.; Du, Y.; Luo, F.; Yan, H.; Sun, L. Dehydration of 1-Butanol with a Deep Eutectic Solvent by Liquid-Liquid Extraction. Ind. Eng. Chem. Res. 2020, 59, 846-855. [CrossRef]

152. Babaee, S.; Daneshfar, A. Magnetic deep eutectic solvent-based ultrasound-assisted liquid-liquid microextraction for determination of hexanal and heptanal in edible oils followed by gas chromatography-Flame ionization detection. Anal. Methods 2018, 10, 4162-4169. [CrossRef]

153. Çabuk, H.; Yılmaz, Y.; Yıldız, E. A vortex-assisted deep eutectic solvent-based liquid-liquid microextraction for the analysis of alkyl gallates in vegetable oils. Acta Chim. Slov. 2019, 66, 385-394. [CrossRef]

154. Ferrone, V.; Genovese, S.; Carlucci, M.; Tiecco, M.; Germani, R.; Preziuso, F.; Epifano, F.; Carlucci, G.; Taddeo, V.A. A green deep eutectic solvent dispersive liquid-liquid micro-extraction (DES-DLLME) for the UHPLC-PDA determination of oxyprenylated phenylpropanoids in olive, soy, peanuts, corn and sunflower oil. Food Chem. 2018, 245, 578-585. [CrossRef]

155. Khezeli, T.; Daneshfar, A.; Sahraei, R. A green ultrasonic-assisted liquid-liquid microextraction based on deep eutectic solvent for the HPLC-UV determination of ferulic, caffeic and cinnamic acid from olive, almond, sesame and cinnamon oil. Talanta 2016, 150, 577-585. [CrossRef]

156. Liu, W.; Zhang, K.; Qin, Y.; Yu, J. A simple and green ultrasonic-assisted liquid-liquid microextraction technique based on deep eutectic solvents for the HPLC analysis of sesamol in sesame oils. Anal. Methods 2017, 9, 4184-4189. [CrossRef]

157. Liu, W.; Zhang, K.; Yu, J.; Bi, Y. A Green Ultrasonic-Assisted Liquid-liquid Microextraction Based on Deep Eutectic Solvent for the HPLC-UV Determination of TBHQ in Edible Oils. Food Anal. Methods 2017, 10, 3209-3215. [CrossRef]

158. Liu, W.; Zong, B.; Yu, J.; Bi, Y. Ultrasonic-Assisted Liquid-liquid Microextraction Based on Natural Deep Eutectic Solvent for the HPLC-UV Determination of Tert-Butylhydroquinone from Soybean Oils. Food Anal. Methods 2018, 11, 1797-1803. [CrossRef]

159. Liu, W.; Zhang, K.; Chen, J.; Yu, J. Ascorbic acid and choline chloride: A new natural deep eutectic solvent for extracting tert-butylhydroquinone antioxidant. J. Mol. Liq. 2018, 260, 173-179. [CrossRef] 
160. Ma, W.; Tang, W.; Row, K.H. Characterization of Deep Eutectic Solvents for Dispersive Liquid-Liquid Microextraction for Phenolics. Anal. Lett. 2017, 50, 2177-2188. [CrossRef]

161. Xie, Q.; Xia, M.; Lu, H.; Shi, H.; Sun, D.; Hou, B.; Jia, L.; Li, D. Deep eutectic solvent-based liquid-liquid microextraction for the HPLC-DAD analysis of bisphenol A in edible oils. J. Mol. Liq. 2020, 306, 112881. [CrossRef]

162. Mohebi, A.; Samadi, M.; Tavakoli, H.R.; Parastouei, K. Homogenous liquid-liquid extraction followed by dispersive liquid-liquid microextraction for the extraction of some antibiotics from milk samples before their determination by HPLC. Microchem. J. 2020, 157, 104988. [CrossRef]

163. Aydin, F.; Yilmaz, E.; Soylak, M. Vortex assisted deep eutectic solvent (DES)-emulsification liquid-liquid microextraction of trace curcumin in food and herbal tea samples. Food Chem. 2018, 243, 442-447. [CrossRef]

164. Altunay, N.; Unal, Y.; Elik, A. Towards green analysis of curcumin from tea, honey and spices: Extraction by deep eutectic solvent assisted emulsification liquid-liquid microextraction method based on response surface design. Food Addit. Contam. Part. A 2020, 37, 869-881. [CrossRef]

165. Bazmandegan-Shamili, A.; Dadfarnia, S.; Shabani, A.M.H.; Moghadam, M.R.; Saeidi, M. Temperature-controlled liquid-liquid microextraction combined with high-performance liquid chromatography for the simultaneous determination of diazinon and fenitrothion in water and fruit juice samples. J. Sep. Sci. 2018, 41, 2411-2418. [CrossRef]

166. Faraji, M. Novel hydrophobic deep eutectic solvent for vortex assisted dispersive liquid-liquid micro-extraction of two auxins in water and fruit juice samples and determination by high performance liquid chromatography. Microchem. J. 2019, 150, 104130. [CrossRef]

167. Farajzadeh, M.A.; Afshar Mogaddam, M.R.; Aghanassab, M. Deep eutectic solvent-based dispersive liquid-liquid microextraction. Anal. Methods 2016, 8, 2576-2583. [CrossRef]

168. Mogaddam, M.R.A.; Farajzadeh, M.A.; Mohebbi, A.; Nemati, M. Stir bar sorptive extraction combined with deep eutectic solvent-based dispersive liquid-liquid microextraction: Application in simultaneous derivatisation and extraction of acidic pesticides. Int. J. Environ. Anal. Chem. 2020, 1-13. [CrossRef]

169. Liu, X.; Chen, M.; Meng, Z.; Qian, H.; Zhang, S.; Lu, R.; Gao, H.; Zhou, W. Extraction of benzoylurea pesticides from tea and fruit juices using deep eutectic solvents. J. Chromatogr. B 2020, 1140, 121995. [CrossRef] [PubMed]

170. Li, H.; Zhao, C.; Tian, H.; Yang, Y.; Li, W. Liquid-Liquid Microextraction Based on Acid-Base-Induced Deep Eutectic Solvents for Determination of $\beta$-Carotene and Lycopene in Fruit Juices. Food Anal. Methods 2019, 12, 2777-2784. [CrossRef]

171. Santana-Mayor, Á.; Socas-Rodríguez, B.; Rodríguez-Ramos, R.; Rodríguez-Delgado, M.Á. A green and simple procedure based on deep eutectic solvents for the extraction of phthalates from beverages. Food Chem. 2020, 312, 125798. [CrossRef]

172. Shishov, A.; Volodina, N.; Nechaeva, D.; Gagarinova, S.; Bulatov, A. Deep eutectic solvents as a new kind of dispersive solvent for dispersive liquid-liquid microextraction. RSC Adv. 2018, 8, 38146-38149. [CrossRef]

173. Shishov, A.; Volodina, N.; Nechaeva, D.; Gagarinova, S.; Bulatov, A. An automated homogeneous liquid-liquid microextraction based on deep eutectic solvent for the HPLC-UV determination of caffeine in beverages. Microchem. J. 2019, 144, 469-473. [CrossRef]

174. Zhu, S.; Zhou, J.; Jia, H.; Zhang, H. Liquid-liquid microextraction of synthetic pigments in beverages using a hydrophobic deep eutectic solvent. Food Chem. 2018, 243, 351-356. [CrossRef]

175. Farajzadeh, M.A.; Mohebbi, A.; Tofigh Gharamaleki, V.; Abbaspour, M.; Sorouraddin, S.M. Low temperature-induced homogeneous liquid-liquid extraction and ternary deep eutectic solvent-based dispersive liquid-liquid microextraction followed by gas chromatography in the assessment of multiclass pesticide residues in cucumbers. New J. Chem. 2019, 43, 12453-12461. [CrossRef]

176. Farajzadeh, M.A.; Sohrabi, H.; Mohebbi, A.; Mogaddam, M.R.A. Combination of a modified quick, easy, cheap, efficient, rugged and safe extraction method with a deep eutectic solvent based microwave-assisted dispersive liquid-liquid microextraction: Application in extraction and preconcentration of multiclass pestic. J. Sep. Sci. 2019, 42, 1273-1280. [CrossRef] [PubMed]

177. Farajzadeh, M.A.; Abbaspour, M.; Kazemian, R. Synthesis of a green high density deep eutectic solvent and its application in microextraction of seven widely used pesticides from honey. J. Chromatogr. A 2019, 1603, 51-60. [CrossRef] [PubMed] 
178. Rastpour, N.; Khandaghi, J.; Farajzadeh, M.A.; Mogaddam, M.R.A. Deep eutectic solvent-based QuEChERS method combined with dispersive liquid-liquid microextraction for extraction of benzoylurea insecticides in cabbage leaves samples. Int. J. Environ. Anal. Chem. 2020, 1-14. [CrossRef]

179. Jouyban, A.; Farajzadeh, M.A.; Nemati, M.; Alizadeh Nabil, A.A.; Afshar Mogaddam, M.R. Preparation of ferrofluid from toner powder and deep eutectic solvent used in air-assisted liquid-liquid microextraction: Application in analysis of sixteen polycyclic aromatic hydrocarbons in urine and saliva samples of tobacco smokers. Microchem. J. 2020, 154, 104631. [CrossRef]

180. Saei, A.; Javadi, A.; Mogaddam, M.R.A.; Mirzaei, H.; Nemati, M. Determination of three antibiotic residues in hamburger and cow liver samples using deep eutectic solvents based pretreatment method coupled with ion mobility spectrometry. Int. J. Environ. Anal. Chem. 2020, 1-15. [CrossRef]

181. Li, K.; Jin, Y.; Jung, D.; Park, K.; Kim, H.; Lee, J. In situ formation of thymol-based hydrophobic deep eutectic solvents: Application to antibiotics analysis in surface water based on liquid-liquid microextraction followed by liquid chromatography. J. Chromatogr. A 2020, 1614, 460730. [CrossRef]

182. An, Y.; Ma, W.; Row, K.H. Preconcentration and Determination of Chlorophenols in Wastewater with Dispersive Liquid-Liquid Microextraction Using Hydrophobic Deep Eutectic Solvents. Anal. Lett. 2020, 53, 262-272. [CrossRef]

183. Chen, Y.-C.; Ao, Y.-T.; Ding, W.-H. Determination of microcystins in water samples by deep eutectic solvent-based vortex-assisted liquid-liquid microextraction coupled with ultrahigh-performance liquid chromatography-high resolution mass spectrometry. RSC Adv. 2019, 9, 38669-38676. [CrossRef]

184. Diuzheva, A.; Balogh, J.; Jekő, J.; Cziáky, Z. Application of liquid-liquid microextraction for the effective separation and simultaneous determination of 11 pharmaceuticals in wastewater samples using high-performance liquid chromatography with tandem mass spectrometry. J. Sep. Sci. 2018, 41, 2870-2877. [CrossRef]

185. Faraji, M.; Adeli, M.; Noormohammadi, F. Deep eutectic solvent-based dispersive liquid-liquid micro-extraction for extraction of malachite green and crystal violet in water samples prior their determination using high performance liquid chromatography. Int. J. Environ. Anal. Chem. 2020, 1-9. [CrossRef]

186. Li, Y.; Li, X.; Tang, S.; Yang, Y. Emulsification liquid-liquid micro-extraction based on natural deep eutectic solvent for (triarylmethane) dyes determination. Chem. Pap. 2020, 74, 3617-3626. [CrossRef]

187. Farajzadeh, M.A.; Afshar Mogaddam, M.R.; Feriduni, B. Simultaneous synthesis of a deep eutectic solvent and its application in liquid-liquid microextraction of polycyclic aromatic hydrocarbons from aqueous samples. RSC Adv. 2016, 6, 47990-47996. [CrossRef]

188. Makoś, P.; Przyjazny, A.; Boczkaj, G. Hydrophobic deep eutectic solvents as "green" extraction media for polycyclic aromatic hydrocarbons in aqueous samples. J. Chromatogr. A 2018, 1570, 28-37. [CrossRef] [PubMed]

189. Ge, D.; Zhang, Y.; Dai, Y.; Yang, S. Air-assisted dispersive liquid-liquid microextraction based on a new hydrophobic deep eutectic solvent for the preconcentration of benzophenone-type UV filters from aqueous samples. J. Sep. Sci. 2018, 41, 1635-1643. [CrossRef]

190. Wang, H.; Hu, L.; Liu, X.; Yin, S.; Lu, R.; Zhang, S.; Zhou, W.; Gao, H. Deep eutectic solvent-based ultrasound-assisted dispersive liquid-liquid microextraction coupled with high-performance liquid chromatography for the determination of ultraviolet filters in water samples. J. Chromatogr. A 2017, 1516, 1-8. [CrossRef] [PubMed]

191. Zhang, K.; Li, S.; Wang, Y.; Fan, J.; Zhu, G. Air-assisted liquid-liquid microextraction based on solidification of floating deep eutectic solvent for the analysis of ultraviolet filters in water samples by high performance liquid chromatography with the aid of response surface methodology. J. Chromatogr. A 2020, 1618, 460876. [CrossRef]

192. Ge, D.; Wang, Y.; Jiang, Q.; Dai, E. A Deep Eutectic Solvent as an Extraction Solvent to Separate and Preconcentrate Parabens in Water Samples Using in situ Liquid-liquid Microextraction. J. Braz. Chem. Soc. 2019, 30, 1203-1210. [CrossRef]

193. El-Deen, A.K.; Shimizu, K. Deep eutectic solvent as a novel disperser in dispersive liquid-liquid microextraction based on solidification of floating organic droplet (DLLME-SFOD) for preconcentration of steroids in water samples: Assessment of the method deleterious impact on the e. Microchem. J. 2019, 149, 103988. [CrossRef] 
194. Khezeli, T.; Daneshfar, A.; Sahraei, R. Emulsification liquid-liquid microextraction based on deep eutectic solvent: An extraction method for the determination of benzene, toluene, ethylbenzene and seven polycyclic aromatic hydrocarbons from water samples. J. Chromatogr. A 2015, 1425, 25-33. [CrossRef]

195. Yang, M.; Hong, K.; Li, X.; Ge, F.; Tang, Y. Freezing temperature controlled deep eutectic solvent dispersive liquid-liquid microextraction based on solidification of floating organic droplets for rapid determination of benzoylureas residual in water samples with assistance of metallic salt. RSC Adv. 2017, 7, 56528-56536. [CrossRef]

196. Zeng, H.; Qiao, K.; Li, X.; Yang, M.; Zhang, S.; Lu, R.; Li, J.; Gao, H.; Zhou, W. Dispersive liquid-liquid microextraction based on the solidification of deep eutectic solvent for the determination of benzoylureas in environmental water samples. J. Sep. Sci. 2017, 40, 4563-4570. [CrossRef] [PubMed]

197. Lamei, N.; Ezoddin, M.; Abdi, K. Air assisted emulsification liquid-liquid microextraction based on deep eutectic solvent for preconcentration of methadone in water and biological samples. Talanta 2017, 165, 176-181. [CrossRef] [PubMed]

198. Liu, L.; Zhu, T. Emulsification liquid-liquid microextraction based on deep eutectic solvents: An extraction method for the determination of sulfonamides in water samples. Anal. Methods 2017, 9, 4747-4753. [CrossRef]

199. Ma, Y.; Wang, Q.; Zhu, T. Comparison of hydrophilic and hydrophobic deep eutectic solvents for pretreatment determination of sulfonamides from aqueous environments. Anal. Methods 2019, 11, 5901-5909. [CrossRef]

200. Qu, Q.; Lv, Y.; Liu, L.; Row, K.H.; Zhu, T. Synthesis and characterization of deep eutectic solvents (five hydrophilic and three hydrophobic) and hydrophobic application for microextraction of environmental water samples. Anal. Bioanal. Chem. 2019, 411, 7489-7498. [CrossRef]

201. Gabbana, J.V.; de Oliveira, L.H.; Paveglio, G.C.; Trindade, M.A.G. Narrowing the interface between sample preparation and electrochemistry: Trace-level determination of emerging pollutant in water samples after in situ microextraction and electroanalysis using a new cell configuration. Electrochim. Acta 2018, 275, 67-75. [CrossRef]

202. Liu, Y.; Xu, W.; Zhang, H.; Xu, W. Hydrophobic deep eutectic solvent-based dispersive liquid-liquid microextraction for the simultaneous enantiomeric analysis of five $\beta$-agonists in the environmental samples. Electrophoresis 2019, 40, 2828-2836. [CrossRef]

203. Makoś, P.; Fernandes, A.; Przyjazny, A.; Boczkaj, G. Sample preparation procedure using extraction and derivatization of carboxylic acids from aqueous samples by means of deep eutectic solvents for gas chromatographic-mass spectrometric analysis. J. Chromatogr. A 2018, 1555, 10-19. [CrossRef]

204. Matong, J.; Mpupa, A.; Nomngongo, P. Ultrasound Assisted-Homogeneous Liquid-liquid Phase Microextraction based on Deep Eutectic Solvents and Ethyl Acetate for Preconcentration of Selected Organochlorine Pesticides in Water Samples. Eurasian J. Anal. Chem. 2018, 13, 1-15. [CrossRef]

205. Tomai, P.; Lippiello, A.; D’Angelo, P.; Persson, I.; Martinelli, A.; Di Lisio, V.; Curini, R.; Fanali, C.; Gentili, A. A low transition temperature mixture for the dispersive liquid-liquid microextraction of pesticides from surface waters. J. Chromatogr. A 2019, 1605, 360329. [CrossRef]

206. Jouyban, A.; Farajzadeh, M.A.; Afshar Mogaddam, M.R. Dispersive liquid-liquid microextraction based on solidification of deep eutectic solvent droplets for analysis of pesticides in farmer urine and plasma by gas chromatography-mass spectrometry. J. Chromatogr. B 2019, 1124, 114-121. [CrossRef] [PubMed]

207. Majidi, S.M.; Hadjmohammadi, M.R. Hydrophobic borneol-based natural deep eutectic solvents as a green extraction media for air-assisted liquid-liquid micro-extraction of warfarin in biological samples. J. Chromatogr. A 2020, 1621, 461030. [CrossRef] [PubMed]

208. Nugbienyo, L.; Shishov, A.; Garmonov, S.; Moskvin, L.; Andruch, V.; Bulatov, A. Flow method based on liquid-liquid extraction using deep eutectic solvent for the spectrofluorimetric determination of procainamide in human saliva. Talanta 2017, 168, 307-312. [CrossRef] [PubMed]

209. Shishov, A.; Gerasimov, A.; Nechaeva, D.; Volodina, N.; Bessonova, E.; Bulatov, A. An effervescence-assisted dispersive liquid-liquid microextraction based on deep eutectic solvent decomposition: Determination of ketoprofen and diclofenac in liver. Microchem. J. 2020, 156, 104837. [CrossRef]

210. Zhang, K.; Li, S.; Liu, C.; Wang, Q.; Wang, Y.; Fan, J. A hydrophobic deep eutectic solvent-based vortex-assisted dispersive liquid-liquid microextraction combined with HPLC for the determination of nitrite in water and biological samples. J. Sep. Sci. 2019, 42, 574-581. [CrossRef] 
211. Zounr, R.A.; Tuzen, M.; Khuhawar, M.Y. Ultrasound assisted deep eutectic solvent based on dispersive liquid liquid microextraction of arsenic speciation in water and environmental samples by electrothermal atomic absorption spectrometry. J. Mol. Liq. 2017, 242, 441-446. [CrossRef]

212. Lashari, A.A.; Kazi, T.G.; Baig, J.A.; Afridi, H.I. Developed a modified liquid-liquid micro-extraction method for the preconcentration of cadmium in groundwater samples of aquifers at different depth in a coal mining area. Int. J. Environ. Anal. Chem. 2019, 1-12. [CrossRef]

213. Sorouraddin, S.M.; Farajzadeh, M.A.; Okhravi, T. Development of dispersive liquid-liquid microextraction based on deep eutectic solvent using as complexing agent and extraction solvent: Application for extraction of heavy metals. Sep. Sci. Technol. 2020, 55, 2995-2996. [CrossRef]

214. Arpa, Ç.; Albayati, S.; Yahya, M. Effervescence-assisted dispersive liquid-liquid microextraction based on deep eutectic solvent for preconcentration and FAAS determination of copper in aqueous samples. Int. J. Environ. Anal. Chem. 2018, 98, 938-953. [CrossRef]

215. Ali, J.; Tuzen, M.; Citak, D.; Uluozlu, O.D.; Mendil, D.; Kazi, T.G.; Afridi, H.I. Separation and preconcentration of trivalent chromium in environmental waters by using deep eutectic solvent with ultrasound-assisted based dispersive liquid-liquid microextraction method. J. Mol. Liq. 2019, 291, 111299. [CrossRef]

216. Habila, M.A.; Alabdullkarem, E.A.; ALOthman, Z.A.; Yilmaz, E.; Soylak, M. Thiomalic acid/ferric chloride-based deep eutectic solvent for microextraction of chromium in natural water samples prior to FAAS analysis. Int. J. Environ. Anal. Chem. 2020, 1-9. [CrossRef]

217. Pourmohammad, M.; Faraji, M.; Jafarinejad, S. Extraction of chromium (VI) in water samples by dispersive liquid-liquid microextraction based on deep eutectic solvent and determination by UV-Vis spectrophotometry. Int. J. Environ. Anal. Chem. 2019, 1-14. [CrossRef]

218. Rad, A.S.; Rahnama, R.; Zakeri, M.; Jamali, M.R. Dispersive liquid-liquid microextraction based on green type solvents-“deep eutectic solvents"-for highly selective separation and efficient preconcentration of nickel in water samples. J. Iran. Chem. Soc. 2019, 16, 1715-1722. [CrossRef]

219. Abdi, K.; Ezoddin, M.; Pirooznia, N. Temperature-controlled liquid-liquid microextraction using a biocompatible hydrophobic deep eutectic solvent for microextraction of palladium from catalytic converter and road dust samples prior to ETAAS determination. Microchem. J. 2020, 157, 104999. [CrossRef]

220. Panhwar, A.H.; Tuzen, M.; Kazi, T.G. Ultrasonic assisted dispersive liquid-liquid microextraction method based on deep eutectic solvent for speciation, preconcentration and determination of selenium species (IV) and (VI) in water and food samples. Talanta 2017, 175, 352-358. [CrossRef]

221. Altunay, N.; Elik, A.; Gürkan, R. Monitoring of some trace metals in honeys by flame atomic absorption spectrometry after ultrasound assisted-dispersive liquid liquid microextraction using natural deep eutectic solvent. Microchem. J. 2019, 147, 49-59. [CrossRef]

222. Sorouraddin, S.M.; Farajzadeh, M.A.; Dastoori, H. Development of a dispersive liquid-liquid microextraction method based on a ternary deep eutectic solvent as chelating agent and extraction solvent for preconcentration of heavy metals from milk samples. Talanta 2020, 208, 120485. [CrossRef]

223. Seidi, S.; Alavi, L. Novel and Rapid Deep Eutectic Solvent (DES) Homogeneous Liquid-Liquid Microextraction (HLLME) with Flame Atomic Absorption Spectrometry (FAAS) Detection for the Determination of Copper in Vegetables. Anal. Lett. 2019, 52, 2092-2106. [CrossRef]

224. Shishov, A.; Terno, P.; Moskvin, L.; Bulatov, A. In-syringe dispersive liquid-liquid microextraction using deep eutectic solvent as disperser: Determination of chromium (VI) in beverages. Talanta 2020, 206, 120209. [CrossRef]

225. Sorouraddin, S.M.; Farajzadeh, M.A.; Dastoori, H.; Okhravi, T. Development of an air-assisted liquid-liquid microextraction method based on a ternary solidified deep eutectic solvent in extraction and preconcentration of Cd(II) and Zn(II) ions. Int. J. Environ. Anal. Chem. 2019, 1-14. [CrossRef]

226. Zounr, R.A.; Tuzen, M.; Khuhawar, M.Y. Novel ultrasonic-assisted deep eutectic solvent-based dispersive liquid-liquid microextraction for determination of vanadium in food samples by electrothermal atomic absorption spectrometry: A multivariate study. Appl. Organomet. Chem. 2018, 32, e4144. [CrossRef]

227. Habibollahi, M.H.; Karimyan, K.; Arfaeinia, H.; Mirzaei, N.; Safari, Y.; Akramipour, R.; Sharafi, H.; Fattahi, N. Extraction and determination of heavy metals in soil and vegetables irrigated with treated municipal wastewater using new mode of dispersive liquid-liquid microextraction based on the solidified deep eutectic solvent followed by GFAAS. J. Sci. Food Agric. 2019, 99, 656-665. [CrossRef] [PubMed] 
228. Panhwar, A.H.; Tuzen, M.; Deligonul, N.; Kazi, T.G. Ultrasonic assisted deep eutectic solvent liquid-liquid microextraction using azadipyrromethene dye as complexing agent for assessment of chromium species in environmental samples by electrothermal atomic absorption spectrometry. Appl. Organomet. Chem. 2018, 32, e4319. [CrossRef]

229. Ezoddin, M.; Lamei, N.; Siami, F.; Abdi, K.; Karimi, M.A. Deep Eutectic Solvent Based Air Assisted Ligandless Emulsification Liquid-Liquid Microextraction for Preconcentration of Some Heavy Metals in Biological and Environmental Samples. Bull. Environ. Contam. Toxicol. 2018, 101, 814-819. [CrossRef] [PubMed]

230. Mamidipally, P.K.; Liu, S.X. First approach on rice bran oil extraction using limonene. Eur. J. Lipid Sci. Technol. 2004, 106, 122-125. [CrossRef]

231. Liu, S.X.; Mamidipally, P.K. Quality Comparison of Rice Bran Oil Extracted with d-Limonene and Hexane. Cereal Chem. J. 2005, 82, 209-215. [CrossRef]

232. Virot, M.; Tomao, V.; Ginies, C.; Chemat, F. Total Lipid Extraction of Food Using d-Limonene as an Alternative to n-Hexane. Chromatographia 2008, 68, 311-313. [CrossRef]

233. Virot, M.; Tomao, V.; Ginies, C.; Visinoni, F.; Chemat, F. Green procedure with a green solvent for fats and oils' determination. J. Chromatogr. A 2008, 1196-1197, 147-152. [CrossRef]

234. Bertouche, S.; Tomao, V.; Hellal, A.; Boutekedjiret, C.; Chemat, F. First approach on edible oil determination in oilseeds products using alpha-pinene. J. Essent. Oil Res. 2013, 25, 439-443. [CrossRef]

235. Li, Y.; Fine, F.; Fabiano-Tixier, A.-S.; Abert-Vian, M.; Carre, P.; Pages, X.; Chemat, F. Evaluation of alternative solvents for improvement of oil extraction from rapeseeds. Comptes Rendus Chim. 2014, 17, $242-251$. [CrossRef]

236. Sicaire, A.-G.; Abert Vian, M.; Fine, F.; Carré, P.; Tostain, S.; Chemat, F. Experimental approach versus COSMO-RS assisted solvent screening for predicting the solubility of rapeseed oil. OCL 2015, 22, D404. [CrossRef]

237. Yara-Varón, E.; Selka, A.; Fabiano-Tixier, A.S.; Balcells, M.; Canela-Garayoa, R.; Bily, A.; Touaibia, M.; Chemat, F. Solvent from forestry biomass. Pinane a stable terpene derived from pine tree byproducts to substitute n-hexane for the extraction of bioactive compounds. Green Chem. 2016, 18, 6596-6608. [CrossRef]

238. Madji, S.; Hilali, S.; Fabiano-Tixier, A.-S.; Tenon, M.; Bily, A.; Laguerre, M.; Chemat, F. Para-Menthane as a Stable Terpene Derived from Orange By-Products as a Novel Solvent for Green Extraction and Solubilization of Natural Substances. Molecules 2019, 24, 2170. [CrossRef] [PubMed]

239. Chemat-Djenni, Z.; Ferhat, M.A.; Tomao, V.; Chemat, F. Carotenoid Extraction from Tomato Using a Green Solvent Resulting from Orange Processing Waste. J. Essent. Oil Bear. Plants 2010, 13, 139-147. [CrossRef]

240. Filly, A.; Fabiano-Tixier, A.-S.; Lemasson, Y.; Roy, C.; Fernandez, X.; Chemat, F. Extraction of aroma compounds in blackcurrant buds by alternative solvents: Theoretical and experimental solubility study. Comptes Rendus Chim. 2014, 17, 1268-1275. [CrossRef]

241. Filly, A.; Fabiano-Tixier, A.S.; Fernandez, X.; Chemat, F. Alternative solvents for extraction of food aromas. Experimental and COSMO-RS study. LWT-Food Sci. Technol. 2015, 61, 33-40. [CrossRef]

242. Villanueva Bermejo, D.; Angelov, I.; Vicente, G.; Stateva, R.P.; Rodriguez García-Risco, M.; Reglero, G.; Ibañez, E.; Fornari, T. Extraction of thymol from different varieties of thyme plants using green solvents. J. Sci. Food Agric. 2015, 95, 2901-2907. [CrossRef]

243. Veillet, S.; Tomao, V.; Ruiz, K.; Chemat, F. Green procedure using limonene in the Dean-Stark apparatus for moisture determination in food products. Anal. Chim. Acta 2010, 674, 49-52. [CrossRef]

244. Bertouche, S.; Tomao, V.; Ruiz, K.; Hellal, A.; Boutekedjiret, C.; Chemat, F. First approach on moisture determination in food products using alpha-pinene as an alternative solvent for Dean-Stark distillation. Food Chem. 2012, 134, 602-605. [CrossRef]

245. Grazhdannikov, A.E.; Kornaukhova, L.M.; Rodionov, V.I.; Pankrushina, N.A.; Shults, E.E.; Fabiano-Tixier, A.S.; Popov, S.A.; Chemat, F. Selecting a Green Strategy on Extraction of Birch Bark and Isolation of Pure Betulin Using Monoterpenes. ACS Sustain. Chem. Eng. 2018, 6, 6281-6288. [CrossRef]

246. Dejoye Tanzi, C.; Abert Vian, M.; Ginies, C.; Elmaataoui, M.; Chemat, F. Terpenes as Green Solvents for Extraction of Oil from Microalgae. Molecules 2012, 17, 8196-8205. [CrossRef] [PubMed]

247. Dejoye Tanzi, C.; Abert Vian, M.; Chemat, F. New procedure for extraction of algal lipids from wet biomass: A green clean and scalable process. Bioresour. Technol. 2013, 134, 271-275. [CrossRef] [PubMed] 
248. Bligh, E.G.; Dyer, W.J. A rapid method of total lipid extraction and purification. Can. J. Biochem. Physiol. 1959, 37, 911-917. [CrossRef]

249. Golmakani, M.-T.; Mendiola, J.A.; Rezaei, K.; Ibáñez, E. Pressurized limonene as an alternative bio-solvent for the extraction of lipids from marine microorganisms. J. Supercrit. Fluids 2014, 92, 1-7. [CrossRef]

250. Castro-Puyana, M.; Herrero, M.; Urreta, I.; Mendiola, J.A.; Cifuentes, A.; Ibáñez, E.; Suárez-Alvarez, S. Optimization of clean extraction methods to isolate carotenoids from the microalga Neochloris oleoabundans and subsequent chemical characterization using liquid chromatography tandem mass spectrometry. Anal. Bioanal. Chem. 2013, 405, 4607-4616. [CrossRef] [PubMed]

251. Hamiche, S.; Bouzidi, N.; Daghbouche, Y.; Badis, A.; Garrigues, S.; de la Guardia, M.; El Hattab, M. Eucalyptol-based green extraction of brown alga Zonaria tournefortii. Sustain. Chem. Pharm. 2018, 10, 97-102. [CrossRef]

252. Gironi, F.; Gonzalez Farias, I.; Lamberti, L. Liquid-liquid Equilibria for the Water + Ethanol + Citral and Water + Ethanol + Limonene Systems at 293 K. J. Chem. Eng. Data 1995, 40, 578-581. [CrossRef]

253. Cháfer, A.; Muñoz, R.; Burguet, M.C.; Berna, A. The influence of the temperature on the liquid-liquid equlibria of the mixture limonene + ethanol + H2O. Fluid Phase Equilib. 2004, 224, 251-256. [CrossRef]

254. Cháfer, A.; de la Torre, J.; Muñoz, R.; Burguet, M.C. Liquid-liquid equlibria of the mixture linalool+ethanol+water at different temperatures. Fluid Phase Equilib. 2005, 238, 72-76. [CrossRef]

255. Gramajo de Doz, M.B.; Cases, A.M.; Díaz, P.A.; Sólimo, H.N. (Liquid + Liquid) Equilibria for Water + Ethanol + Citral Multicomponent System at 303.15 K. J. Chem. Eng. Data 2007, 52, 1710-1714. [CrossRef]

256. Tamura, K.; Li, H. Mutual Solubilities of Terpene in Methanol and Water and Their Multicomponent Liquid-Liquid Equilibria. J. Chem. Eng. Data 2005, 50, 2013-2018. [CrossRef]

257. Li, H.; Tamura, K. Ternary and quaternary (liquid + liquid) equilibria for (water + ethanol $+\alpha$-pinene, + $\beta$-pinene or + limonene) and (water + ethanol $+\alpha$-pinene + limonene) at the temperature 298.15K. J. Chem. Thermodyn. 2005, 38, 1036-1041. [CrossRef]

258. Li, H.; Tamura, K. Ternary liquid-liquid equilibria for (water + terpene +1 -propanol or 1-butanol) systems at the temperature 298.15K. Fluid Phase Equilib. 2008, 263, 223-230. [CrossRef]

259. Li, X.; Tamura, K. (Ternary liquid + liquid) equilibria for (water + acetone $+\alpha$-pinene or $\beta$-pinene or limonene) mixtures. J. Chem. Thermodyn. 2010, 42, 1400-1405. [CrossRef]

260. Li, H.; Zhang, T.; Fu, W.; Tamura, K. Liquid-Liquid Phase Behaviors of Geraniol in Aqueous Alcohol Mixtures. J. Chem. Eng. Data 2012, 57, 148-154. [CrossRef]

261. Zhang, T.; Li, H.; Zhang, W.; Tamura, K. Ternary (liquid + liquid) equilibria for $\beta$-citronellol in aqueous alcohol at different temperatures. J. Chem. Thermodyn. 2012, 53, 16-22. [CrossRef]

262. Li, H.; Huang, C.; Ma, X.; Feng, Y. Liquid-liquid Equilibria for Linalool in Aqueous Alcohol Mixtures. Adv. Mater. Res. 2013, 634-638, 1022-1025. [CrossRef]

263. Oliveira, C.M.; Koshima, C.C.; Capellini, M.C.; Carvalho, F.H.; Aracava, K.K.; Gonçalves, C.B.; Rodrigues, C.E.C. Liquid-liquid equilibrium data for the system limonene + carvone + ethanol + water at 298.2K. Fluid Phase Equilib. 2013, 360, 233-238. [CrossRef]

264. Huang, C.; Li, H.; Yan, Y.; Han, Y. Liquid-liquid Equillibria for the (Water + Methanol + Citral) System at 283.15 and 313.15 K. Adv. Mater. Res. 2013, 634-638, 408-411. [CrossRef]

265. Li, H.; Han, Y.; Huang, C.; Yang, C. (Liquid + liquid) equilibria for (water + 1-propanol or acetone + $\beta$-citronellol) at different temperatures. J. Chem. Thermodyn. 2015, 86, 20-26. [CrossRef]

266. Li, H.; Feng, Z.; Wan, L.; Huang, C.; Zhang, T.; Fang, Y. (Liquid + liquid) equilibria of four alcohol-Water systems containing 1,8-cineole at $\mathrm{T}=298.15 \mathrm{~K}$. J. Chem. Thermodyn. 2016, 101, 387-394. [CrossRef]

267. Wan, L.; Li, H.; Huang, C.; Feng, Y.; Chu, G.; Zheng, Y.; Tan, W.; Qin, Y.; Sun, D.; Fang, Y. Influence of the temperature on the (liquid + liquid) phase equilibria of (water + 1-propanl + linalool or geraniol). J. Chem. Thermodyn. 2016, 109, 109-116. [CrossRef]

268. Li, H.; Wan, L.; Chu, G.; Tan, W.; Liu, B.; Qin, Y.; Feng, Y.; Sun, D.; Fang, Y. (Liquid + liquid) extraction of phenols from aqueous solutions with cineole. J. Chem. Thermodyn. 2016, 107, 95-103. [CrossRef]

269. Pourreza, N.; Naghdi, T. d -Limonene as a green bio-solvent for dispersive liquid-liquid microextraction of $\beta$-cyclodextrin followed by spectrophotometric determination. J. Ind. Eng. Chem. 2017, 51, 71-76. [CrossRef]

270. Farajzadeh, M.A.; Goushjuii, L. Study of menthol as a green extractant in dispersive liquid-liquid microextraction; application in extraction of phthalate esters from pharmaceutical products. Anal. Methods 2013, 5, 1975-1982. [CrossRef] 
271. Faure, K.; Bouju, E.; Suchet, P.; Berthod, A. Use of Limonene in Countercurrent Chromatography: A Green Alkane Substitute. Anal. Chem. 2013, 85, 4644-4650. [CrossRef]

272. Medvedovici, A.; Udrescu, S.; David, V. Use of a green (bio) solvent-limonene-as extractant and immiscible diluent for large volume injection in the RPLC-tandem MS assay of statins and related metabolites in human plasma. Biomed. Chromatogr. 2013, 27, 48-57. [CrossRef]

273. Nikakhtari, H.; Vagi, L.; Choi, P.; Liu, Q.; Gray, M.R. Solvent screening for non-aqueous extraction of Alberta oil sands. Can. J. Chem. Eng. 2013, 91, 1153-1160. [CrossRef]

(C) 2020 by the authors. Licensee MDPI, Basel, Switzerland. This article is an open access article distributed under the terms and conditions of the Creative Commons Attribution (CC BY) license (http://creativecommons.org/licenses/by/4.0/). 